Fabricio Leite de CaRVALHo

\title{
Caracterização das disfunções miccionais em pacientes portadores do espectro da neuromielite óptica e suas associações com o comprometimento neurológico e a qualidade de vida
}

Tese apresentada à Faculdade de Medicina da Universidade de São Paulo para obtenção do título de Doutor em Ciências

Programa de: Urologia

Orientador: Dr. Cristiano Mendes Gomes

São Paulo 2013 


\section{Dados Internacionais de Catalogação na Publicação (CIP)}

Preparada pela Biblioteca da

Faculdade de Medicina da Universidade de São Paulo

Creprodução autorizada pelo autor

\section{Carvalho, Fabricio Leite de}

Caracterização das disfunções miccionais em pacientes portadores do espectro da neuromielite óptica e suas associações com o comprometimento neurológico e a qualidade de vida / Fabricio Leite de Carvalho. -- São Paulo, 2013.

Tese(doutorado)--Faculdade de Medicina da Universidade de São Paulo.

Programa de Urologia.

Orientador: Cristiano Mendes Gomes.

Descritores: 1.Neuromielite óptica 2.Sintomas do trato urinário inferior 3.Urodinâmica 4.Doenças desmielinizantes 5.Qualidade de vida

USP/FM/DBD-447/13 
DEDICATÓRIA 
Aos pacientes avaliados neste estudo que mesmo num momento singular de suas vidas, deixaram de lado suas individualidades e, em prol de um senso comum, contribuíram para melhor entendimento desta doença. 
AGRADECIMENTOS 
Ao Prof. Dr. Miguel Srougi, professor Titular da Disciplina de Urologia da Faculdade de Medicina da Universidade de São Paulo, pela oportunidade de poder realizar este estudo.

Ao Prof. Dr. Homero Bruschini, coordenador da Pós Graduação em Urologia da Faculdade de Medicina da Universidade de São Paulo e Chefe de Setor de Disfunções Miccionais do Hospital das Clinicas da Faculdade de Medicina da Universidade de São Paulo, pelo apoio e viabilização do projeto.

Ao Dr. Cristiano Mendes Gomes, meu orientador, por ter me acolhido como aluno, compartilhado seu conhecimento e, sobretudo me incentivado a superar minhas limitações.

À Dra . Samira Luísa Apóstolos Pereira, neurologista do Ambulatório de Doenças Desmielinizantes do Hospital das Clínicas da Faculdade de Medicina da Universidade de São Paulo, por ter acreditado nesta proposta de estudo e comigo compartilhado pacientes.

Ao Dr. José de Bessa Jr. pelo inestimável apoio e incentivo pessoal, além da notável contribuição nas avaliações estatísticas.

Ao Prof. Dr. Dagoberto Callegaro, Dr. Luís Augusto Seabra Rios e Dr. Leopoldo Ribeiro Filho, membros da banca de qualificação, por terem me auxiliado a tornar este um trabalho melhor. 
À equipe de enfermagem do Laboratório de Urodinâmica do HCFMUSP, em especial à Sra. Zilda e Sr. Renato Carvalho, pelo apoio no atendimento e realização dos estudos urodinâmicos.

À equipe de atendimento do Ambulatório de Urologia do HCFMUSP, em especial às Sras. Clélia e Madalena Quintino, pelo apoio logístico do atendimento aos pacientes.

Especial agradecimento aos meus pais Sérgio Carvalho e Maria Aparecida Leite de Carvalho, e à minha irmã Carol, que ao meu lado sempre estiveram presentes, me apoiando e me incentivando na busca de minhas realizações. 


\section{NORMATIZAÇÃO}

Esta tese está de acordo com as seguintes normas, em vigor no momento desta publicação:

Referências: adaptado de International Committe of Medical Journals Editors (Vancouver).

Universidade de São Paulo. Faculdade de Medicina. Divisão de Biblioteca e Documentação. Guia de apresentação de dissertações, teses e monografias. Elaborado por Anneliese Carneiro da Cunha, Maria Júlia de A. L. Freddi, Maria F. Crestana, Marinalva de Souza Aragão, Suely Campos Cardoso, Valéria Vilhena. $3^{a}$ ed. São Paulo: Divisão de Biblioteca e Documentação; 2011.

Abreviaturas dos títulos dos periódicos de acordo com List of Journals Indexed in Index Medicus. 
SUMÁRIO 
Lista de Abreviaturas, Siglas e Símbolos

Lista de Figuras

Lista de Tabelas

Resumo

Summary

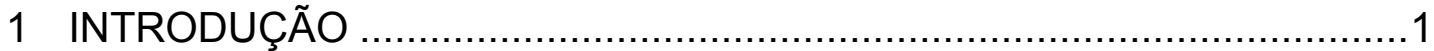

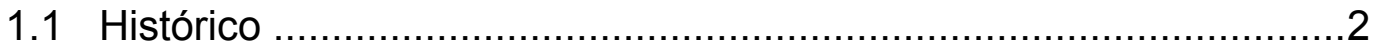

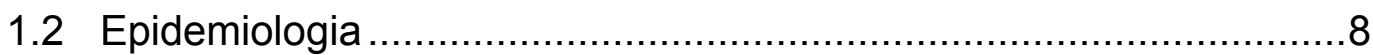

1.3 Patogenia da neuromielite óptica .......................................... 8

1.4 Apresentações clínicas......................................................... 10

1.5 Métodos diagnósticos ........................................................... 13

1.5.1 Testes imunológicos ................................................. 13

1.5.2 Exames de imagem ............................................. 14

1.6 Diagnóstico diferencial ........................................................ 17

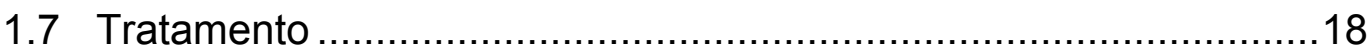

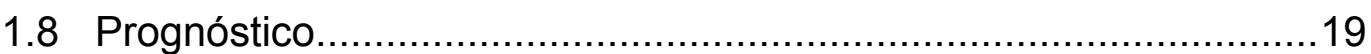

1.9 Neurofisiologia do trato urinário inferior ....................................20

1.10 Lesão neurológica e distúrbios miccionais ..............................25

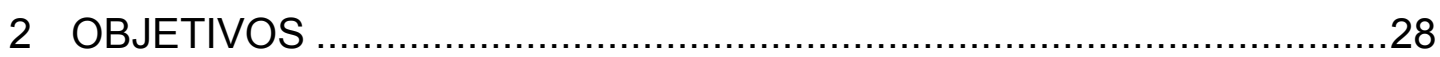

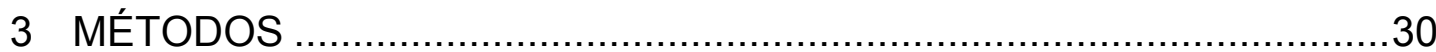

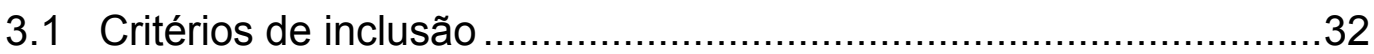

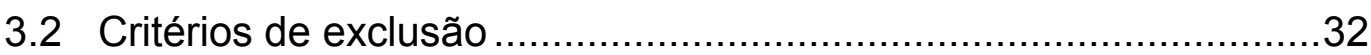

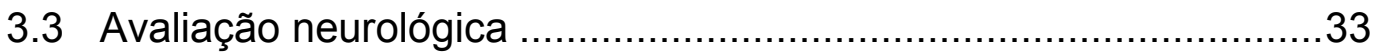

3.4 Avaliação urológica ......................................................... 34

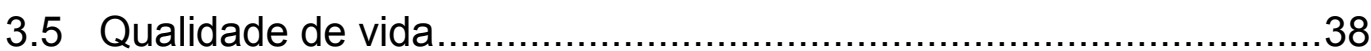

3.6 Associação entre os distúrbios urinários e o comprometimento neurológico ...................................................................40

3.7 Impacto dos sintomas do trato urinário inferior e comprometimento neurológico na qualidade de vida geral ............40

3.8 Análise Estatística .............................................................40

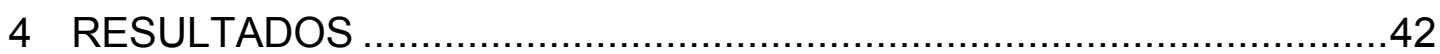

4.1 Comprometimento neurológico em pacientes portadores do espectro da neuromielite óptica.... 
4.2 Sintomas do trato urinário inferior e avaliação urodinâmica m pacientes portadores do espectro da neuromielite óptica

4.3 Qualidade de vida geral nos pacientes portadores do espectro da neuromielite óptica

4.4 Associação entre sintomas do trato urinário inferior e disfunção miccional com o comprometimento neurológico

4.5 Impacto dos sintomas do trato urinário inferior e do comprometimento neurológico na qualidade de vida geral

5 DISCUSSÃO .63

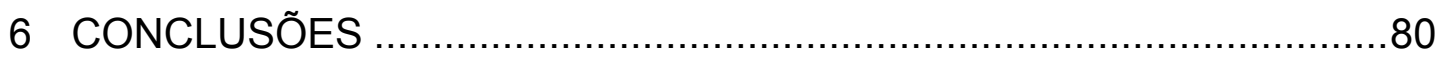

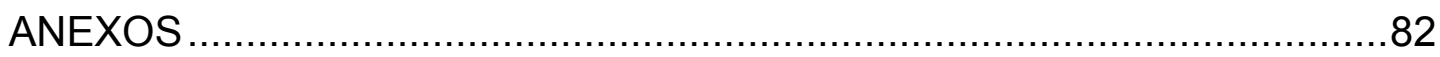

Anexo A: Escala expandida do estado de incapacidade (EDSS) ............83

Anexo B: Questionário de Avaliação da Bexiga Hiperativa (OAB-V8) .....85

Anexo C: Escore Internacional de Sintomas Prostáticos (I-PSS) ............86

Anexo D: Questionário de Satisfação com a Vida (LiSat-9) .....................87

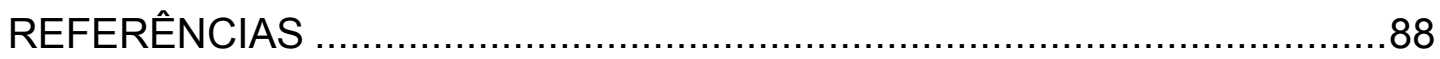

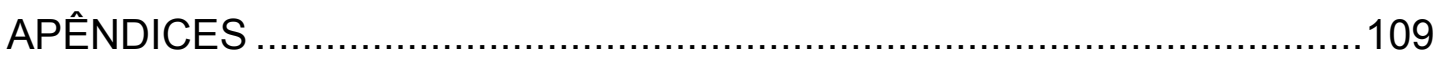

Apêndice I - Aprovação da Comissão de Ética para Análise de Projetos de Pesquisa - CAPPesq da Diretoria Clínica do Hospital das Clínicas e da Faculdade de Medicina da Universidade de São Paulo

Apêndice II - Termo de consentimento livre e esclarecido 
LISTAS 


\section{LISTA DE ABREVIATURAS, SIGLAS E SÍMBOLOS}

$\begin{array}{ll}\text { AQP4 } & \text { Aquaporina-4 } \\ \mathrm{cm}^{3} & \text { centímetros cúbicos } \\ \mathrm{cmH}_{2} \mathrm{O} & \text { centímetros de água } \\ \mathrm{CPM} & \text { Centro pontinho da micção } \\ \mathrm{DP} & \text { desvio padrão } \\ \mathrm{DDE} & \text { Dissinergia detrusor-esfincteriana } \\ \mathrm{EDSS} & \text { Escala expandida do estado de incapacidade } \\ \mathrm{EM} & \text { Esclerose múltipla } \\ \mathrm{EMG} & \text { Eletromiografia } \\ \mathrm{g} & \text { gramas } \\ \mathrm{HD} & \text { Hiperatividade detrusora } \\ \mathrm{IgG} & \text { Imunoglobulina } \mathrm{G} \\ \mathrm{I}-\mathrm{PSS} & \text { Escore internacional de sintomas prostáticos } \\ \mathrm{IUE} & \text { Incontinência urinária de esforço } \\ \mathrm{LiSat}-9 & \text { Questionário de satisfação com a vida } \\ \mathrm{máx} & \text { máximo } \\ \mathrm{mg} & \text { miligramas } \\ \mathrm{min} & \text { mínimo } \\ \mathrm{ml} & \text { mililitros } \\ \mathrm{ml} / \mathrm{cm} \mathrm{H}_{2} \mathrm{O} & \text { mililitros por centímetros de água } \\ \mathrm{ml} / \mathrm{s} & \text { mililitros por segundo } \\ \mathrm{MTLE} & \text { Mielite transversa longitudinalmente extensa } \\ \mathrm{n} & \text { número } \\ \mathrm{ng} / \mathrm{dl} & \text { nanogramas por decilitro } \\ \mathrm{NMO} & \text { Neuromielite óptica } \\ \mathrm{NMO-IgG} & \text { Autoanticorpo lgG } \\ \mathrm{NMO-SD} & \text { Espectro da neuromielite óptica } \\ \mathrm{NO} & \text { Neurite óptica } \\ \mathrm{OAB}-\mathrm{V} 8 & \text { Questionário de avaliação da bexiga hiperativa } \\ \mathrm{OSMS} & \text { Forma óptico-espinhal da Esclerose Múltipla } \\ p & \text { significância } \\ & \end{array}$




$\begin{array}{ll}\text { PSA } & \text { Antígeno prostático específico } \\ \text { QV } & \text { Qualidade de vida } \\ \text { RM } & \text { Ressonância magnética } \\ \text { SF } & \text { Sistema funcional } \\ \text { SNC } & \text { Sistema nervoso central } \\ \text { STUI } & \text { Sintomas do trato urinário inferior } \\ \text { TUI } & \text { Trato urinário inferior } \\ \text { TRM } & \text { Trauma raquimedular } \\ \% & \text { porcentagem } \\ > & \text { maior que } \\ < & \text { menor que } \\ = & \text { igual a } \\ \pm & \text { mais ou menos } \\ \geq & \text { maior ou igual a } \\ \leq & \text { menor ou igual a }\end{array}$




\section{LISTA DE FIGURAS}

Figura 1 - Processo de destruição de um astrócito por ativação do complemento através da AQP4. Uma vez que o anticorpo IgG anti-AQP4 atravessa a barreira hemato-encefálica, ele se liga a AQP4 no pé dos astrócitos, fixa e ativa o complemento. A ativação do complemento mobiliza neutrófilos e eosinófilos, que então produzem severo dano tecidual e causam desmielinização secundária. Ruptura dos astrócitos prolonga o edema vasogênico causado por inflamação. (Adaptado de Kira et al., 2011)

Figura 2 - Ressonância Magnética, padrão de acometimento longitudinal medular e encefálico. Achados típicos de NMO ao exame de RM: (A) RM de coluna cervical em corte sagital demonstrando lesão holomedular com efeito tumefativo que se estende desde o bulbo (seta superior) até a sexta vértebra cervical (seta inferior), caracterizada por hipersinal na aquisição ponderada em T2; (B) RM do encéfalo em corte axial demonstrando ausência de alterações patológicas.

Figura 3 - Grau de comprometimento neurológico de acordo com a escala EDSS

Figura 4 - Padrão de acometimento longitudinal das lesões medulares

Figura 5- Escore médio dos sintomas do trato urinário inferior

Figura 6 - Prevalência dos sintomas do trato urinário inferior.

Figura 7 - Índice de avaliação da qualidade de vida (questão 8 do IPSS): grau de satisfação em função dos sintomas do trato urinário inferior.

Figura 8 Achados urodinâmicos em pacientes portadores de NMOSD 
Figura 9 - Vídeo-urodinâmica de mulher de 36 anos (paciente 19) demonstrando hiperatividade detrusora e dissinergia detrusor-esfincteriana: (A) Cistometria demonstra hiperatividade detrusora (seta preta) com aumento simultâneo da atividade eletromiográfica (seta vermelha); (B) Estudo fluxo/pressão mostra elevada pressão detrusora (seta preta), fluxo baixo e intermitente (seta azul) e aumento da atividade eletromiográfica (seta vermelha); (C) Monitorização fluoroscópica da fase miccional demonstra colo vesical aberto e uretra proximal dilatada devido ao esfíncter dissinérgico

Figura 10 - Avaliação combinada de estudo urodinâmico mais uretrocistografia miccional em homem de 53 anos (paciente 28) demonstrando hiperatividade detrusora e dissinergia detrusor-esfincteriana: (A) Cistometria demonstra hiperatividade detrusora (seta preta) com discreto aumento simultâneo da atividade eletromiográfica (seta vermelha); (B) Estudo fluxo/pressão mostra elevada pressão detrusora (seta preta), fluxo baixo e intermitente (seta azul) e aumento da atividade eletromiográfica (seta vermelha); (C) Uretrocistografia miccional demonstra bexiga de capacidade reduzida, trabeculações e pequeno divertículo (seta preta); uretra prostática dilatada devido ao esfíncter dissinérgico (seta vermelha)

Figura 11 - Escore médio dos itens do LiSat-9 …………………….....58

Figura 12 - Correlação entre gravidade da doença neurológica (EDSS) e sintomas do trato urinário inferior medidos pelo I-PSS $(r=0,42 ; p=0,018)$.

Figura 13 - Correlação entre gravidade da doença neurológica (EDSS) e sintomas do trato urinário inferior medidos pelo OAB-V8 $(r=0,48 ; p=0,006)$.

Figura 14 - Comparação do comprometimento neurológico medido pela escala EDSS entre pacientes com e sem dissinergia detrusor-esfincteriana

Figura 15 - Correlação entre grau de comprometimento neurológico (EDSS) e qualidade de vida geral (LiSat-9). 


\section{LISTA DE TABELAS}

Tabela 1 - Características clínicas, laboratoriais e demográficas dos 30 pacientes portadores do espectro da neuromielite óptica.

Tabela 2 - Correlação entre o índice de qualidade de vida do I-PSS e os escores de sintomas do trato urinário inferior (I-PSS e OAB-V8); e entre o índice de avaliação da qualidade de vida do I-PSS e o grau de comprometimento neurológico (EDSS)

Tabela 3 - Parâmetros urodinâmicos e escore de sintomas do trato urinário inferior (I-PSS e OAB-V8) em pacientes com e sem dissinergia detrusor-esfincteriana

Tabela 4 - Dados clínicos, laboratoriais e demográficos de pacientes portadores do espectro NMO previamente publicados e deste estudo.

Tabela 5 - Prevalência de sintomas do trato urinário inferior em pacientes com Esclerose Múltipla e na presente série.

Tabela 6 - Anormalidades urodinâmicas em pacientes com Esclerose Múltipla avaliados antes de 2001(Litwiller et al. 1999)

Tabela 7 - Anormalidades urodinâmicas em pacientes com Esclerose Múltipla avaliados após 2001 e na presente série 
RESUMO 
Carvalho FL. Caracterização das disfunções miccionais em pacientes portadores do espectro da neuromielite óptica e suas associações com o comprometimento neurológico e com a qualidade de vida [tese]. São Paulo: Faculdade de Medicina, Universidade de São Paulo; 2013.

INTRODUÇÃO: Neuromielite óptica (NMO) e suas formas limitadas são doenças desmielinizantes autoimunes do sistema nervoso central que acometem preferencialmente a medula espinhal e o nervo óptico. Várias formas clínicas do espectro da NMO (NMO-SD) tem sido descritas e incluem desde um evento único de mielite transversa longitudinalmente extensa (MTLE) à NMO recorrente. O comprometimento neurológico destes pacientes pode levar a diversas disfunções autonômicas, incluindo disfunção miccional. OBJETIVOS: Determinar a prevalência e as características dos sintomas do trato urinário inferior (STUI) e dos achados urodinâmicos em pacientes portadores de NMO-SD, e analisar suas associações com o grau de comprometimento neurológico e qualidade de vida (QV). MÉTODOS: Avaliamos 30 pacientes (23 mulheres e 7 homens) com diagnóstico estabelecido de NMO-SD, que foram convidados a participar do estudo a despeito de apresentarem ou não STUI. A avaliação neurológica foi realizada por meio da Escala Expandida do Estado de Incapacidade (EDSS), ressonância magnética de crânio e coluna vertebral, e dosagem de NMOIgG. Os STUI foram avaliados pelo Questionário de Avaliação da Bexiga Hiperativa (OAB-V8) e pelo Escore Internacional de Sintomas Prostáticos (IPSS). A qualidade de vida de forma geral foi avaliada pelo questionário de Satisfação com a Vida (LiSat-9). Todos os pacientes foram submetidos ao estudo videourodinâmico. RESULTADOS: A idade média dos pacientes foi de 41,1 $\pm 13,5$ anos (intervalo de 13 a 70) e o tempo médio de duração da doença neurológica foi de 33,8 $\pm 30,8$ meses (intervalo de 3 a 135). A avaliação neurológica mostrou pacientes com EDSS médio de 5,3 $\pm 1,8$ (intervalo de 1 a 8,5). O escore médio do OAB-V8 foi de 17,5 $\pm 14,0$ (intervalo de 0 a 40) e de 14,3 $\pm 10,6$ (intervalo de 0 a 35) para o I-PSS. A média da QV geral medida pelo Lisat-9 foi de 38,9 $\pm 6,8$ (intervalo de 26 a 49). Os STUI mais comuns foram urgência em 15 (50\%) pacientes, noctúria em $15(50 \%)$, jato urinário fraco em $15(50 \%)$, intermitência em 14 (46,6\%), esvaziamento incompleto em $13(43,3 \%)$, hesitação em $13(43,3 \%)$, aumento da frequência urinária em $13(43,3 \%)$ e urge-incontinência em 5 (16\%). Os achados urodinâmicos mais comuns foram hiperatividade detrusora (HD) com dissinergia detrusor-esfincteriana (DDE) em $11(36,6 \%)$ pacientes, DDE sem HD em 7 (23,3\%), HD sem DDE em 6 (20\%), e incontinência urinária de esforço em $1(3,3 \%)$. Cinco $(16,6 \%)$ pacientes apresentaram estudo videourodinâmico sem anormalidades. Sintomas urinários medidos pelo IPSS e pelo OAB-V8 correlacionaram-se com maior comprometimento neurológico ( $r=0,42 ; p=0,018$ e $r=0,48 ; p=0,006$ respectivamente). Pacientes portadores de DDE foram aqueles que mostraram maior comprometimento neurológico $(p=0,027)$. Da mesma forma, pacientes dissinérgicos apresentaram maiores escores ao I-PSS $(p=0,029)$ e ao OAB-V8 $(p=0,008)$. Pacientes com maior comprometimento neurológico foram aqueles que apresentaram pior QV ( $r=-0,410 ; p=0,022)$. CONCLUSÃO: Encontramos alta 
prevalência de STUI e disfunção miccional em portadores de NMO, sendo DDE e a HD as anormalidades urodinâmicas mais frequentes. Dissinergia detrusor-esfincteriana e STUI se correlacionam com a gravidade da doença neurológica. A severidade da doença neurológica correlaciona-se com a qualidade de vida geral.

Descritores: 1- neuromielite óptica; 2- sintomas do trato urinário inferior; 3 urodinâmica; 4- doenças desmielinizantes; 5- qualidade de vida 
SUMMARY 
Carvalho FL. Voiding dysfunction in patients with neuromyelitis optica spectrum disorder and its association with neurological impairment and quality of life [thesis]. São Paulo: "Faculdade de Medicina, Universidade de São Paulo"; 2013.

INTRODUCTION: Neuromyelitis optica (NMO) and its limited forms are demyelinating autoimmune diseases of the central nervous system that preferentially affects the spinal cord and optic nerve. Several clinical forms of NMO spectrum disorders (NMO-SD) have been described and range from a limited event of longitudinally extensive transverse myelitis (LETM) to relapsing NMO. The neurological damage in these patients may lead to a range of autonomic dysfunctions, including voiding dysfunction. OBJECTIVES: To determine the prevalence and characteristics of the lower urinary tract symptoms (LUTS) and the urodynamic findings in patients with NMO-SD and analyze their correlations with the level of neurological damage and quality of life (QoL). METHODS: We evaluated 30 patients (23 women and 7 men) with an established diagnosis of NMO-SD based on stringent criteria. All patients were invited to participate irrespective of the presence of LUTS. Neurological impairment was assessed with the Expanded Disability Status Scale (EDSS), magnetic resonance imaging of the brain and spinal cord and NMO-IgG status. LUTS were evaluated with the Overactive Bladder V8 (OAB-V8) questionnaire and by the International Prostate Symptom Score (I-PSS). Quality of Life was evaluated using the Life Satisfaction questionnaire (LiSat-9). All patients underwent videourodynamics, transabdominal urinary tract sonography, urine culture and serum creatinine levels. RESULTS: The mean age of the patients was $41.1 \pm 13.5$ years (range 13 to 70 ) and the mean time of neurological disease duration was $33.8 \pm 30.8$ months (range 3 to 135). Neurological evaluation showed a mean EDSS score of $5.3 \pm 1.8$ (range 1 to 8.5 ). The mean OAB-V8 score was 17.5 \pm 14.0 (range 0 to 40 ) and the mean I-PSS score was $14.3 \pm 10.6$ (range of 0 to 35 ). Mean general QoL measured by the Lisat-9 was $38.9 \pm 6.8$ (range 26 to 49). The most common urinary symptoms were urgency in $15(50 \%)$ patients, nocturia in $15(50 \%)$, weak urinary stream in $15(50 \%)$, intermittence in $14(46.6 \%)$, incomplete emptying in $13(43.3 \%)$, hesitation in $13(43.3 \%)$, increased urinary frequency in $13(43.3 \%)$ and urge-incontinence in 5 $(16,6 \%)$. The most frequent urodynamic findings were detrusor overactivity (DO) with sphincter dyssinergia (DSD) in 11 (36.6\%) patients, DSD alone in 7 (23.3\%), DO without DSD in $6(20 \%)$ and stress urinary incontinence (SUI) in $1(3.3 \%)$. Five (16.6\%) patients had normal findings. Voiding dysfunction assessed by I-PSS and OAB-V8 increased with the degree of neurological impairment ( $r=0.42 ; p=0.018$ and $r=0.48 ; p=0.006$ respectively). Patients with DSD had significantly higher symptoms based in the I-PSS $(p=0.029)$ as well as the OAB- V8 scores $(p=0.008)$ and greater neurological impairment $(p=0.027)$. Patients with more severe neurological impairment were associated with worse Qol ( $r=-0.410 ; p=0.022)$. CONCLUSION: We have shown a high prevalence of LUTS and voiding dysfunction, with DSD and DO as the main urodynamic findings. Detrusor-sphincter dyssinergia and LUTS 
correlates with more severe neurological impairment. The severity of neurological impairment correlates with QoL.

Descriptors: 1- neuromyelitis optica; 2- lower urinary tract symptoms; 3urodynamics; 4- demyelinating diseases; 5- quality of life 
1 INTRODUÇÃO 
Neuromielite óptica (NMO) é uma grave doença inflamatória do sistema nervoso central (SNC) que acomete preferencialmente a medula espinhal e os nervos ópticos. Por muito tempo, a NMO foi considerada um subtipo de esclerose múltipla (EM). Entretanto, evidências clínicas e recentes descobertas laboratoriais demonstraram tratar-se de doenças distintas. Atualmente, a NMO é a primeira doença inflamatória desmielinizante autoimune do SNC para a qual um antígeno específico tenha sido identificado, o canal de água aquaporina-4 (AQP-4). Um autoanticorpo específico para este canal de água, denominado NMO-IgG, é considerado o biomarcador clinicamente validado que distingue a NMO da EM. Contribuem ainda para a diferenciação com EM, a ausência de um curso progressivo secundário e o fato de que o dano neurológico, resultado dos frequentes ataques de recorrência, é cumulativo e de evolução mais rápida ${ }^{(1)}$.

\subsection{HISTÓRICO}

O acometimento associado da medula espinhal e dos nervos ópticos foi descrito pela primeira vez, em 1870, por Sir T. Clifford Albutt ${ }^{(2)}$. 
Em 1894, o médico francês Eugène Devic, por meio de um relato de caso (Myélite subaiguë compliquée de nevrite optique), descreveu a doença e a caracterizou do ponto de vista clínico e patológico ${ }^{(3)}$.

Da reunião desse caso com outros 16 descritos na literatura especializada em outros países, Fernand Gault, em 1894, escreveu uma tese a respeito, intitulada "De la neuromyélite aiguë". O epônimo "doença de Devic" só foi utilizado pela primeira vez, em 1907, por Peppo Acchiote ${ }^{(3)}$.

Em 1999, Wingerchuck et al. propuseram critérios diagnósticos para NMO, que se baseavam principalmente em: (1) evidência de lesão medular com extensão $\geq 3$ corpos vertebrais, também denominada mielite transversa longitudinalmente extensa (MTLE); (2) presença de neurite óptica (NO) de ocorrência simultânea ou não à mielite; e (3) ausência de acometimento clínico além do nervo óptico e da medula espinhal ${ }^{(4)}$.

Até então, os conhecimentos existentes de sua fisiopatologia associados aos achados clínicos e laboratoriais não permitiam uma clara diferenciação diagnóstica entre NMO e EM. A descoberta, em 2004, do autoanticorpo NMO-lgG que se ligava a constituintes da barreira hematoencefálica em portadores de NMO e da forma óptico espinhal da EM (OSMS) provocou uma grande mudança no conhecimento da NMO ${ }^{(5)}$. Nesta descoberta, Lennon et al. dosaram o autoanticorpo NMO-IgG em três grupos diferentes de pacientes: portadores de NMO clinicamente definida, portadores da OSMS e portadores de EM clássica. A positividade NMO-IgG mostrou $73 \%$ de sensibilidade e $91 \%$ de especificidade em pacientes portadores de $\mathrm{NMO}$, e $58 \%$ de sensibilidade e $100 \%$ de especificidade em 
pacientes portadores da OSMS. Apenas $9 \%$ dos pacientes portadores de EM clássica se mostraram soropositivos. Tais resultados apontavam para novas perspectivas: (1) a de que NMO e OSMS talvez compartilhassem de uma mesma fisiopatologia; (2) talvez os pacientes portadores de OSMS fossem portadores de NMO e não de EM; e (3) a descoberta de um método diagnóstico que pudesse distinguir NMO da EM.

Em 2005 Lennon et al., em nova e importante descoberta, conseguiram identificar o antígeno ao qual a imunoglobulina NMO-IgG se ligava. Trata-se de uma proteína altamente concentrada no SNC denominada aquaporina-4 (AQP4) ${ }^{(6)}$. Essa proteína faz parte da membrana plasmática dos astrócitos e células ependidimárias, e está localizada de maneira abundante, principalmente, nos pés dos astrócitos, na região da interface dessas células com pequenos vasos ${ }^{(7)}$. As aquaporinas são proteínas de membrana que constituem os canais de água, estruturas fundamentais na regulação do fluxo de água por gradiente osmótico ${ }^{(8)}$. A distribuição destes canais ocorre de forma desigual ao longo do SNC, e o acometimento preferencial da NMO, ainda que não exclusivo dos nervos ópticos e da medula espinhal, parece ser decorrência da maior expressão de AQP4 nesses sítios anatômicos ${ }^{(9)}$. O fato de que, após alguns anos de seguimento, $60 \%$ dos pacientes com diagnóstico de NMO podem apresentar lesões encefálicas difusas em exames de ressonância magnética (RM), sugere que tais lesões possivelmente estejam relacionadas à essa presença disseminada da AQP4 no sistema nervoso central ${ }^{(10)}$. 
A partir desses novos conhecimentos sobre sua fisiopatologia, foi criada uma nova classificação para a NMO, que deixou de ser tratada como uma doença inflamatória desmielinizante idiopática e passou a ser considerada como a primeira doença inflamatória desmielinizante autoimune do SNC para a qual um antígeno específico tenha sido identificado, a AQP4.

Em 2006, de posse dos novos conceitos de sua fisiopatologia e dos métodos de imunodiagnóstico, Wingerchuck et al. propuseram revisão dos critérios diagnósticos da NMO. Nesta revisão, um novo critério relacionado à presença do autoanticorpo NMO-IgG foi incluído, com o propósito de facilitar sua distinção da $E M^{(11)}$. Estes novos critérios foram assim definidos:

- NMO definida

- Presença dos dois critérios maiores:

1- Neurite óptica

2- Mielite aguda

- E pelo menos dois dos três critérios de apoio seguintes:

1- Ressonância magnética com evidência de lesão medular contínua com extensão maior ou igual a três corpos vertebrais no eixo craniocaudal (Figura A);

2- Ressonância magnética de encéfalo que não preenche critérios diagnósticos para esclerose múltipla (Figura B);

3- $\quad$ NMO-lgG sérico positivo.

Um novo paradigma começou a ser construído quando pesquisadores de vários centros começaram a apresentar estudos que exibiam testes 
positivos para NMO-IgG (em graus variáveis de sensibilidade e especificidade) em pacientes que possuíam forte suspeita clínica de serem portadores de NMO definida, porém apresentavam apenas uma manifestação clínica definida, fosse ela MTLE ou NO bilateral e/ou recorrente ${ }^{(12-14)}$. Tais achados permitiram gerar evidências de que estas patologias também compartilhavam a mesma fisiopatologia da NMO definida e da OSMS. A partir destes dados, em 2007, este grupo de doenças passou a ser reconhecido pelo termo espectro da NMO (NMO-SD), e foi assim classificado por Wingerchuck et al. ${ }^{(15)}$ :

1- Neuromielite óptica definida

2- Formas limitadas de neuromielite óptica:

- Episódio único ou recorrente de mielite transversa longitudinalmente extensa (MTLE), apresentando extensão maior ou igual a três corpos vertebrais no eixo craniocaudal.

- Neurite óptica (NO) recorrente ou simultânea bilateral

3- Forma óptico-espinhal da Esclerose Múltipla (OSMS)

4- Neurite óptica (NO) ou mielite transversa longitudinalmente extensa (MTLE) associada à doença autoimune sistêmica

5- Neurite óptica (NO) ou mielite transversa longitudinalmente extensa (MTLE) associada a lesões cerebrais típicas de neuromielite óptica (hipotalâmica, corpo caloso, periventricular ou tronco cerebral).

Ainda corroborando para a hipótese de que todas estas apresentações clínicas compartilham de uma patogenia em comum, estudos posteriores demonstraram que pacientes portadores destas formas limitadas 
da NMO (MTLE ou NO bilateral, por exemplo) podem, com o tempo, evoluir para NMO clinicamente definida. Bizzoco et al. (2009), seguindo 13 pacientes com formas limitadas da NMO num período de dois anos, observaram que $53 \%$ destes pacientes evoluíram para NMO clinicamente definida ${ }^{(16)}$.

Assim sendo, as doenças do NMO-SD passaram a integrar o grupo das doenças neurológicas com envolvimento de um canal de água específico, a aquaporina 4.

Denomina-se canalopatias todas as doenças produzidas por uma anomalia do funcionamento dos canais iônicos. Entre as principais canalopatias podemos citar aquelas que afetam os músculos em geral, como a miastenia grave e as paramiotonias; as que acometem o sistema nervoso, como a esclerose lateral amioatrófica; e aquelas que levam a um comprometimento da função cardíaca. Estas últimas são as canalopatias mais conhecidas e, em geral, são canalopatias hereditárias. Entre elas podemos citar a síndrome do QT longo, síndrome do QT curto, síndrome de Brugada e taquicardia ventricular polimórfica catecolaminérgica.

Até então não havia ainda sido descrita uma canalopatia do SNC de causa autoimune, o que só veio a acontecer após as descobertas da fisiopatologia da NMO, descritas por Lennon et al. ${ }^{(5)}$. 


\subsection{EPIDEMIOLOGIA}

NMO definida é nove vezes mais prevalente em mulheres do que em homens $^{(4 ; 13 ; 15 ; 17)}$. A idade média de apresentação (39 anos) é maior que a idade média de apresentação da EM (29 anos), embora NMO possa também ocorrer em crianças e idosos ${ }^{(18 ; 19)}$. Em contraste com a EM, NMO é relativamente mais comum em indivíduos não brancos e em populações com menor contribuição europeia em sua composição genética, como no Brasil e Ásia ${ }^{(20 ; 21 ; 22 ; 23)}$.

\subsection{PATOGENIA DA NEUROMIELITE ÓPTICA}

Baseado na alta especificidade do anticorpo anti AQP4 e na perda seletiva de AQP4 nas lesões da NMO, postula-se que a ativação do complemento pelo anticorpo anti-AQP4 desenvolva papel fundamental no desenvolvimento das lesões em NMO ${ }^{(24)}$. Uma vez que o anticorpo atravessa a barreira hematoencefálica, liga-se a moléculas de AQP4 nos pés dos astrócitos e ativa o complemento (Figura 1) ${ }^{(25)}$. A ativação do complemento mobiliza neutrófilos e eosinófilos, que passam a facilitar a destruição tecidual. A constatação de que os anticorpos anti-AQP4 até agora examinados são todos subclasse $\lg$ (NMO-lgG), e de que podem eficazmente fixar o complemento, é consistente com essa hipótese. Na NMO a desmielinização é secundária à destruição dos astrócitos, oposto à desmielinização primária, onde o processo se dá por ação dos 
autoanticorpos anti-mielina que se ligam a antígenos específicos da mielina que envolve os axônios ${ }^{(26)}$.

À microscopia, as lesões ativas exibem edema, infiltrado de macrófagos, micróglia ativada, graus variados de desmielinização, perda axonal, necrose proeminente e variável inflamação perivascular com evidência de eosinófilos e produtos de sua exocitose. A ruptura dos astrócitos prolonga o edema vasogênico ${ }^{(26-28)}$.

As lesões crônicas são caracterizadas por gliose, degeneração cística, cavitação e atrofia ${ }^{(26-28)}$.

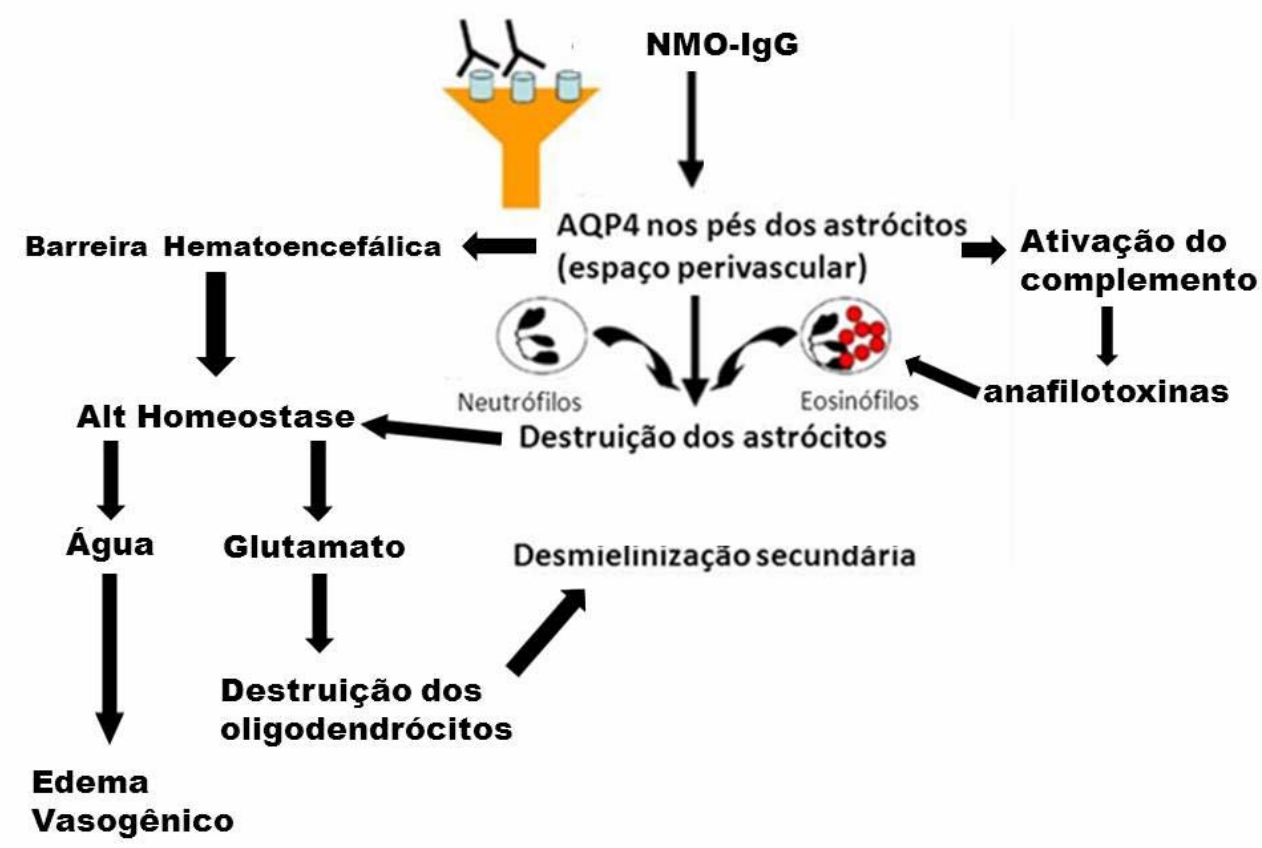

Figura 1 - Processo de destruição de um astrócito por ativação do complemento através da AQP4. Uma vez que o anticorpo IgG anti-AQP4 atravessa a barreira hemato-encefálica, ele liga-se à AQP4 no pé dos astrócitos, fixa e ativa o complemento. A ativação do complemento mobiliza neutrófilos e eosinófilos, que então produzem severo dano tecidual e causam desmielinização secundária. Ruptura dos astrócitos prolonga o edema vasogênico causado por inflamação. (Adaptado de Kira et al., 2011) 
A fisiopatologia da doença nos pacientes com NMO-SD com sorologia NMO-IgG negativa ainda permanece incerta. Dados obtidos de estudos clínicos, sorológicos, imunopatológicos e terapêuticos revelam similaridades entre os pacientes soropositivos e soronegativos portadores de NMO recorrente, sugerindo que pacientes NMO-IgG soronegativos possam fazer parte de uma patologia cujo antígeno seja similar ou possua em sua constituição proteínas análogas à AQP4 ${ }^{(7 ; 29)}$. A identificação destes antígenos nos casos de NMO-IgG soronegativos poderá proporcionar fundamentos para novas estratégias de pesquisa para elucidar os mecanismos imunopatogênicos de desmielinização na NMO, permitindo nova classificação das doenças inflamatórias desmielinizantes do SNC, servindo de base para novas pesquisas terapêuticas.

\subsection{APRESENTAÇÕES CLÍNICAS}

As duas principais apresentações da NMO definida são mielite transversa, que acomete extensamente a medula, e neurite óptica. Estas duas condições podem ocorrer simultaneamente, numa sucessão rápida, ou serem separados por alguns anos. Alguns pacientes têm episódios repetidos de neurite óptica antes que a mielite ocorra, mas o contrário também pode acontecer. A maioria dos afetados (> 80\%) terá episódios de recorrência (NMO recorrente). Alguns pacientes podem ter apenas o evento inicial (doença monofásica) ${ }^{(4 ; 30)}$. Recorrência pode ocorrer em até $55 \%$ dos pacientes no primeiro ano de seguimento e em até $90 \%$ em 5 anos ${ }^{(30)}$. É 
importante ressaltar que o dano neurológico na NMO é adquirido como consequência das recorrências, sendo raro o dano progressivo na ausência de episódios recorrentes ${ }^{(12)}$.

O quadro de mielite tem instalação variada, de algumas horas, dias ou mesmo semanas, sendo clinicamente expresso por sinais e sintomas de disfunção das estruturas medulares, compondo uma síndrome medular aguda, com alterações sensitivas, motoras e autonômicas. As alterações sensitivas cursam com distribuição dermatomal ou segmentar, podendo haver diminuição ou perda de uma ou mais modalidades sensoriais, bem como dores ou diestesias nos dermátomos afetados. Em geral, o nível sensitivo de dor/temperatura é o mais específico para se localizar o nível da lesão medular. Os déficits motores variam conforme o local e o grau da lesão, e seguem o tipo mielite transversa completa, com para ou tetraparesia quase sempre simétrica ${ }^{(4)}$. Os segmentos afetados cursam inicialmente com paralisia flácida e, posteriormente, com paralisia espástica e hiperreflexia, após a fase de choque medular, de duração variável, em geral menor do que quatro semanas. A intensidade do quadro clínico tende a ser mais severa que aquela encontrada na EM, onde os sintomas são mais leves e assimétricos, em decorrência de mielite transversa parcial.

As disfunções autonômicas, assim como as demais, também dependem do grau e do local de lesão. Inicialmente, podemos observar anidrose, vasodilatação e aumento da temperatura da pele, com posterior vasoconstrição e diminuição da temperatura, sudorese e piloereção. As alterações esfincterianas e sexuais são muito comuns. Na fase de choque a 
atonia e retenção urinária estão geralmente presentes. Após esta fase, hiperatividade detrusora com diminuição da capacidade vesical prevalecem. Urgência miccional, incontinência urinária e fecal, priapismo, sensação de esvaziamento vesical e evacuação incompleta são queixas frequentes.

Sinais e sintomas decorrentes do acometimento do tronco encefálico, particularmente do assoalho do IV ventrículo, tais como náuseas, vômitos, soluços intratáveis, vertigem, perda auditiva, paresia facial, neuralgia trigeminal, diplopia, ptose e nistagmo já foram descritos como primeira manifestação da NMO em até $17 \%$ dos casos ${ }^{(10 ; 31)}$.

Em menor frequência, encefalopatia, disfunção hipotalâmica e alterações cognitivas podem ser encontradas ${ }^{(32)}$. Embora manifestações clínicas destas anormalidades cerebrais sejam incomuns em adultos, $45 \%$ das crianças NMO-IgG soropositivas vão desenvolver precocemente ataques cerebrais sintomáticos, incluindo vômitos intratáveis, soluços e encefalopatia $^{(33)}$.

A neurite óptica que ocorre na NMO é geralmente mais grave do que a habitualmente encontrada na EM. Wingerchuckt et al., mostraram em uma série, que $60 \%$ dos pacientes portadores de NMO recorrente estavam cegos após 7,7 anos de seguimento ${ }^{(4)}$.

Neuromielite óptica pode ocasionalmente estar associada com algumas doenças sistêmicas, como as doenças vasculares do colágeno; infecções pelos vírus da varicela-zoster, vírus Epstein-Barr e HIV; lúpus 
eritematoso sistêmico; síndrome de Sjogren; e exposição ao clioquinol e às drogas para tratamento de tuberculose ${ }^{(34-36)}$.

As manifestações clínicas das demais doenças que compõem o espectro NMO têm semelhança com o quadro clínico da NMO definida, exceto pelo fato de que estas frequentemente apresentam um quadro clínico mais restrito, contemplando a mielite transversa longitudinal extensa ou neurite óptica recorrente.

Muitos estudos já foram realizados no intuito de avaliar as características clínicas e laboratoriais da mielite e da neurite óptica. Entretanto, segundo nosso conhecimento, não existe até hoje na literatura médica estudo sobre as características e prevalência dos distúrbios miccionais encontrados em pacientes com NMO-SD.

\subsection{MÉTODOS DIAGNÓSTICOS}

\subsubsection{Testes imunológicos}

A identificação do anticorpo anti-aquaporina 4 (NMO-lgG) em pacientes com quadro clínico suspeito indica envolvimento humoral e contribui para a diferenciação imunológica com a esclerose múltipla ${ }^{(37)}$. Esta distinção é importante, pois como descrito a seguir, pode influenciar o tratamento dos pacientes, já que a abordagem terapêutica é diferente. Entretanto, isto nem sempre é possível no momento dea apresentação da doença, pois os anticorpos NMO-IgG por vezes tornam-se detectáveis 
somente anos depois do início do quadro clínico ${ }^{(38)}$. Além disso, acrescentase à dificuldade diagnóstica, o fato de que 5 a $10 \%$ dos pacientes com EM clássica podem apresentar o anticorpo lgG-NMO ${ }^{(6 ; 37)}$.

Outra importante aplicabilidade clínica da NMO-IgG é a capacidade de predizer recorrência em pacientes do espectro $\mathrm{NMO}^{(30)}$.

Várias séries de estudos realizadas em diferentes centros, utilizando as técnicas de imunofluorescência e imunoprecipitação para detecção da NMO-IgG, têm apontado uma sensibilidade entre 33 e $73 \%$, e especificidade de 91 a 100\% para diagnóstico de NMO ${ }^{(5 ; 14 ; 39 ; 0)}$. Duas recentes séries brasileiras realizadas com pacientes portadores de NMO recorrente apontaram 41 e $64,3 \%$ de positividade para NMO-lgG ${ }^{(41 ; 42)}$.

Nos pacientes que apresentam as outras formas do espetro da NMO, a sensibilidade para NMO-IgG parece ser menor. Estudos realizados em pacientes com MTLE indicam sensibilidade entre 15 e $50 \%$, e nos pacientes com neurite óptica recorrente, as taxas podem variar de 14 a $25 \%{ }^{(12-14 ; 43)}$. No Brasil, Adoni et al. (2010), após avaliarem 11 pacientes com neurite óptica recorrente e 13 com mielite longitudinal extensa, encontraram 27,3\% e $23 \%$ de positividade para NMO-lgG, respectivamente ${ }^{(44)}$.

\subsubsection{Exames de imagem}

O exame de imagem com melhor acurácia para diagnóstico das lesões neurológicas é a ressonância magnética (RM). Durante a fase aguda da mielite, a lesão medular indicativa da NMO pode se apresentar lateral, 
centro ou holomedular no plano axial e tipicamente se estende longitudinalmente por três ou mais corpos vertebrais, com hipersinal na aquisição ponderada em T2 (Figura 2.A). Nesta fase, há captação de gadolínio e o edema com alargamento medular é comum. As lesões cervicais podem se estender até as porções inferiores do bulbo. $\mathrm{Na}$ fase crônica, as lesões podem se resolver completamente ou podem surgir atrofia e cavitação central da medula ${ }^{(45 ; 46)}$.

A NMO tem sido definida como uma doença sem lesões cerebrais à RM (Figura 2.B). Classicamente, a imagem cerebral que apoia o diagnóstico da NMO é normal nas fases iniciais. Entretanto, recentemente, diversos estudos têm mostrado que até $65 \%$ dos pacientes portadores da doença podem ter lesões encefálicas subcorticais difusas assintomáticas, em estágio mais tardio da doença ${ }^{(47 ; 4)}$. Estas alterações da RM de encéfalo raramente são semelhantes às lesões da EM a ponto de preencher critérios de Barkhof ${ }^{(10 ; 49)}$ e possivelmente estão relacionadas à presença disseminada de AQP4 no sistema nervoso central, principalmente na região periventricular, no hipotálamo e no tronco encefálico ${ }^{(10)}$. 


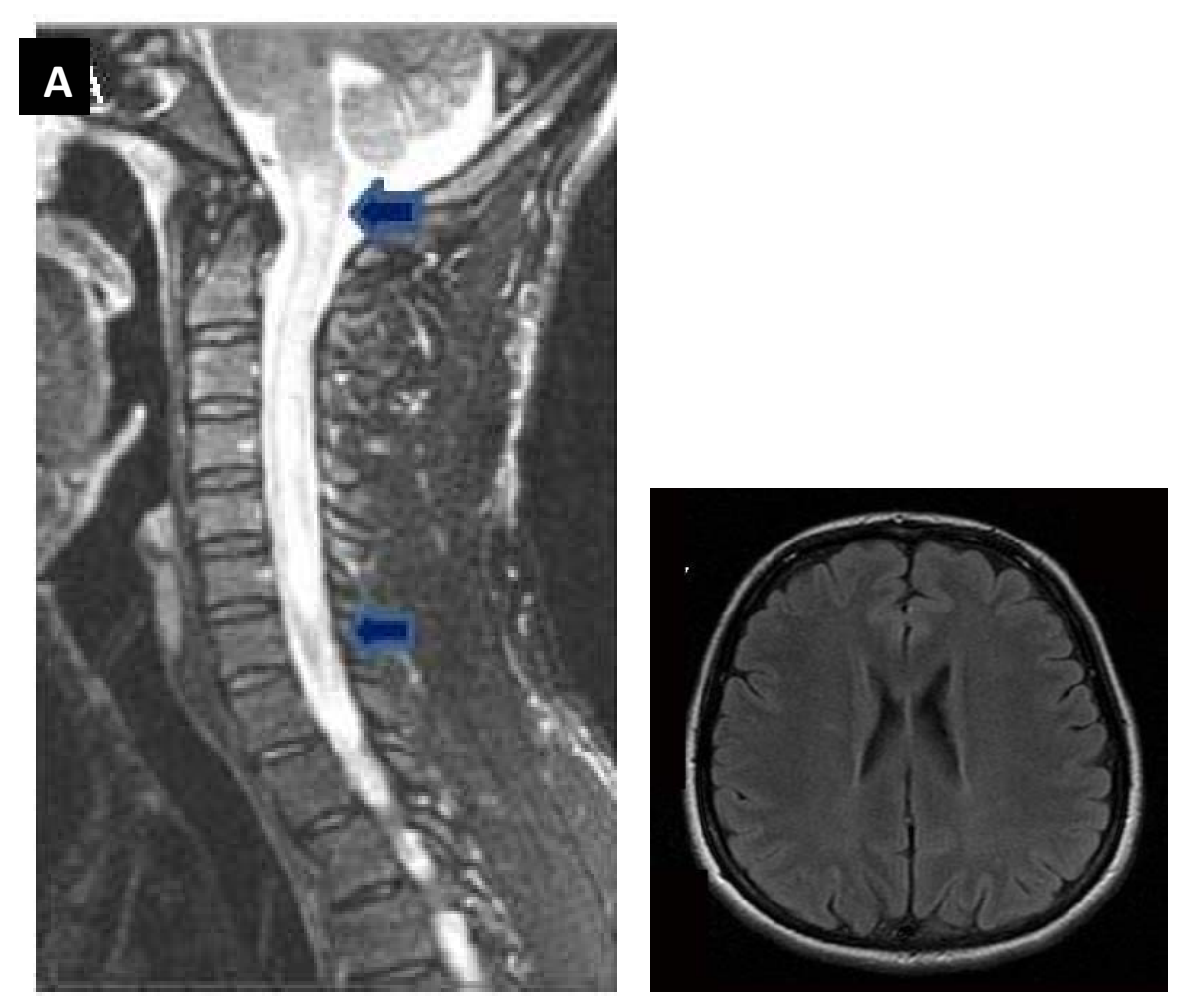

Figura 2 - Ressonância Magnética: padrão de acometimento longitudinal medular e encefálico. Achados típicos de $\mathrm{NMO}$ ao exame de RM: (A) RM de coluna cervical em corte sagital demonstrando lesão holomedular com efeito tumefativo que se estende desde o bulbo (seta superior) até a sexta vértebra cervical (seta inferior), caracterizada por hipersinal na aquisição ponderada em T2; (B) RM do encéfalo em corte axial demonstrando ausência de alterações patológicas

A RM na neurite óptica aguda evidencia captação de contraste na porção pré-quiasmática do nervo óptico em $94 \%$ dos casos e hipersinal em T2 em $84 \%$. Na fase de remissão, há aumento do sinal do nervo óptico em T2 em $20 \%$ dos casos ${ }^{(50)}$. 


\subsection{DIAGNÓSTICO DIFERENCIAL}

O principal desafio está no diagnóstico diferencial com a EM e com a Síndrome Clinicamente Isolada (CIS - clinically isolated syndrome). Porém, devem ser ainda consideradas a esclerose concêntrica de Balo, Marbug, forma tumefativa da EM e encefalopatia aguda disseminada (ADEM - acute disseminated encephalomyelitis), incluindo a forma de leucoencefalite hemorrágica aguda ${ }^{(34 ; 51)}$.

Em todo quadro de mielopatia aguda é importante que se avalie rapidamente a presença de compressão. Outras causas de compressão medular aguda que também devem ser consideradas no diagnóstico diferencial incluem: hérnias de disco, fraturas patológicas, abscessos, hemorragias e neoplasias primárias ou metastáticas. $\mathrm{O}$ diagnóstico diferencial inclui ainda ADEM, doença de Behçet, doença mista do tecido conjuntivo, granulomatose de Wegener, lúpus eritematoso sistêmico, sarcoidose, síndrome de Sjögren, além de doenças infecciosas, como cisticercose, esquistossomose, infecções pelo vírus da imunodeficiência humana (HIV), vírus linfotrópico da célula humana (HTLV-I/II), herpes, deficiência de vitamina B12, e intoxicação por tolueno e etanol. 


\subsection{TRATAMENTO}

A partir de 2004, com a descoberta da mediação humoral da NMO através de anticorpos da classe IgG, houve mudança na abordagem terapêutica, que antes desse período se baseava, sem sucesso, nos mesmos princípios destinados à EM.

O tratamento da NMO visa aliviar os sintomas e prevenir recorrências e/ou instalação de déficits neurológicos irreversíveis. Usualmente, o tratamento de um quadro agudo inicial inclui corticoesteroides para conter a crise aguda, e drogas imunossupressoras para prevenção de ataques subsequentes ${ }^{(52)}$. Pacientes com recorrências frequentes podem necessitar de uma baixa dose de corticoesteroides por longos períodos ${ }^{(53)}$. Embora o uso de imunomoduladores tenha sido descrito como eficaz no tratamento e redução do risco de recorrência e progressão em esclerose múltipla, tal terapia não tem apresentado resposta favorável na NMO ${ }^{(54)}$.

Os pacientes que não apresentam resposta favorável aos corticosteroides devem ser submetidos à plasmaferese ou à pulsoterapia com ciclofosfamida ${ }^{(55)}$. Atualmente, outras opções de tratamento incluem o mitoxantrone na fase aguda, e o rituximab, que é um anticorpo monoclonal anti-CD20, para a fase de manutenção ${ }^{(56 ; 57)}$. 


\subsection{PROGNÓSTICO}

Muitos indivíduos portadores do espectro da NMO têm um curso imprevisível, com episódios agudos de crise ocorrendo com meses ou anos de intervalo. $\mathrm{O}$ dano neurológico é geralmente cumulativo e acontece em decorrência das sequelas dos episódios clínicos de mielite e neurite óptica. O número de episódios de recorrência nos dois primeiros anos de NMO é sabidamente um preditor de pior prognóstico ${ }^{(58)}$. Diferentemente da esclerose múltipla (EM), não há progressão da doença entre estes episódios ${ }^{(11)}$. Alguns indivíduos são severamente afetados pela NMO e podem perder a visão em ambos os olhos. A sensibilidade e motricidade dos membros também podem ser afetadas. Após cinco anos do início da doença, cerca de $50 \%$ dos pacientes são incapazes de deambular sem auxílio, ou apresentam perda visual total em pelo menos um dos olhos ${ }^{(4)}$. Em casos graves, a perda da força muscular pode causar dificuldade respiratória e requerer o uso de ventilação artificial. A taxa de mortalidade é alta, e a morte destes pacientes se dá geralmente por complicações respiratórias nos episódios de recorrência da mielite cervical. No final da década de 90, a estimativa de sobrevida em 5 anos era de $68 \%{ }^{(58)}$. Em séries brasileiras foram encontradas taxas de mortalidade com variação entre 9 e $50 \%{ }^{(23 ; 44 ; 59)}$.

A descoberta recente do marcador sérico NMO-IgG representou um grande avanço na abordagem dos pacientes portadores do espectro da NMO. Pode permitir o diagnóstico mais precoce além de ter caráter prognóstico ${ }^{(30 ; 60)}$. Possui ainda importância na escolha terapêutica, já que o 
uso de imunomoduladores, tão comum na EM, pode até piorar o curso clínico da $\mathrm{NMO}^{(61)}$.

\subsection{NEUROFISIOLOGIA DO TRATO URINÁRIO INFERIOR}

O acometimento medular em pacientes portadores de NMO-SD pode, como já mencionado, evoluir com disfunções do sistema nervoso autônomo. Disfunções miccionais, neste caso, são manifestações clínicas esperadas. Para uma melhor compreensão da fisiopatologia destas manifestações, faremos antes, um breve resumo da neurofisiologia do TUI.

O trato urinário inferior (TUI) realiza duas funções básicas, o armazenamento e o esvaziamento de urina. Para que essas funções possam ocorrer adequadamente, é necessário que ocorra relaxamento da musculatura lisa vesical e aumento coordenado do tônus esfincteriano uretral durante a fase de enchimento da bexiga, e o oposto durante a micção. A coordenação das atividades da bexiga e do esfíncter uretral envolve uma complexa interação entre os sistemas nervosos (central e periférico) e os fatores regulatórios locais. Assim sendo, o funcionamento da bexiga é coordenado em diferentes níveis do sistema nervoso central, localizados na medula, na ponte e em centros superiores, e também no centro sacral da micção, localizado na medula espinal, entre os segmentos S2 e S4 ${ }^{(62)}$. Os estímulos nervosos inibitórios ou excitatórios que partem do SNC e se dirigem aos órgãos do TUI (estímulos eferentes), bem como 
aqueles que se originam destes e se dirigem ao SNC (estímulos aferentes) são mediados por neurotransmissores, e dependem do tipo de fibra nervosa envolvida ${ }^{(63)}$. A musculatura lisa da bexiga, a região uretrotrigonal e a uretra proximal são inervadas por fibras do plexo pélvico. Este plexo, localizado profundamente na cavidade pélvica, é composto por fibras nervosas mescladas entre os nervos pélvicos (parassimpático), e os nervos hipogástricos (simpático). O plexo pélvico representa uma verdadeira rede de fibras nervosas que incorpora vários gânglios, com função de distribuir as diferentes funções de ambas as divisões do sistema nervoso autônomo. Perifericamente, o TUI é inervado por três tipos diferentes de fibras eferentes (62).

1. Parassimpáticas: a inervação vesical parassimpática origina-se de neurônios localizados na coluna intermediolateral dos segmentos S2-S4 da medula e é conduzida pelo nervo pélvico até os gânglios localizados no plexo pélvico. Este se localiza lateralmente ao reto e origina as fibras parassimpáticas pós-ganglionares, que se dirigem para a bexiga e uretra.

2. Simpáticas: a inervação eferente simpática é originada no segmento toracolombar da medula, de T10 a L2, e direciona-se, através da cadeia simpática, ao plexo hipogástrico superior (préaórtico). A subdivisão caudal deste plexo forma o nervo hipogástrico, contendo os eferentes pós-ganglionares simpáticos para a bexiga e uretra. 
3. Somáticas: a inervação da musculatura estriada do esfíncter uretral é predominantemente somática. Origina-se no núcleo de Onuf, localizado no corno anterior de um ou mais segmentos da medula espinhal sacral (S2-S4). Fibras somatomotoras originadas deste núcleo inervam o esfíncter uretral, através dos nervos pudendos, sem conexão em gânglios periféricos.

As inervações aferentes (sensitiva) da bexiga e da uretra estão igualmente contidas nas ramificações do plexo pélvico, e atingem a medula espinhal via nervos pélvicos ou hipogástricos. Dividem-se nos seguintes grupos $^{(63 ; 64)}$ :

1. Fibras nocioceptivas: a sensação de dor é causada por processos irritativos de natureza físico-química relacionadas como a presença de cálculos vesicais, processos infamatórios e infecciosos, etc. As fibras chegam à medula através das raízes S2 e S4 posteriores, terminando na substância cinzenta pósterolateral. Os impulsos trafegam nos tratos espinotalâmicos laterais até o tálamo, e daí é transmitida para o córtex e a sensação dolorosa torna-se consciente.

2. Fibras proprioceptivas: são relacionadas à percepção da distensão vesical. Estas fibras originam-se no detrusor e seguem através do plexo hipogástrico até os seguimentos T10 A L2 da medula espinal. Esses impulsos trafegam através do fascículo grácil em direção à ponte e ao córtex cerebral 
3. Fibras C: são fibras desmielinizadas e têm função no reflexo da micção. Em animais que têm lesão medular na fase crônica, o reflexo da micção ocorre com estímulo das fibras C. Nos animais sem lesão neurológica, o reflexo é fraco ou indetectável. No homem, as fibras C estão relacionadas à hiperatividade detrusora em pacientes com lesão neurológica como, por exemplo, a esclerose múltipla.

A atividade dos centros medulares é controlada por centros superiores, através de tratos descendentes cefaloespinhais. A micção é coordenada no tronco encefálico, especificamente na substância pontinomesencefálica, denominado centro pontino da micção (CPM), que é a via final comum para os motoneurônios da bexiga, localizados na medula espinhal. Em circunstâncias normais, a micção depende de um reflexo espino-bulbo-espinhal liberado pelo CPM. Este recebe influências do córtex cerebral, do cerebelo, dos glânglios da base, do tálamo e do hipotálamo (influências suprapontinas), em sua maior parte inibitórios ${ }^{(62)}$.

O ciclo miccional normal pode ser descrito da seguinte maneira:

1. Fase de armazenamento vesical. A distensão da bexiga pelo volume urinário, leva à ativação progressiva dos nervos aferentes vesicais. Esta ativação é acompanhada pela inibição reflexa da bexiga, através do nervo hipogástrico e é simultânea à estimulação do esfíncter externo via nervo pudendo. O CPM é continuamente monitorado sobre as condições de enchimento vesical, mantendo sua influência inibitória sobre o centro medular 
sacral, e liberando progressivamente a ativação do esfíncter externo $^{(65 ; 66)}$.

2. Fase de esvaziamento vesical. Após alcançar um nível crítico de enchimento vesical e sendo a micção desejada naquele momento, o CPM interrompe a inibição sobre o centro sacral da micção (parassimpático), que ativa a contração vesical através do nervo pélvico. Ao mesmo tempo, a influência inibitória sobre a bexiga, feita pelo sistema nervoso simpático através do nervo hipogástrico, é interrompida e ocorre simultânea inibição da ativação somática do esfíncter, relaxando o aparelho esfincteriano e garantindo a coordenação da micção ${ }^{(65 ; 66)}$.

Nestas circunstâncias, o ciclo miccional desenvolve-se como uma alternância destas duas fases, onde em um primeiro momento, ocorre a inibição dos reflexos da micção (inibição vesical através da estimulação simpática e inibição da estimulação parassimpática) e ativação dos reflexos de enchimento vesical (estimulação esfincteriana pudenda). Em um segundo momento, quando se atinge a repleção vesical máxima, este mecanismo é alterado para a ativação dos reflexos da micção (estimulo vesical parassimpático) e inibição dos reflexos de enchimento (inibição da ativação esfincteriana) no intuito de se iniciar a micção. 


\subsection{LESÃO NEUROLÓGICA E DISTÚRBIOS MICCIONAIS}

O conhecimento da neuroanatomia e da neurofisiologia envolvida no controle da micção, nos permite antecipar quais os prováveis distúrbios miccionais que podem ocorrer em decorrência do comprometimento de diferentes estruturas do sistema nervoso. Desta forma, o fator mais importante nesse sentido é a localização destas estruturas afetadas. Vejamos á seguir as prováveis disfunções miccionais segundo a área de comprometimento do SNC:

- Patologias que envolvem estruturas acima do tronco cerebral geralmente resultam em hiperatividade detrusora, com preservação da coordenação detrusor-esfincteriana. Os sintomas associados geralmente são aumento da frequência miccional, urgência, urge-incontinência e noctúria. Raramente existe deterioração do trato urinário superior, já que havendo preservação do sinergismo vesico-esfincteriano, as pressões intravesicais estarão mantidas em baixos níveis. Entre as patologias mais frequentes, destacamos os acidentes vasculares cerebrais, os traumatismos crânio-encefálicos, os tumores cerebrais e doença de Parkinson ${ }^{(67)}$.

- Patologias que acometem a medula espinhal acima do segmento sacral, evoluem na maioria das vezes com o desenvolvimento de hiperatividade detrusora, devido à reorganização de conexões sinápticas na medula e emergência de via reflexa excitatória 
ativada por fibras amielínicas aferentes da bexiga ${ }^{(68)}$. As lesões acima do segmento T6 também podem produzir perda da coordenação entre a função vesical e a esfincteriana, sendo comum nesta situação a presença de hiperatividade detrusora com falta de sinergia detrusor-esfincteriana. A falta de inibição do arco reflexo da micção associa-se à perda da coordenação do relaxamento esfincteriano, já que o CPM também pode estar desconectado dos centros medulares da micção. A principal causa de lesões nesta região são os traumatismos raqui-medulares, as mielodisplasias e as doenças desmielinizantes como a esclerose múltipla e a neuromielite óptica. Nestes pacientes, os sintomas mais frequentes são a incontinência urinária, dificuldade miccional e infecções urinárias de repetição. A maioria dos pacientes apresenta bexiga com pressões vesicais elevadas, em decorrência do aumento da pressão detrusora e da falta de relaxamento esfincteriano. Esta associação, se não tratada, pode levar ao refluxo vésico-ureteral bilateral, hidronefrose e consequente deterioração progressiva do trato urinário superior, podendo inclusive, culminar em perda da função renal ${ }^{(67)}$.

- Nas lesões medulares que acometem o segmento abaixo de S2S4, a acontratilidade detrusora é o padrão mais frequente, uma vez que o centro parassimpático da micção é lesado. O mecanismo esfincteriano pode ser afetado de várias maneiras, mas geralmente mantém um tônus moderado. Os pacientes com 
lesões nesse nível geralmente apresentam sintomas de dificuldade miccional associados à perda total ou parcial da sensibilidade vesical. Podem apresentar também incontinência por transbordamento. Por vezes, pode haver lesão predominante do núcleo de Onuf, responsável pela inervação do rabdoesfincter uretral. Nessas circunstâncias pode ocorrer deficiência esfincteriana. As patologias que mais frequentemente acometem esse segmento da medula são as mielodisplasias e os traumas raqui-medulares ${ }^{(67)}$.

As lesões que acometem estruturas periféricas podem ser bastante semelhantes às lesões dos segmentos medulares sacrais inferiores. Frequentemente, entretanto, o tônus esfincteriano pode ser muito baixo e pode ocorrer deficiência esfincteriana severa. São causadas por traumatismos pélvicos graves e cirurgias pélvicas radicais ${ }^{(67)}$. 
2 OBJETIVOS 
1- Determinar a prevalência dos sintomas do trato urinário inferior em portadores do espectro da NMO;

2- Avaliar as características urodinâmicas dos distúrbios miccionais em portadores do espectro da NMO;

3- Avaliar a associação entre os distúrbios miccionais, a gravidade da doença neurológica e a qualidade de vida dos pacientes portadores do espectro da NMO. 
3 MÉTODOS 
Em um estudo transversal, realizado entre fevereiro de 2010 e fevereiro de 2011, avaliamos prospectivamente 30 pacientes consecutivos portadores do espectro da NMO (NMO-SD). Todos os pacientes foram encaminhados do ambulatório de Neurologia do Instituto Central do Hospital das Clínicas da Faculdade de Medicina da Universidade de São Paulo (HCFMUSP), onde eram acompanhados. Todos os pacientes tinham diagnóstico estabelecido de NMO-SD por neurologista especializado em doenças desmielinizantes. Todos foram previamente submetidos a exames de RM de encéfalo e coluna, e exames laboratoriais rotineiramente utilizados na avaliação destes pacientes, segundo seu protocolo de investigação. Todos os pacientes estavam sendo submetidos à avaliação urológica pela primeira vez e foram convidados a participar deste estudo, a despeito de apresentarem ou não sintomas urinários. Dois pacientes considerados elegíveis não participaram do estudo, por se recusarem a se submeter à avaliação completa.

O projeto de pesquisa foi aprovado pela Comissão de Ética para Análise de Projetos de Pesquisa - CAPPesq da Diretoria Clínica do Hospital das Clínicas e da Faculdade de Medicina da Universidade de São Paulo, sob número 1151/09 (Apêndice 1). 
Os pacientes concordaram em participar após completa divulgação dos propósitos do estudo. O Termo de Consentimento Livre e Esclarecido (TCLE) foi obtido de todos ou de seus representantes legais (Apêndice 2).

Este estudo foi realizado sem subsídio financeiro.

\subsection{CRITÉRIOS DE INCLUSÃO}

Ser portador do espectro NMO, seja da forma definida da NMO ou das formas limitadas da doença. Para isso, foram utilizados os critérios diagnósticos do espectro NMO propostos por Wingerchuck et al. $(2007)^{(15)}$.

\subsection{CRITÉRIOS DE EXCLUSÃo}

Foram considerados critérios de exclusão: volume prostático $\geq 30 \mathrm{~g}$ (aferido por ultrassonografia transabdominal); antecedente de cirurgias pélvicas, vesicais e prostáticas; antecedente de radioterapia pélvica; litíase vesical; cistocele e/ou retocele grau $\geq 3$, segundo classificação de BadenWalker ${ }^{(69)}$. Nenhum dos pacientes avaliados apresentou qualquer fator de exclusão. 


\subsection{AVALIAÇÃO NEUROLÓGICA}

A avaliação neurológica consistiu na realização da Escala Expandida do Estado de Incapacidade (EDSS - Expanded Disability Staus Scale) ${ }^{(70)}$ (Anexo A). Desenvolvida para avaliação da incapacidade neurológica em pacientes portadores de EM, a EDSS tem sido igualmente utilizada em pacientes portadores de NMO. Essa escala é baseada em oito sistemas funcionais (visual, piramidal, sensorial, cerebelar, controle esfincteriano, cerebral, tronco encefálico e capacidade de locomoção). É constituída por 20 intervalos de 0,5 pontos, onde 0 indica exame neurológico normal e 10 significa morte devido a NMO. Apesar de enfatizar a locomoção e apresentar problemas de padronização, sensibilidade, confiabilidade e variabilidade interavaliador, essa é ainda a medida mais utilizada em ensaios clínicos com pessoas com NMO.

O intervalo de tempo entre o início dos sintomas neurológicos e a data da avaliação para inclusão no estudo foi adotado como o tempo de duração da doença. Exames de RM da coluna, que haviam sido previamente realizados por ocasião do diagnóstico neurológico, foram revistos e os pacientes foram classificados de acordo com o nível da lesão medular. A positividade para NMO-IgG foi avaliada em todos os pacientes. 


\subsection{AVALIAÇÃO UROLÓGICA}

Os sintomas do trato urinário inferior (STUI) foram avaliados pelo Questionário de Avaliação da Bexiga Hiperativa (OAB-V8) (Anexo B) e pelo Escore Internacional de Sintomas Prostáticos (I-PSS) ${ }^{(71 ; 72)}$. Este último corresponde às mesmas 7 questões do American Urological Association symptom index, acrescido de uma questão referente à qualidade de vida em função da condição urinária (Anexo C). Antes de respondê-los, os pacientes recebiam uma breve instrução de preenchimento pelo médico investigador. Ambos os questionários foram autoaplicáveis ou nos casos em que a necessidade de auxílio para preenchimento se fez presente, este foi realizado pelo acompanhante do paciente. A intervenção para esclarecimento de eventuais dúvidas somente foi realizada pelo médico investigador quando solicitada.

Optamos por utilizar o OAB-V8 para avaliação dos sintomas de armazenamento vesical como frequência miccional, urgência, urgeincontinência e noctúria. Consideramos importante sua inclusão, pois como descrito na introdução deste trabalho, pacientes portadores de doenças desmielinizantes constituem uma população de risco para apresentar sintomas de bexiga hiperativa. O OAB-V8 é composto por 8 itens pontuados em uma escala de 6 pontos variando em 0 (nada), 1 (quase nada), 2 (um pouco), 3 (o suficiente), 4 (muito) e 5 (muitíssimo). O escore final é constituído pela soma da pontuação das 8 questões e pode variar de 0 a 40 . 
O I-PSS foi escolhido por ser o instrumento mais amplamente utilizado para a avaliação de STUI ${ }^{(73-75)}$. Nele são avaliados sete sintomas específicos, incluindo esvaziamento incompleto (questão I), frequência miccional (questão II), intermitência (questão III), urgência (questão IV), jato fraco (questão V), hesitação (questão VI) e noctúria (questão VII), e uma questão adicional de satisfação com a condição miccional. Noctúria é pontuada de 0 a 5 (5 ou mais micções por noite) e representa o número de micções por noite. Outros sintomas são pontuados em uma escala de 0 a 5 : 0 (nenhuma vez), 1 (menos de 1 vez a cada 5), 2 (menos que a metade das vezes), 3 (cerca de metade das vezes), 4 (mais que a metade das vezes) e 5 (quase sempre). O resultado da soma das sete questões sobre os sintomas urinários constitui o escore final de sintomas, que pode variar de 0 a 35.

Foram considerados sintomáticos os pacientes que apresentassem em pelo menos um destes questionários escore $\geq 8$. Somente foram considerados assintomáticos aqueles que tiveram pontuação $<8$ nos dois questionários. Para análise da presença de cada sintoma urinário utilizamos o I-PSS e a questão 8 do OAB-V8, destinada à avaliação específica de urgeincontinência. Em cada questão do I-PSS, consideramos o sintoma presente quando o escore apresentava-se $\geq 2{ }^{(76)}$. Adotamos este parâmetro pois, assim como sugerido por Tan et al. (1996) acreditamos que pacientes que assinalam escore 1 , têm o sintoma mas nem sempre se sentem incomodados com sua presença, o que por vezes é mais comum em pacientes que assinalam o escore 2. Corroborando a isto, outros autores ao estudarem especificamente noctúria, consideram-na clinicamente relevante, 
quando ocorrem duas ou mais micções por noite, fundamentados no fato de que o grau de incômodo correlaciona-se com o número de micções/noite (77;78). Efeito negativo substancial somente é observado quando ocorrem duas ou mais micções por noite ${ }^{(79)}$. Assim, em nosso estudo, utilizamos a definição de noctúria como duas ou mais vezes. Para a questão 8 do OABV8 consideramos urge-incontinência presente quando a pontuação obtida foi $\geq 1$.

Todos os pacientes foram submetidos a avaliação complementar que incluiu cultura de urina; dosagem creatinina sérica e antígeno prostático específico (PSA, para pacientes do sexo masculino com idade $\geq 40$ anos); e ultrassonografia do trato urinário com avaliação transabdominal do volume prostático. Foram ainda submetidos a exame vídeo-urodinâmico ou estudo urodinâmico associado à uretrocistografia miccional. O estudo urodinâmico foi conduzido segundo as boas práticas urodinâmicas e a terminologia utilizada foi baseada na padronização sugerida pela International Continence Society/ International Urogynecological Association de $201{ }^{(80 ; 81)}$. Os pacientes que eventualmente estivessem usando qualquer medicamento que pudesse influenciar no comportamento detrusor-esfincteriano, foram solicitados a descontinuar seu uso por pelo menos duas semanas antes do exame. Da mesma forma, todos os pacientes que apresentavam urocultura positiva foram adequadamente tratados antes da realização do estudo urodinâmico.

A avaliação urodinâmica consistiu em urofluxometria livre, cistometria, estudo pressão/fluxo, e registro eletromiográfico perineal usando eletrodos 
de superfície. Todos os pacientes permaneceram sentados durante todo o decorrer do exame. Após coleta da fluxometria livre, foi determinado o resíduo pós-miccional através de sondagem vesical. Para a cistometria de enchimento, utilizamos cateteres $6 \mathrm{~F}$ duplo lúmen para registro da pressão intravesical e 12F com balão na extremidade, para registro da pressão abdominal. A pressão detrusora foi determinada pela subtração da pressão abdominal da pressão vesical. As pressões foram medidas por transdutores externos conectados ao paciente por extensores completamente preenchidos por fluidos. O enchimento foi realizado através de infusão de soro fisiológico $0,9 \%$ à temperatura ambiente, em um fluxo de $30 \mathrm{ml} / \mathrm{min}$. Os eletrodos foram colocados transperinealmente na região do músculo bulbocavernoso nos homens e na margem anal às 2 e às 10 horas nas mulheres. Para isso, quando necessária, foi realizada tricotomia local e limpeza da área, com objetivo de se obter boa aderência do eletrodo à pele. Para registro dos dados utilizamos equipamento Uranus ${ }^{\circledR}$ (Alacer/São Paulo - Brasil), de múltiplos canais. Os parâmetros urodinâmicos analisados foram: fluxo livre, resíduo pós-miccional, capacidade cistométrica máxima, complacência vesical, atividade do detrusor (normal ou hiperativo), taxa do fluxo máximo durante o estudo de fluxo/pressão, pressão do detrusor no fluxo máximo e volume de urina residual. Sensibilidade vesical foi considerada normal quando o primeiro desejo miccional ocorreu após infusão intravesical de 150 a $250 \mathrm{ml}$ de soro fisiológico 0,9\%. A sensibilidade foi considerada aumentada quando este desejo ocorreu antes da infusão de $150 \mathrm{ml}$, e diminuída quando o desejo ocorreu após a infusão de $250 \mathrm{ml}$. A 
capacidade vesical foi considerada normal quando a capacidade cistométrica máxima variou de 300 a $400 \mathrm{ml}$. Abaixo deste intervalo foi considerada reduzida e acima deste, considerada aumentada. Complacência foi definida como o valor resultante da divisão do volume vesical pela pressão detrusora na capacidade cistométrica máxima, e foi considerada diminuída quando este valor foi menor que 20. Hiperatividade detrusora foi considerada presente quando sugiram contrações detrusoras involuntárias de qualquer amplitude associadas à urgência, durante a fase de armazenamento. Dissinergia detrusor-esfincteriana foi caracterizada por um aumento involuntário da atividade esfincteriana durante uma contração detrusora, e corroborada pela fluoroscopia quando disponível. Os testes de perda ao esforço foram realizados progressivamente ao mesmo tempo do enchimento vesical (após infusão de 200, 300, $400 \mathrm{ml}$ e em repleção máxima), através de manobra de valsalva. Foi considerada como pressão de perda ao esforço, a menor elevação necessária da pressão vesical para que houvesse perda e na ausência de elevação da pressão detrusora.

\subsection{QUALIDADE DE VIDA}

O comprometimento da qualidade de vida (QV) relacionada aos sintomas urinários foi medido pelo Índice de Avaliação de Qualidade de Vida do questionário I-PSS ${ }^{(82)}$ (questão 8) (Anexo C). Os pacientes deveriam responder como se sentiriam se tivessem que passar o resto da vida com a condição urinária atual: (0) ótimo, (1) muito bem, (2) satisfeito, (3) mais ou 
menos, (4) insatisfeito, (5) mal, e (6) péssimo. Para análise estatística, os pacientes que responderam (0) ótimo ou (1) muito bem foram agrupados e caracterizados como tendo boa qualidade de vida em relação aos sintomas urinários. Os que responderam outras alternativas (2 a 6) foram agrupados e classificados com qualidade de vida comprometida ${ }^{(83 ; 84)}$.

A avaliação da QV geral foi feita pelo questionário de Satisfação com a Vida (LiSat-9) ${ }^{(85)}$ (Anexo D). Ele é composto por 9 itens em uma escala de 1 a 6 , na qual o paciente pode expressar seu grau de satisfação (variação de 1- muito insatisfeito a 6- muito satisfeito) em relação aos seguintes aspectos: (1) vida em geral, (2) capacidade de autos-cuidados, (3) situação profissional, (4) situação financeira, (5) situação de lazer, (6) vida sexual, (7) relacionamento com a parceira, (8) vida em família, (9) contato com amigos e conhecidos. Para cada item, os pacientes foram classificados como não satisfeitos (1-4) ou satisfeitos (5-6). A pontuação final do LiSat-9 varia de 9 a 54, sendo que os números maiores indicam melhor qualidade de vida.

As questões foram autoaplicadas ou no caso de impossibilidade motora por parte do paciente, preenchidas com auxílio do acompanhante. A intervenção do médico investigador para esclarecimento de dúvidas, somente foi realizada quando solicitada. 


\subsection{ASSOCIAÇÃO ENTRE OS DISTÚRBIOS URINÁRIOS E $O$ COMPROMETIMENTO NEUROLÓGICO}

Para avaliarmos a influência do grau de acometimento neurológico nos sintomas urinários do trato urinário inferior (STUI), os escores do EDSS foram correlacionados com o I-PSS e o OAB-V8. Adicionalmente, avaliamos a associação entre os padrões urodinâmicos de disfunção detrusoresfincteriana e a gravidade da doença neurológica.

\subsection{IMPACTO DOS SINTOMAS DO TRATO URINÁRIO INFERIOR E DO COMPROMETIMENTO NEUROLÓGICO NA QUALIDADE DE VIDA GERAL}

Para avaliarmos a influência dos STUI e do comprometimento neurológico na qualidade de vida geral, testamos a correlação entre os escores de I-PSS e OAB-V8 com o LiSat-9, e do EDSS com o LiSat-9.

\subsection{ANÁLISE ESTATÍSTICA}

As variáveis quantitativas, contínuas ou ordinais foram descritas por medidas de tendência central (médias ou mediana) e as respectivas medidas de dispersão (desvios-padrões ou intervalo interquartil). As variáveis qualitativas ou categóricas, foram descritas por seus valores absolutos ou proporções. 
Na comparação das diferenças das variáveis contínuas, utilizamos o teste $\mathrm{t}$ de Student ou teste de Mann-Whitney. Na comparação dos dados categóricos, foram utilizados o teste do qui-quadrado e suas variantes. $\mathrm{Na}$ avaliação das correlações entre variáveis contínuas, empregou-se o teste de correlação de Pearson.

Valores de $p$ inferiores a $0,05 \quad(p<0,05)$ foram considerados estatisticamente significativos.

$\mathrm{Na}$ análise estatística, empregou-se um programa estatístico computacional (GraphPadPrism VERSÃO 5.0.3, GraphPadSoftware, San Diego-CA, USA). 
4 RESULTADOS 
Trinta pacientes foram incluídos no estudo, sendo 23 (76,7\%) mulheres e $7(23,3 \%)$ homens, com média de idade de $41,1 \pm 13,5$ anos (intervalo de 13 a 70 anos). Dezessete (56,7\%) eram afro-descendentes e $13(43,3 \%)$ brancos. Segundo a classificação de espectro NMO sugerida por Wingechuck et al. (2007), nossos pacientes se dividiram em: 14 (46,7\%) pacientes que apresentavam NMO definida e $16(53,3 \%)$ pacientes que apresentavam MTLE (mielite transversa longitudinalmente extensa). Nesta série, nenhum paciente tinha somente neurite óptica como manifestação clínica. A média de duração da doença neurológica foi de 33,8 $\pm 30,8$ meses (variou de 11 a 135 meses). As características clínicas e demográficas dos 30 pacientes estão descritas na Tabela 1. 
Tabela 1- Características clínicas, laboratoriais e demográficas dos 30 pacientes portadores do espectro da neuromielite óptica

\begin{tabular}{|c|c|c|c|c|c|c|c|c|c|c|c|}
\hline Paciente & Sexo & Idade & Etnia & $\begin{array}{l}\text { NMO definidal } \\
\text { MTLE }\end{array}$ & NMO-IgG & Recorrente & Co-morbidades & Gestações & Distopias & Medicamentos em uso & $\begin{array}{c}\begin{array}{c}\text { Tempo de } \\
\text { doença } \\
\text { neurológica } \\
\text { (meses) }\end{array} \\
\end{array}$ \\
\hline 1 & $\mathrm{~F}$ & 34 & B & MTLE & - & Não & obesidade & G2P2C0A0 & NÃO & $\begin{array}{c}\text { azatioprina, predinisona, } \\
\text { omeprazol }\end{array}$ & 24 \\
\hline 2 & $\mathrm{~F}$ & 31 & $A D$ & MTLE & + & Sim & 1 & G1P1C0A0 & NÃO & azatioprina, omeprazol & 60 \\
\hline 3 & $\mathrm{~F}$ & 35 & B & MTLE & - & Sim & 1 & G2P1C1A1 & Cistocele II & azatioprina, predinisona & 12 \\
\hline 4 & $\mathrm{~F}$ & 39 & $A D$ & MTLE & - & Sim & 1 & $\mathrm{G} 2 \mathrm{P} 0 \mathrm{C} 2 \mathrm{~A} 0$ & NÃO & azatiprina, predinisona & 30 \\
\hline 5 & $\mathrm{~F}$ & 22 & B & NMO definida & + & Sim & 1 & GOPOCOAO & NÃO & $\begin{array}{l}\text { azatioprina, predinisona, } \\
\text { carbonato de cálcio, } \\
\text { omeprazol }\end{array}$ & 135 \\
\hline 6 & M & 26 & B & NMO definida & - & Sim & 1 & 1 & 1 & azatioprina, predinisona & 36 \\
\hline 7 & $\mathrm{~F}$ & 32 & $A D$ & MTLE & + & Não & 1 & GOPOCOAO & NÃO & azatioprina, predinisona & 36 \\
\hline 8 & $\mathrm{~F}$ & 70 & $A D$ & MTLE & + & Sim & uveíte & GOPOCOAO & NÃO & azatioprina, predinisona & 11 \\
\hline 9 & M & 28 & $A D$ & MTLE & - & Não & 1 & 1 & 1 & azatioprina, predinisona & 12 \\
\hline 10 & $\mathrm{~F}$ & 40 & B & NMO definida & + & Sim & depressão & G1P0C1A0 & Cistocele I & $\begin{array}{l}\text { azatioprina, predinisona, } \\
\text { fluoxetina }\end{array}$ & 24 \\
\hline 11 & $\mathrm{~F}$ & 34 & $A D$ & NMO definida & + & Sim & depressão & G1P1C0A0 & Cistocele I & $\begin{array}{l}\text { azatiprina, predinisona, } \\
\text { fluoxetina }\end{array}$ & 81 \\
\hline 12 & $\mathrm{~F}$ & 60 & $A D$ & NMO definida & + & Sim & $\begin{array}{l}\text { diabetes II, } \\
\text { asma } \\
\text { brônquica }\end{array}$ & GOPOCOAO & NÃO & $\begin{array}{l}\text { azatioprina, predinisona, } \\
\text { glibenclamida, } \\
\text { amitriptilina }\end{array}$ & 48 \\
\hline 13 & M & 65 & $A D$ & MTLE & - & Sim & ex-etilista & 1 & 1 & azatioprina, predinisona & 20 \\
\hline 14 & $\mathrm{~F}$ & 39 & B & NMO definida & + & Sim & obesidade & G1P0C1A0 & NÃO & azatioprina, predinisona & 41 \\
\hline 15 & M & 56 & B & NMO definida & + & Sim & 1 & 1 & 1 & azatioprina, predinisona & 26 \\
\hline
\end{tabular}


Tabela 1- Características clínicas, laboratoriais e demográficas dos 30 pacientes portadores do espectro da neuromielite óptica (conclusão)

\begin{tabular}{|c|c|c|c|c|c|c|c|c|c|c|c|}
\hline Paciente & Sexo & Idade & Etnia & $\begin{array}{l}\text { NMO definidal } \\
\text { MTLE }\end{array}$ & $\begin{array}{l}\text { NMO- } \\
\text { IgG }\end{array}$ & Recorrente & Co-morbidades & Gestações & Distopias & Medicamentos em uso & $\begin{array}{c}\begin{array}{c}\text { Tempo de } \\
\text { doença } \\
\text { neurológica } \\
\text { (meses) }\end{array} \\
\end{array}$ \\
\hline 16 & $F$ & 47 & B & MTLE & - & Sim & obesidade & $\mathrm{G} 2 \mathrm{P} 1 \mathrm{C} 1 \mathrm{~A} 0$ & NÃO & $\begin{array}{l}\text { azatioprina, predinisona, } \\
\text { carbamazepina }\end{array}$ & 30 \\
\hline 17 & $\mathrm{~F}$ & 45 & B & NMO definida & + & Sim & 1 & G3P3C0A0 & Cistocele I & azatioprina, predinisona & 16 \\
\hline 18 & $\mathrm{~F}$ & 50 & B & NMO definida & - & Sim & 1 & G3P1C2A0 & Cistocele II & $\begin{array}{l}\text { azatioprina, predinisona, } \\
\text { carbonato de cálcio }\end{array}$ & 18 \\
\hline 19 & $\mathrm{~F}$ & 36 & B & MTLE & + & Sim & 1 & $\mathrm{G} 2 \mathrm{P} 2 \mathrm{C} 0 \mathrm{~A} 0$ & NÃO & $\begin{array}{l}\text { azatioprina, } \\
\text { carbamazepina }\end{array}$ & 31 \\
\hline 20 & $\mathrm{~F}$ & 46 & B & NMO definida & + & Sim & 1 & G3P1C2A0 & Cistocele II & $\begin{array}{l}\text { azatioprina, levotiroxina, } \\
\text { carbonato de cálcio, } \\
\text { alendronato }\end{array}$ & 110 \\
\hline 21 & $\mathrm{~F}$ & 64 & B & NMO definida & + & Sim & 1 & G5P3C1A1 & Cistocele II & azatioprina, predinisona & 10 \\
\hline 22 & $F$ & 49 & $A D$ & NMO definida & + & Sim & $\begin{array}{l}\text { anacusia } \\
\text { congênita }\end{array}$ & G1P0C1A0 & NÃO & azatioprina, predinisona & 12 \\
\hline 23 & $\mathrm{~F}$ & 41 & $A D$ & MTLE & + & Sim & diabetes I & G2P0C2A0 & Cistocele II & azatioprina, predinisona & 34 \\
\hline 24 & $\mathrm{~F}$ & 29 & B & NMO definida & - & Sim & 1 & G1P0C1A0 & NÃO & azatioprina, predinisona & 15 \\
\hline 25 & $\mathrm{~F}$ & 36 & $A D$ & NMO definida & + & Sim & obesidade & G3P3C0A0 & Cistocele II & $\begin{array}{c}\text { azatioprina, predinisona, } \\
\text { omeprazol, carbonato } \\
\text { de cálcio }\end{array}$ & 41 \\
\hline 26 & $\mathrm{~F}$ & 13 & B & MTLE & - & Não & 1 & GOPOCOAO & NÃO & azatioprina, predinisona & 20 \\
\hline 27 & $\mathrm{~F}$ & 43 & B & MTLE & - & Não & 1 & G3P3C0A0 & Cistocele II & azatioprina, predinisona & 15 \\
\hline 28 & M & 53 & B & MTLE & - & Sim & 1 & 1 & 1 & azatioprina, predinisona & 72 \\
\hline 29 & M & 24 & $A D$ & MTLE & - & Sim & tuberculose & 1 & 1 & azatioprina, predinisona & 12 \\
\hline 30 & M & 47 & $A D$ & MTLE & + & Sim & miastenia gravis & 1 & 1 & azatioprina & 22 \\
\hline
\end{tabular}

F: feminino; M: masculino; AD: afro-descendente; B: branco; NMO: neuromielite óptica; MTLE: mielite transversa longitudinalmente extensa; G: gestações; P: partos normais; C: partos cesareanos 


\subsection{COMPROMETIMENTO NEUROLÓGICO EM PACIENTES PORTADORES DO ESPECTRO DA NEUROMIELITE ÓPTICA}

A avaliação neurológica mostrou pontuação média do EDSS de 5,3 \pm 1,8 (intervalo de 1 a 8,5). A figura 3 apresenta a distribuição dos pacientes quanto ao escore do comprometimento neurológico avaliado pelo EDSS. O tempo médio de duração da doença neurológica foi de $33,8 \pm 30,8$ meses (intervalo de 3 a 135). Onze (78,5\%) dos 14 pacientes avaliados portadores de NMO definida e, $6(37,5 \%)$ dos 16 pacientes portadores de MTLE apresentaram teste de NMO-IgG positiva. Vinte e um $(70,0 \%)$ pacientes foram considerados recorrentes, pois já haviam apresentado pelo menos um episódio de recorrência de mielite ou de neurite óptica após um evento índice. Todos os pacientes se apresentavam em período de remissão, ou seja, encontravam-se há seis meses ou mais sem novo quadro agudo de MTLE.

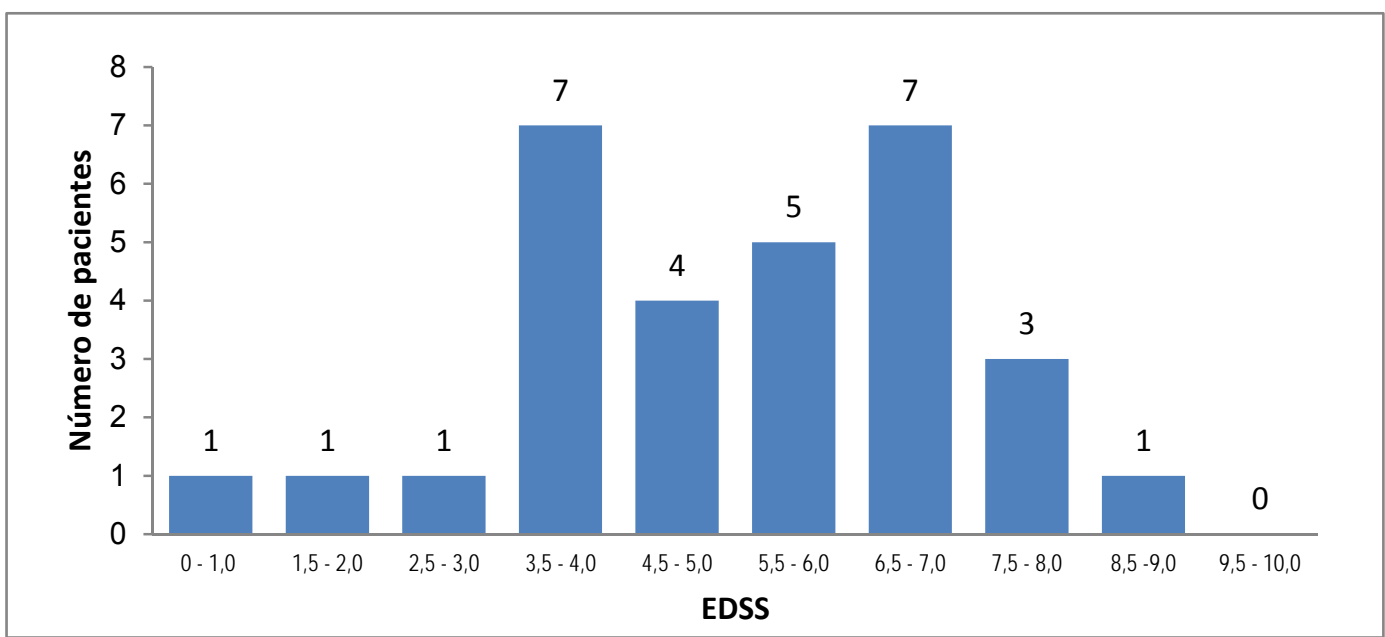

Figura 3 - Grau de comprometimento neurológico de acordo com a escala EDSS 
Todos os pacientes avaliados apresentaram padrão habitual de lesão medular à RM, que se estendia por pelo menos três segmentos da medula espinhal. Catorze $(46,6 \%)$ pacientes apresentavam lesões medulares cervicais; 13 (43,3\%) apresentavam lesões cervicais e torácicas; e 3 (10,0\%) apresentavam lesões torácicas (Figura 4).

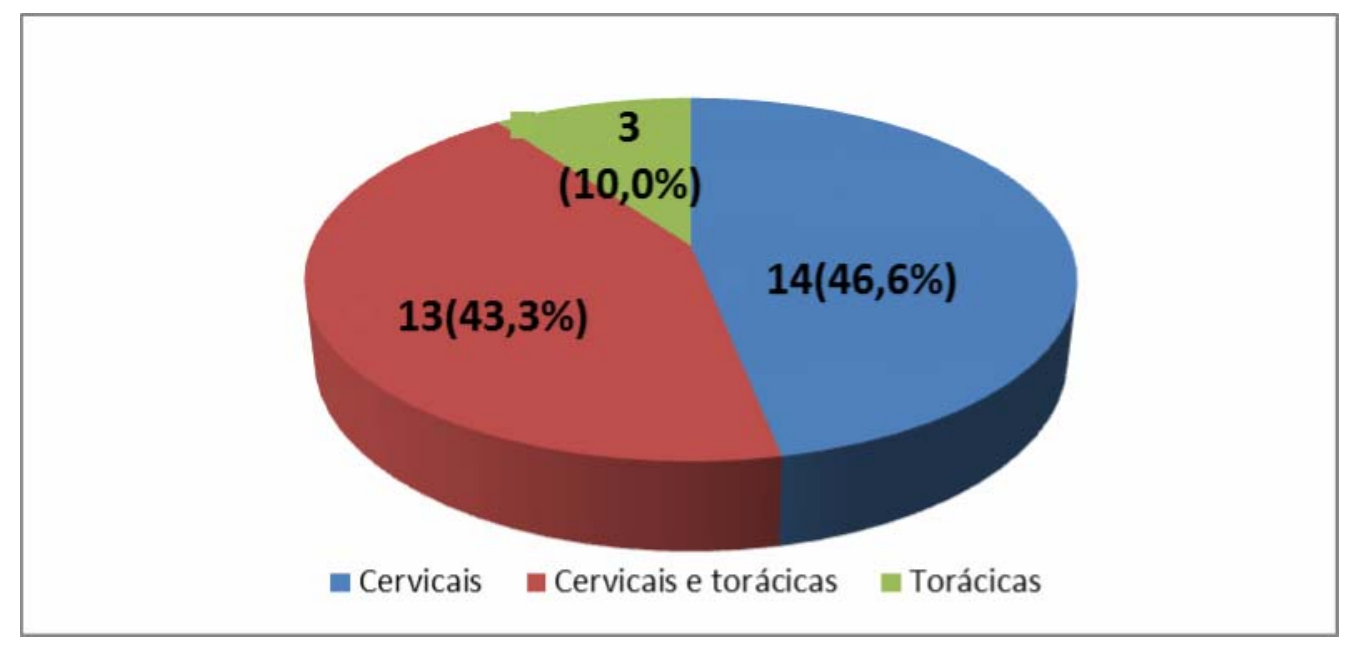

Figura 4 - Padrão de acometimento longitudinal das lesões medulares 


\subsection{SINTOMAS DO TRATO URINÁRIO INFERIOR E AVALIAÇÃO URODINÂMICA EM PACIENTES PORTADORES DO ESPECTRO DA NEUROMIELITE ÓPTICA}

A média do escore do questionário OAB-V8 foi de 17,5 $\pm 14,0$ (intervalo de 0 a 40) e do I-PSS foi 14,3 \pm 10,6 (intervalo de 0 a 35). Avaliando cada item do I-PSS isoladamente, noctúria e urgência foram os sintomas que apresentaram os maiores escores médios $(2,4 \pm 1,7$ e 2,2 \pm 1,9 respectivamente), seguidos de frequência aumentada $(2,1 \pm 2,2)$, intermitência $(2,0 \pm 1,9)$, esvaziamento incompleto $(1,9 \pm 2,1)$, jato fraco $(1,8$ $\pm 1,7)$ e hesitação $(1,6 \pm 1,8)$. Urge-incontinência, avaliada pela questão 8 do OAB-V8, apresentou média de 1,8 \pm 2,3 (Figura 5).

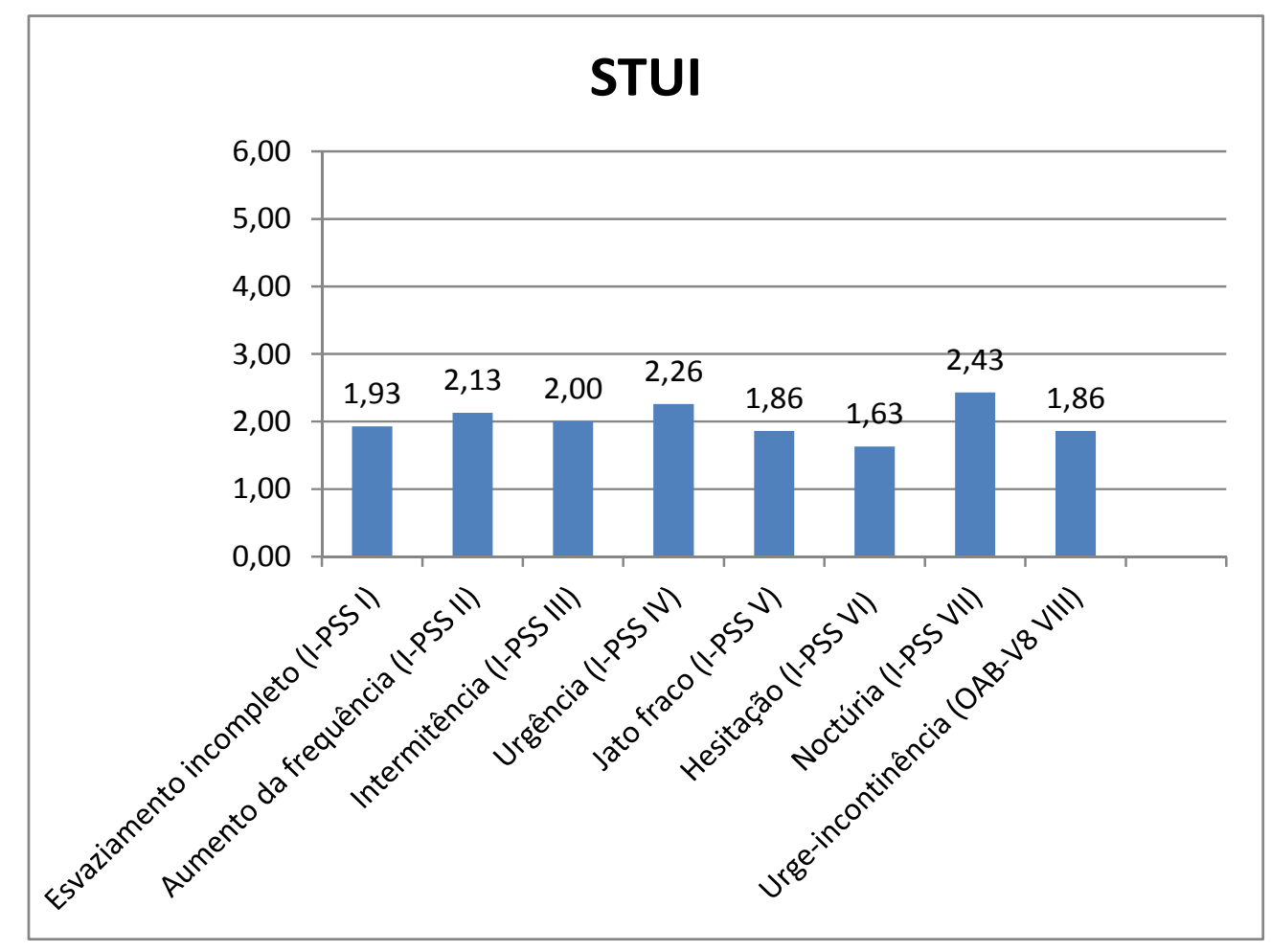

Figura 5 - Escore médio dos sintomas do trato urinário inferior 
Os sintomas urinários mais comuns foram urgência, presente em 15 (50,0\%) pacientes, noctúria em 15 (50,0\%), jato urinário fraco em 15 (50,0\%), intermitência em $14(46,6 \%)$, esvaziamento incompleto em 13 (43,3\%), hesitação em 13 (43,3\%), aumento da frequência urinária em 13 $(43,3 \%)$ e urge-incontinência em 11 (33,3\%)(Figura 6). Vinte e cinco pacientes $(83,4 \%)$ foram considerados sintomáticos e $5(16,6 \%)$ foram considerados assintomáticos.

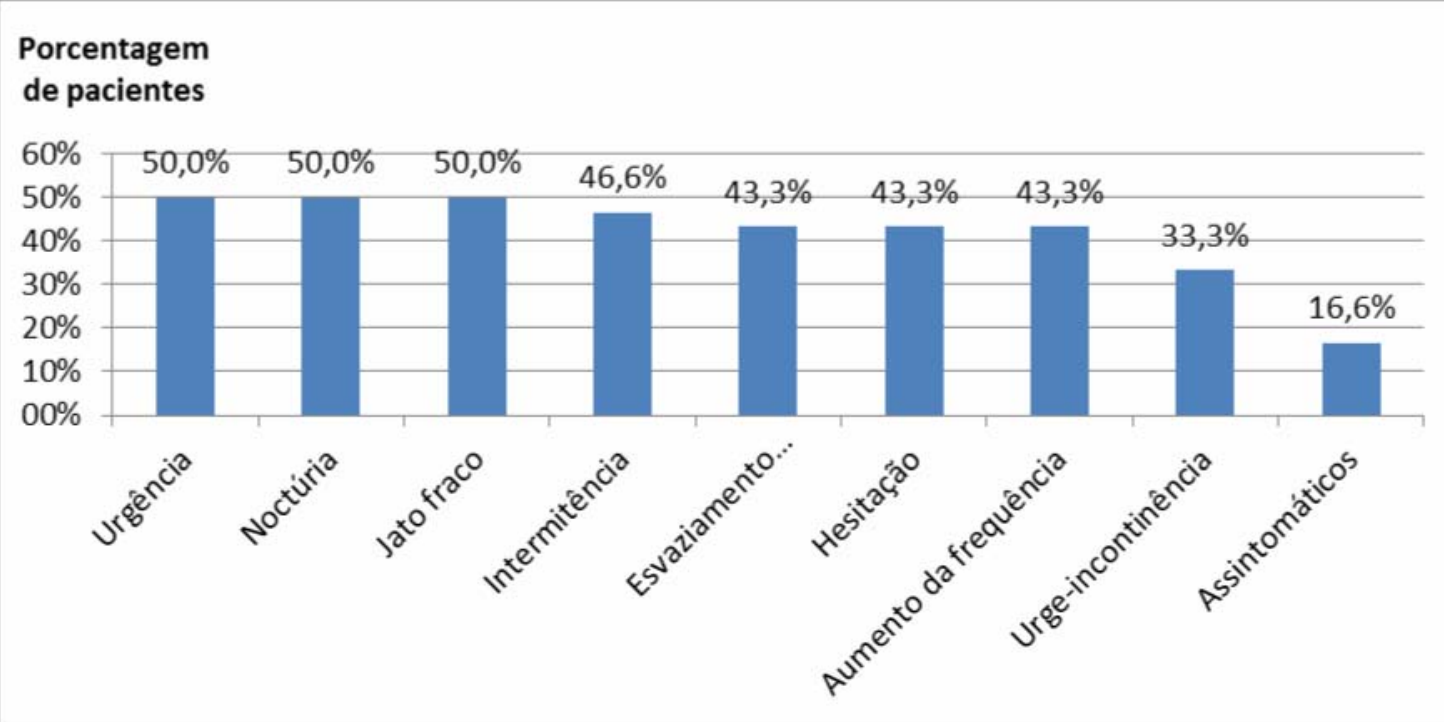

Figura 6 - Prevalência dos sintomas do trato urinário inferior

Nenhum paciente estava em uso de cateter vesical de demora ou em programa de cateterismo vesical intermitente. Sete $(23,3 \%)$ usavam absorventes diariamente. 
A mediana do Índice de Avaliação de Qualidade de Vida (questão 8 do I-PSS) foi de 1 (intervalo de 0 a 6). Através desta avaliação de QV relacionada aos STUI, $16(53,3 \%)$ pacientes se disseram "ótimo" ou "muito bem" e foram classificados como tendo boa QV. Catorze $(47,6 \%)$ pacientes foram considerados com QV comprometida, pois se disseram "satisfeito", "mais ou menos", "insatisfeito", "mal" ou "péssimo". A figura 7 demonstra a distribuição dos pacientes em relação aos escores de QV.

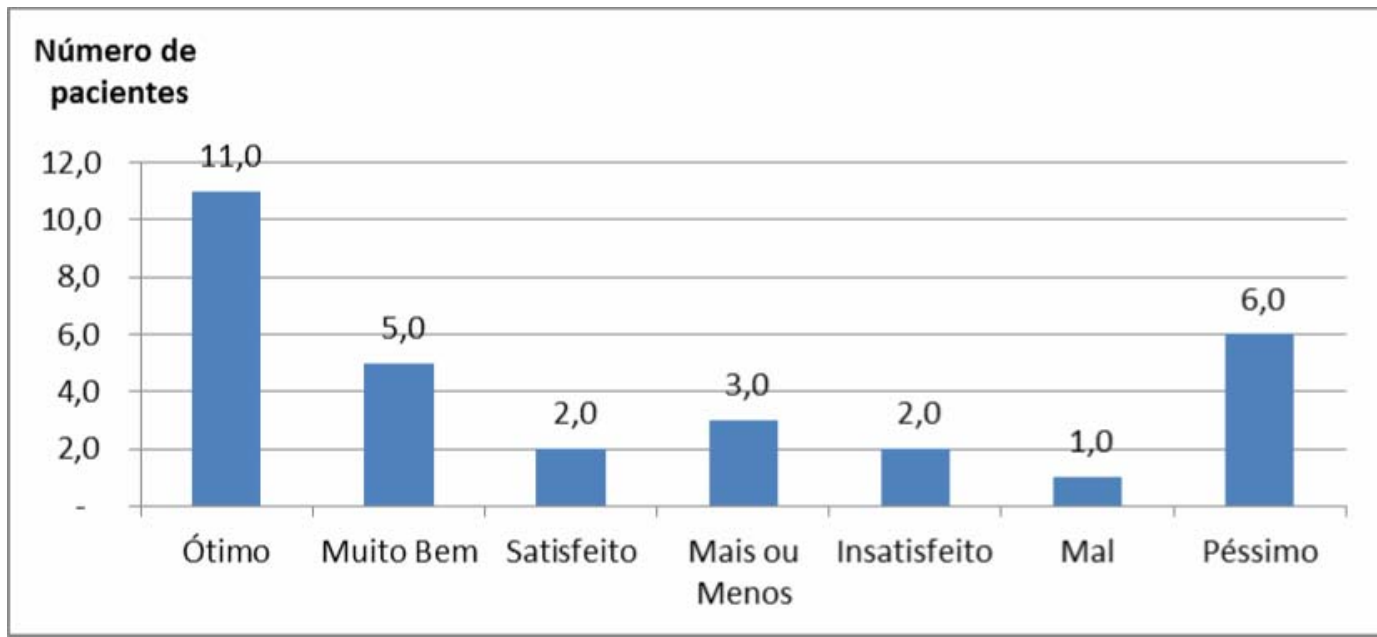

Figura 7 - Índice de avaliação da qualidade de vida (questão 8 do I-PSS): grau de satisfação em função dos sintomas do trato urinário inferior 
Por esta avaliação da QV, ao compararmos os pacientes que apresentaram boa qualidade de vida com os que apresentaram qualidade de vida comprometida, observamos maior intensidade dos STUI nestes, tanto pelo escore do IPSS como pelo escore do OAB-V8. Concomitantemente, pacientes considerados com pior QV nesta avaliação, foram aqueles que apresentaram maior comprometimento neurológico (Tabela 2).

Tabela 2- Correlação entre o índice de avaliação da qualidade de vida do I-PSS e os escores de sintomas do trato urinário inferior (I-PSS e OAB- V8); e entre o índice de avaliação da qualidade de vida e o grau de comprometimento neurológico (EDSS)

\begin{tabular}{lccc}
\hline & $\begin{array}{c}\text { Boa } \\
\text { Qualidade de Vida }\end{array}$ & $\begin{array}{c}\text { Qualidade de Vida } \\
\text { Comprometida }\end{array}$ & Valor do $p$ \\
\hline $\mathrm{N}$ & 16 & 14 & \\
\hline I-PSS & $8,82 \pm 8,11$ & $21,38 \pm 9,41$ & $<0,001$ \\
\hline OAB-V8 & $10,63 \pm 11,17$ & $25,29 \pm 13,16$ & 0,003 \\
\hline EDSS & $4,36 \pm 1,81$ & $6,14 \pm 1,59$ & 0,023 \\
\hline
\end{tabular}

I-PSS: escore internacional de sintomas prostáticos; OAB-V8: questionário de avaliação de bexiga hiperativa; EDSS: escala expandida do estado de incapacidade 
A média dos níveis de creatinina sérica medida em $\mathrm{mg} / \mathrm{dl}$ foi de $0,74 \pm$ 0,14 (min de 0,54 e máx de 1,1). Os níveis de PSA foram avaliados apenas nos 4 pacientes do sexo masculino e com idade superior a 40 anos (pacientes 13, 15, 28 e 30). Sua média em $\mathrm{ng} / \mathrm{ml}$ foi de $0,79 \pm 0,49$ (min de $0,2$ e max de 1,4$)$. Seis $(20,0 \%)$ pacientes tiveram urocultura positiva e foram subsequentemente tratados antes da realização do estudo urodinâmico.

A ultrassonografia do trato urinário se mostrou normal em $23(76,6 \%)$ pacientes. Sete $(23,3 \%)$ pacientes tinham espessamento da parede vesical. Nenhum paciente apresentou dilatação das vias urinárias superiores. Todos os homens avaliados possuíam volume prostático $\leq 30 \mathrm{~cm}^{3}$.

Todos os pacientes foram submetidos a estudo vídeo-urodinâmico ou à avaliação combinada de estudo urodinâmico mais uretrocistografia miccional. Nove $(30,0 \%)$ pacientes foram submetidos a estudo vídeourodinâmico e $21(70,0 \%)$ a avaliação combinada de estudo urodinâmico mais uretrocistografia miccional. A distribuição dos achados urodinâmicos representada na figura 8 , revelou hiperatividade detrusora com dissinergia detrusor-esfincteriana em 11 (36,6\%) pacientes (Figuras 9 e 10), dissinergia detrusor-esfincteriana sem hiperatividade detrusora em 7 (23,3\%), hiperatividade detrusora sem dissinergia detrusor-esfincteriana em 6 (20,0\%), e incontinência urinária de esforço (IUE) em 1 (3,3\%). Cinco (16,6\%) pacientes apresentaram estudo urodinâmico dentro dos padrões de normalidade. Baixa complacência foi um achado complementar em 6 (20\%) pacientes. 


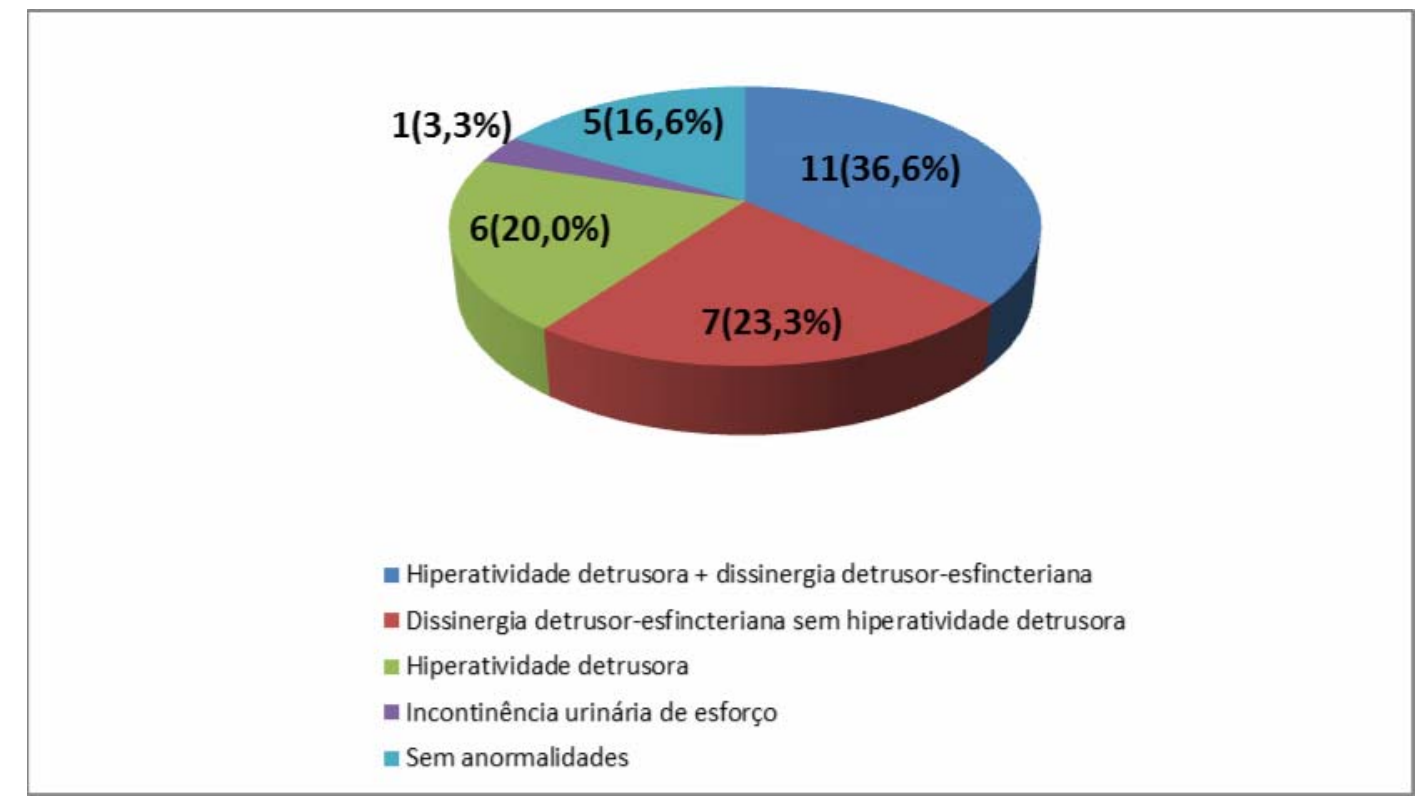

Figura 8 - $\quad$ Achados urodinâmicos em pacientes portadores de NMO-SD 

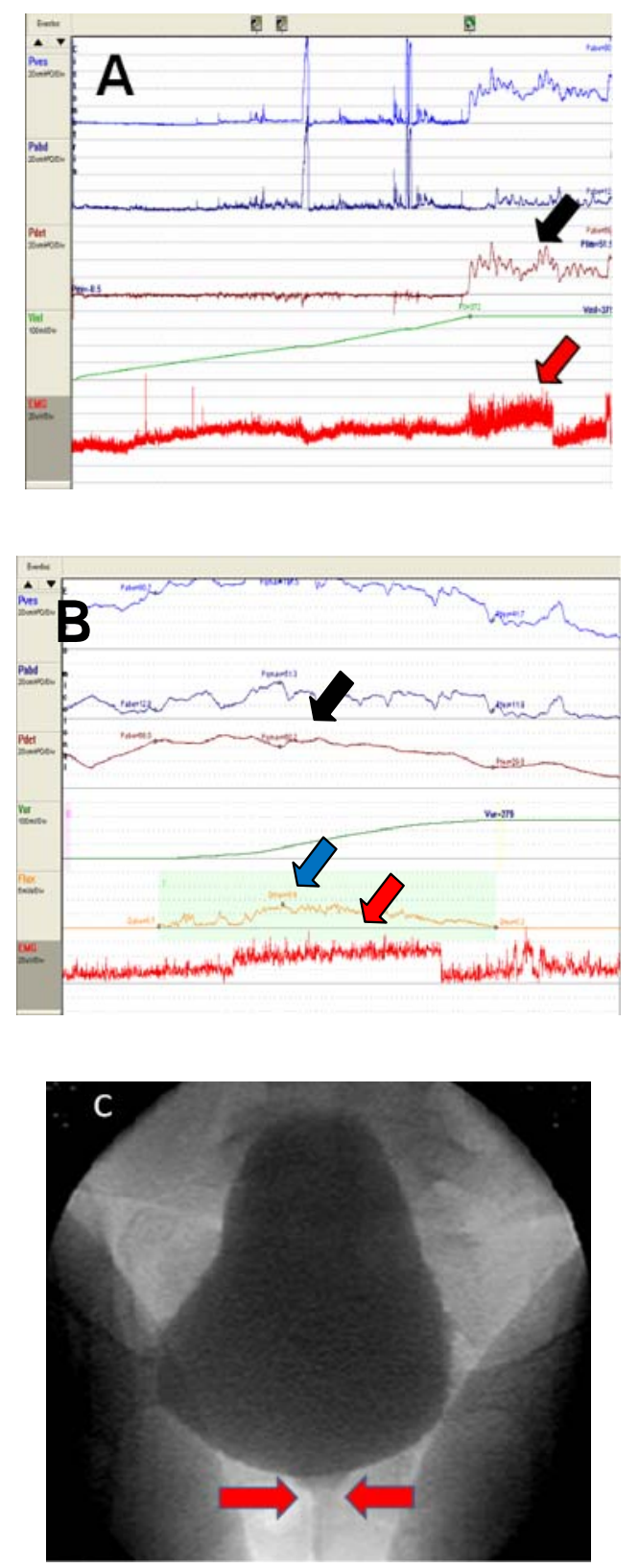

Figura 9 - Vídeo-urodinâmica de mulher de 36 anos (paciente 19) demonstrando hiperatividade detrusora e dissinergia detrusoresfincteriana: (A) Cistometria demonstra hiperatividade detrusora (seta preta) com aumento simultâneo da atividade eletromiográfica (seta vermelha); (B) Estudo fluxo/pressão mostra elevada pressão detrusora (seta preta), fluxo baixo e intermitente (seta azul) e aumento da atividade eletromiográfica (seta vermelha); (C) Monitorização fluoroscópica da fase miccional demonstra colo vesical aberto e uretra proximal dilatada devido ao esfíncter dissinérgico 

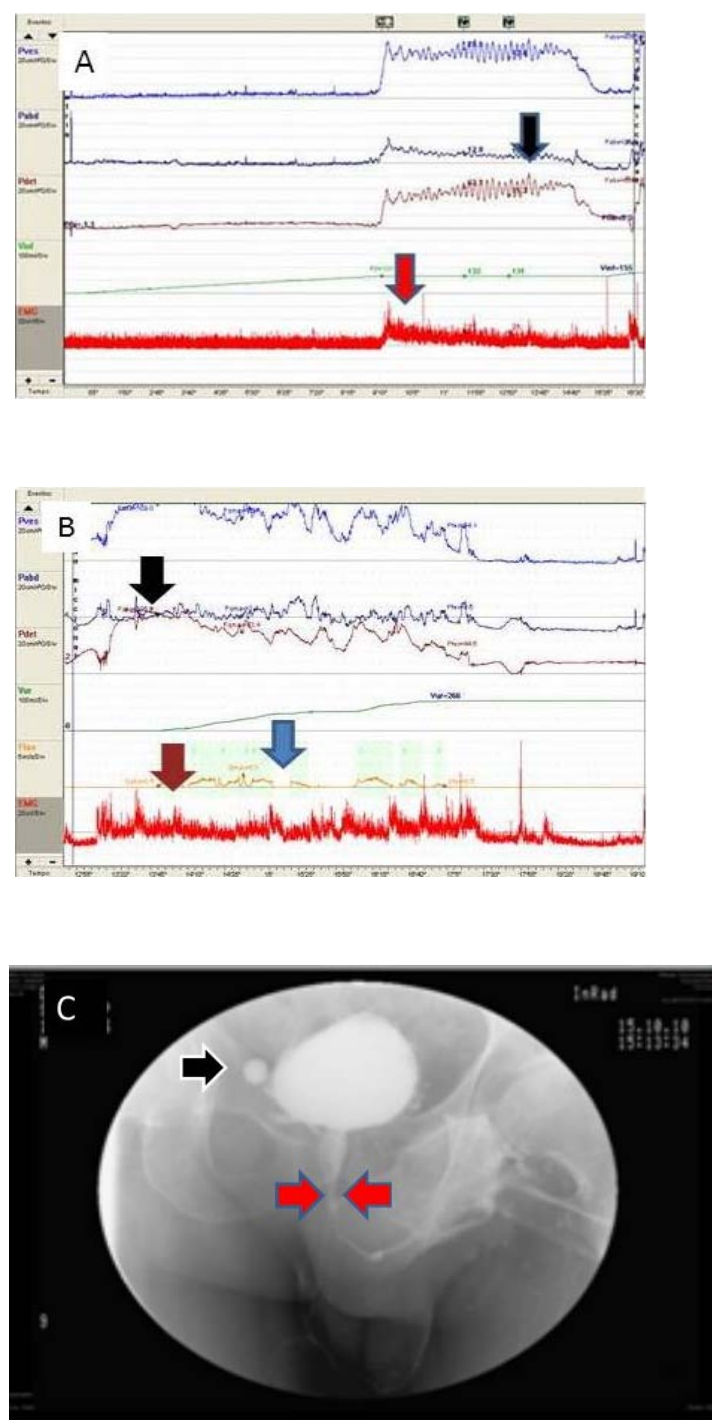

Figura 10- Avaliação combinada de estudo urodinâmico e uretrocistografia miccional em homem de 53 anos (paciente 28) demonstrando hiperatividade detrusora e dissinergia detrusor-esfincteriana: (A) Cistometria demonstra hiperatividade detrusora (seta preta) com discreto aumento simultâneo da atividade eletromiográfica (seta vermelha); (B) Estudo fluxo/pressão mostra elevada pressão detrusora (seta preta), fluxo baixo e intermitente (seta azul) e aumento da atividade eletromiográfica (seta vermelha); (C) Uretrocistografia miccional demonstra bexiga de capacidade reduzida, trabeculações e pequeno divertículo (seta preta); uretra prostática dilatada devido ao esfíncter dissinérgico (seta vermelha) 
Dos cinco pacientes considerados assintomáticos, 2 (40,0\%) pacientes (12 e 18) apresentavam dissinergia detrusor-esfincteriana sem hiperatividade detrusora e $3(60,0 \%)$ pacientes $(8,10,23)$ apresentaram avaliação urodinâmica sem anormalidades. Dos pacientes considerados sintomáticos, apenas $2(8, \%)$ pacientes (3 e 16) apresentaram estudo urodinâmico normal.

A dissinergia detrusor-esfincteriana isolada ou associada à hiperatividade detrusora foi o achado urodinâmico mais prevalente. Quando comparamos os pacientes sem DDE àqueles portadores de DDE, seja ela associada ou não à HD, observamos que estes apresentaram maior pressão detrusora no fluxo máximo $(59,2 \pm 19,6$ vs $35,8 \pm 28,4 ; p=0,023)$, menor volume urinado $(226,6 \pm 161,1$ vs $434,2 \pm 172,5 ; p=0,004)$ e maior resíduo pós-miccional $(226,6 \pm 161,1$ vs $434,2 \pm 172,5 ; p=0,004)$. Outros parâmetros urodinâmicos como capacidade cistométrica máxima, complacência, presença de hiperatividade detrusora e amplitude das contrações detrusoras involuntárias não apresentaram diferenças significativas entre pacientes com e sem dissinergia detrusor-esfincteriana (DDE). Pacientes dissinérgicos foram aqueles que apresentaram STUI de maior severidade, quando comparamos os escores de I-PSS e OAB-V8 (Tabela 3). 
Tabela 3 - Parâmetros urodinâmicos e escore de sintomas do trato urinário inferior (I-PSS e OAB-V8) em pacientes com e sem dissinergia detrusor-esfincteriana

\begin{tabular}{lccc}
\hline \multicolumn{1}{c}{ Variável } & $\begin{array}{c}\text { Pacientes com } \\
\text { DDE }(\mathrm{n=18})\end{array}$ & $\begin{array}{c}\text { Pacientes sem } \\
\text { DDE }(\mathrm{n}=12)\end{array}$ & Valor P \\
\hline Capacidade cistométrica $(\mathrm{ml})$ & $393,6 \pm 141,4$ & $456,8 \pm 149,8$ & 0,278 \\
\hline Complacência & $49,1 \pm 35,5$ & $100,5 \pm 84,9$ & 0,149 \\
\hline Hiperatividade detrusora (n=15/ 50\%) & $10(55,5 \%)$ & $5(41,6 \%)$ & 0,711 \\
\hline Amplitude das contrações detrusoras & $34,3 \pm 10,8$ & $21,5 \pm 9,6$ & 0,176 \\
\hline PdetQmax (cmH20) & $59,2 \pm 19,6$ & $35,8 \pm 28,4$ & 0,023 \\
\hline Volume urinado (ml) & $226,6 \pm 161,1$ & $434,2 \pm 172,5$ & 0,004 \\
\hline Volume pós-miccional (ml) & $105,5 \pm 133,7$ & $21,6 \pm 47,2$ & 0,039 \\
\hline I-PSS & $18,5 \pm 11,4$ & $7,0 \pm 9,2$ & 0,029 \\
\hline OAB-V8 & $22,8 \pm 15,9$ & $9,1 \pm 7,8$ & 0,008 \\
\hline
\end{tabular}

DDE: dissinergia detrusor-esfincteriana; I-PSS: Escore Internacional de Sintomas Prostáticos; OAB-V8: Questionário de Avaliação da Bexiga Hiperativa 


\subsection{QUALIDADE DE VIDA GERAL NOS PACIENTES PORTADORES DO ESPECTRO DA NEUROMIELITE ÓPTICA}

A pontuação média do LiSat-9 foi de 38,9 \pm 6,8 (intervalo de 26 a 49).

Entre os itens avaliados pelo LiSat-9, o mais comprometido foi vida sexual $(3,20 \pm 1,69)$, seguido por relacionamento com a parceira/o $(4,00 \pm 1,64)$, lazer $(4,00 \pm 1,39)$, situação financeira $(4,03 \pm 1,40)$ e situação profissional $(4,13 \pm 1,63)$. Os itens com menor comprometimento foram: capacidade de autos-cuidados $(4,60 \pm 1,40)$, vida em geral $(4,73 \pm 1,20)$, vida familiar $(5,10$ $\pm 0,99)$ e contato com amigos e conhecidos $(5,10 \pm 0,92)$ (Figura 11).

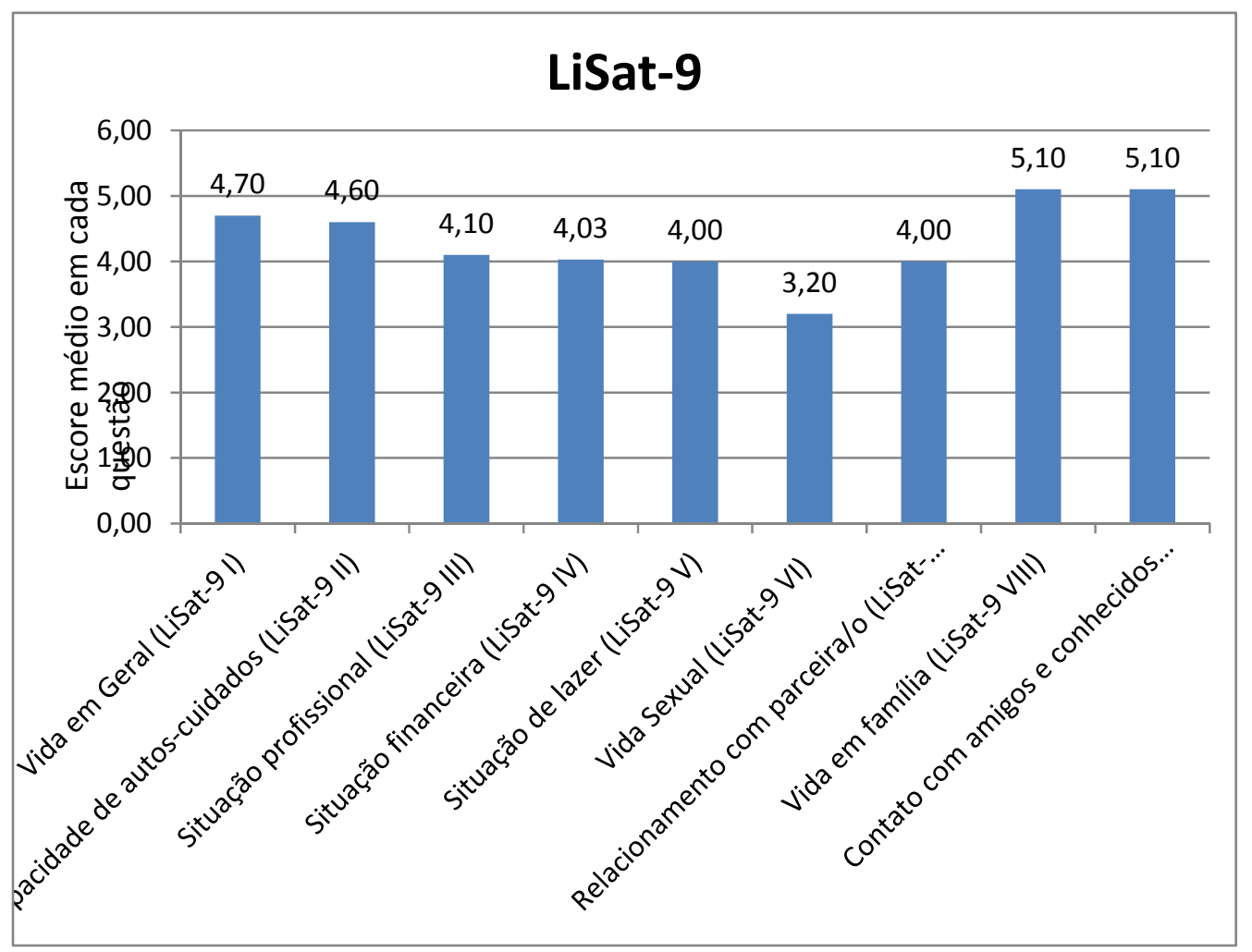

Figura 11 - Escore médio dos itens do LiSat-9 


\subsection{ASSOCIAÇÃO ENTRE SINTOMAS DO TRATO URINÁRIO INFERIOR E DISFUNÇÃO MICCIONAL COM O COMPROMETIMENTO NEUROLÓGICO}

Observou-se correlação positiva entre o comprometimento neurológico medido pela escala EDSS e os sintomas urinários medidos pelos escores I-PSS ( $r=0,43 ; p=0,018)$ (Figura 12) e OAB-V8 ( $r=0,49$; $p=0,006)($ Figura 13). 


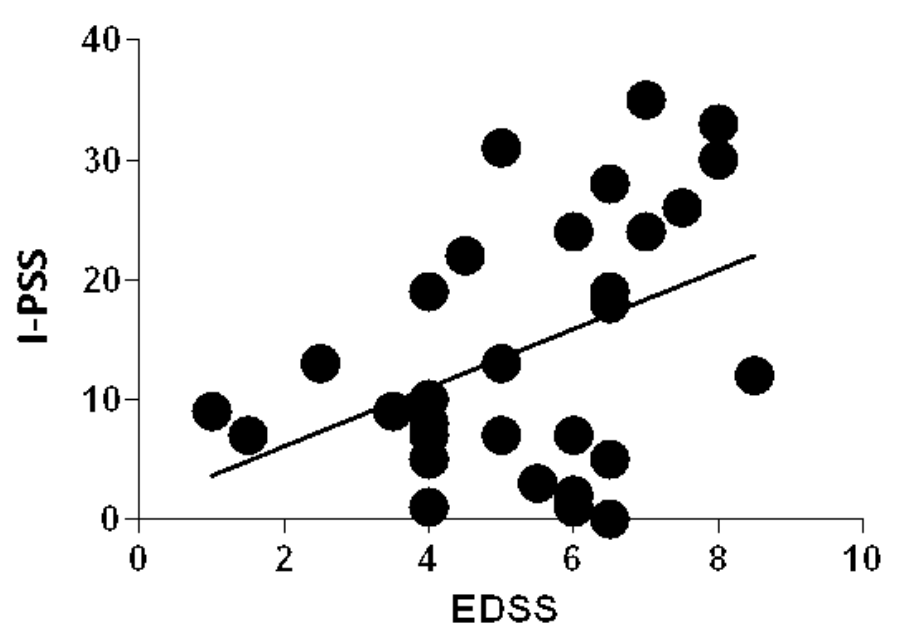

Figura 12 - Correlação entre gravidade da doença neurológica (EDSS) e sintomas do trato urinário inferior medidos pelo I-PSS $(r=0,42$; $p=0,018$ )

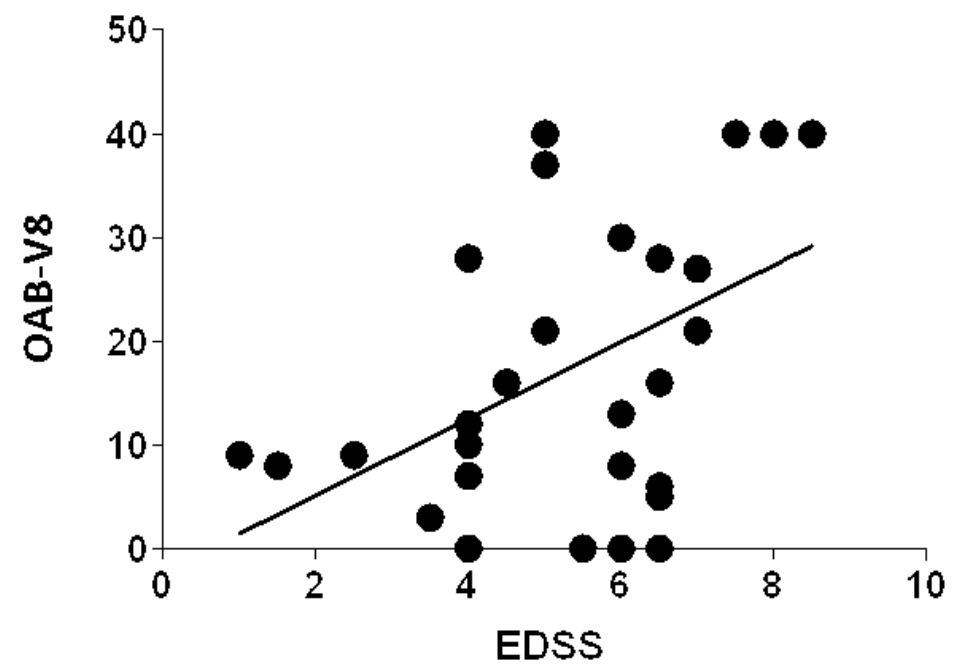

Figura 13 - Correlação entre gravidade da doença neurológica (EDSS) e sintomas do trato urinário inferior medidos pelo OAB-V8 $(r=0,48 ; p=0,006)$ 
Não houve associação entre tempo de doença neurológica e gravidade dos sintomas urinários avaliados pelo I-PSS ( $r=-0,07 ; p=0,704)$.

O EDSS médio dos pacientes portadores de DDE foi de 5,9 \pm 1,8 (min 1 e máx: 8,5$)$ e daqueles sem DDE foi de $4,5 \pm 1,5$ ( $\min 1,5$ e máx 7$)$. Houve correlação positiva entre os pacientes portadores de DDE e o maior comprometimento neurológico, medido pela escala EDSS $(p=0,027)$ (Figura 14).

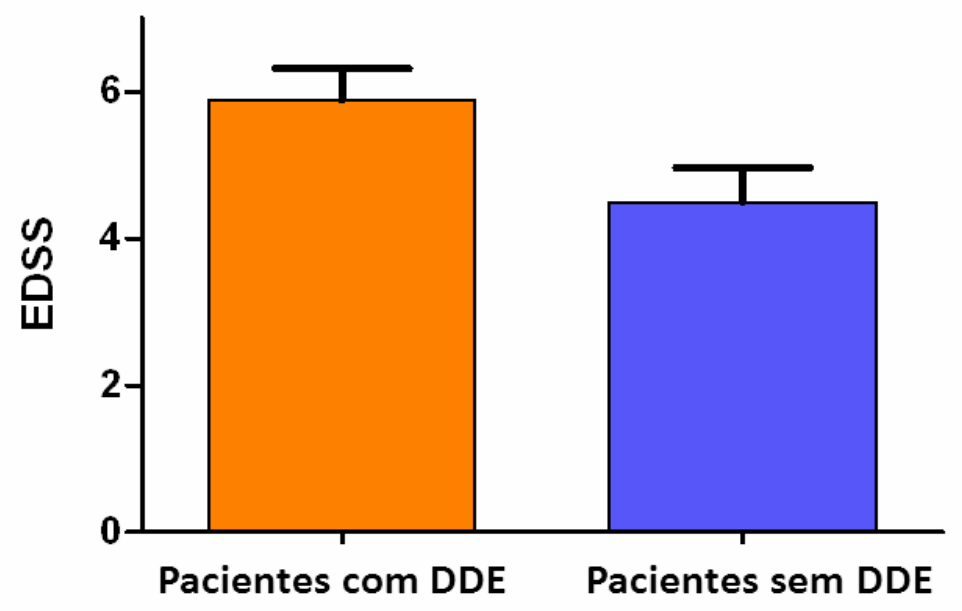

Figura 14 - Comparação do comprometimento neurológico medido pela escala EDSS entre pacientes com e sem dissinergia detrusoresfincteriana 


\subsection{IMPACTO DOS SINTOMAS DO TRATO URINÁRIO INFERIOR E DO COMPROMETIMENTO NEUROLÓGICO NA QUALIDADE DE VIDA GERAL}

A qualidade de vida geral, analisada pelo escore de sintomas do LiSat-9, correlacionou-se negativamente, porém de forma não significativa, com a intensidade dos sintomas urinários, representada pelos escores I-PSS $(r=-0,12 ; p=0,518)$ e OAB-V8 $(r=-0.34 ; p=0,059)$, respectivamente.

O comprometimento neurológico medido pela escala EDSS correlacionou-se com a QV geral, avaliada pelo LiSat-9. Pacientes com maior comprometimento neurológico apresentaram menor grau de satisfação com a vida, aferidos por pontuação total do LiSat-9 ( $r=-0,410$; $p=0,022)($ Figura 15).

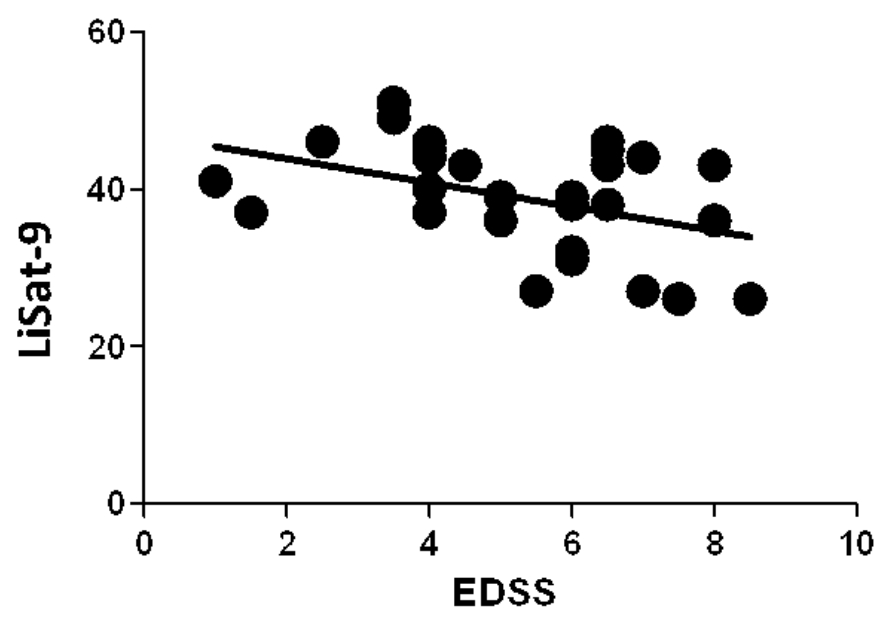

Figura 15 - Correlação entre grau de comprometimento neurológico (EDSS) e qualidade de vida geral (LiSat-9) 
5 DISCUSSÃO 
A NMO é a doença do sistema nervoso central que sofreu a maior mudança em seu entendimento fisiopatológico nos últimos anos. Classificada previamente como uma forma variante da esclerose múltipla, passou a integrar o grupo das canalopatias autoimunes. Não só isso, mas se tornou a primeira canalopatia conhecida que afeta o funcionamento da AQP4 no sistema nervoso central.

A descoberta da mediação humoral da NMO via autoanticorpos da classe lgG mudou a abordagem terapêutica, que antes deste período baseava-se, sem sucesso, nos mesmos princípios destinados à esclerose múltipla.

Distúrbios miccionais e STUI já foram amplamente estudados em pacientes portadores de esclerose múltipla. Entretanto, em portadores de NMO estes ainda não haviam sido objeto de um estudo de prevalência.

O presente trabalho, em virtude da caracterização das disfunções miccionais em pacientes portadores do espectro da neuromielite óptica, bem como suas correlações com o comprometimento neurológico e a qualidade de vida, pretende contribuir para a melhor identificação e tratamento destes pacientes.

A prevalência e a incidência da NMO definida e das demais doenças que fazem parte do espectro NMO têm sido difíceis de serem calculadas. Isto se deve principalmente à dificuldade para a efetivação do diagnóstico, 
que atualmente exige a realização de RM do SNC e dos testes imunológicos específicos, nem sempre disponíveis universalmente. Atualmente, NMO representa menos de $1 \%$ das doenças desmielinizantes do sistema nervoso central em caucasianos ${ }^{(86)}$. Esta frequência, porém, tende a ser maior em populações não brancas e naquelas com menor contribuição de genes de ascendência europeia em sua composição genética ${ }^{(15)}$. Nossa amostra apresenta predominância de mulheres $(3,2: 1)$ e de pacientes com episódios recorrentes (70\%), o que está de acordo com outras séries (Tabela 4). Em nossa série, a positividade da NMO-IgG para NMO definida e para MTLE foi de $78 \%$ e $37,5 \%$ respectivamente, semelhante aos achados de outros estudos, nos quais foi verificada variação de 54 a 83,3\% para NMO definida, e de 12,5 a $50 \%$ para MTLE ${ }^{(13 ; 14 ; 41 ; 43)}$. Esta variação de taxas encontradas em diferentes centros pode ser explicada pelo fato de que a detecção da NMO-IgG é baseada em um método não padronizado, qualitativo e observador dependente ${ }^{(87)}$.

Em nossa série, a maioria dos pacientes avaliados apresentava doença neurológica em grau moderado, sendo o EDSS médio de 5,3. Resultados semelhantes foram relatados por outras séries de estudos realizados em pacientes portadores de NMO (Tabela 4), bem como em pacientes com EM que tiveram a função miccional previamente avaliada ${ }^{(88)}$. Porém, diferentemente das demais séries, nossos pacientes apresentavam doença neurológica com menor tempo de evolução (Tabela 4). Este achado talvez possa indicar que nossos pacientes tenham uma evolução mais grave da doença neurológica. 
Tabela 4 - Dados clínicos, laboratoriais e demográficos de pacientes portadores do espectro NMO previamente publicados e do presente estudo

\begin{tabular}{|c|c|c|c|c|c|c|c|c|}
\hline & Ano & $\begin{array}{c}\text { Espectro } \\
\text { NMO }\end{array}$ & $\mathbf{N}$ & $\begin{array}{l}\text { Idade } \\
\text { (anos) }\end{array}$ & $\mathbf{M}: \mathbf{H}$ & $\begin{array}{c}\text { EDSS } \\
\left(\begin{array}{l}0 \text { a } 10)\end{array}\right.\end{array}$ & $\begin{array}{c}\text { NMO-IgG } \\
\text { Positivo } \\
\text { (\%) }\end{array}$ & $\begin{array}{c}\text { Tempo } \\
\text { de } \\
\text { doença } \\
\text { (anos) }\end{array}$ \\
\hline $\begin{array}{l}\text { Ghezzi A }^{(89)} \\
\text { (coorte Itália) }\end{array}$ & 2004 & NMO & 46 & 35 & 4.1:1 & 6 & ND & 8,8 \\
\hline Lennon VA ${ }^{(5)}$ & 2004 & NMO & 124 & 41 & $5.4: 1$ & ND & $90(73)$ & ND \\
\hline Weinshenker ${ }^{(30)}$ & 2006 & MTLE & 29 & $\begin{array}{c}48,9 \text { SPR } \\
39,5 \text { SPNR } \\
50,3 \mathrm{SN}\end{array}$ & $\begin{array}{c}5: 1 \text { SPR } \\
3: 2 \text { SPNR } \\
8: 10 \mathrm{SN}\end{array}$ & ND & $11(37,9)$ & ND \\
\hline Saiz A ${ }^{(43)}$ & 2007 & $\begin{array}{l}\text { MTLE } \\
\text { NMO }\end{array}$ & $\begin{array}{l}11 \\
16\end{array}$ & $\begin{array}{c}48 \\
40,5\end{array}$ & $\begin{array}{l}4,3: 1 \\
0,8: 1\end{array}$ & $\begin{array}{l}7,0 \\
5,5\end{array}$ & $\begin{array}{c}3(27,3) \\
10(62,5)\end{array}$ & ND \\
\hline $\begin{array}{l}\text { Wingerchuk } \\
\text { DM }^{(1)}\end{array}$ & 2007 & NMO & 96 & 38 & $2,5: 1$ & 6 & ND & 7,6 \\
\hline $\begin{array}{l}\text { Rivera JF }{ }^{(90)} \\
\text { (coorte Mexico) }\end{array}$ & 2008 & NMO & 34 & 35 & $2,4: 1$ & 5 & ND & 5.8 \\
\hline $\begin{array}{l}\text { Bichuetti DB } \\
(42)\end{array}$ & 2009 & NMO & 41 & 32 & $2,4: 1$ & 5,2 & $17(41)$ & 7 \\
\hline $\begin{array}{l}\text { Collongues }{ }^{(40)} \\
\text { (coorte França) }\end{array}$ & 2010 & NMO & 125 & 34,5 & $3: 1$ & 6 & $\begin{array}{c}49 / 111 \\
(54)\end{array}$ & 10 \\
\hline Adoni $T^{(44)}$ & 2010 & NMO & 28 & 26 & $8,3: 1$ & 5,5 & $18(64,3)$ & 7 \\
\hline $\mathrm{Kim} \mathrm{SH}^{(13)}$ & 2010 & $\begin{array}{l}\text { MTLE } \\
\text { NMO }\end{array}$ & $\begin{array}{c}8 \\
20\end{array}$ & $\begin{array}{l}42 \\
53\end{array}$ & $1: 3$ & $\begin{array}{c}3 \\
4,3\end{array}$ & $\begin{array}{c}1(12,5) \\
10(83,3)\end{array}$ & $\begin{array}{l}5 \\
5\end{array}$ \\
\hline Este estudo & 2013 & $\begin{array}{l}\text { NMO- } \\
\text { SD: } \\
\text { - NMO } \\
\text { - MTLE }\end{array}$ & $\begin{array}{l}30 \\
14 \\
16\end{array}$ & 41 & $\begin{array}{c}3,2: 1 \\
6: 1 \\
2,2: 1\end{array}$ & 5,3 & $\begin{array}{l}11(78) \\
6(37,5)\end{array}$ & 2,8 \\
\hline
\end{tabular}

N/A: não disponível; SPR: soropositivo recorrente; SPNR: soropositivo não recorrente; SN: soronegativo; NMO: neuromielite óptica; MTLE: mielite transversa longitudinalmente extensa

No presente trabalho a prevalência de pacientes considerados sintomáticos para STUI foi de $72 \%$. Resultados semelhantes foram relatados em metanálise realizada por Litwiller et al. (1999) em pacientes portadores de $\operatorname{EM}(52-97 \%)^{(91)}$. Obviamente devemos considerar que esta variação, 
provavelmente, deve estar associada aos diferentes critérios utilizados em cada estudo para se considerar o que é sintomático e o que não o é.

Sintomas de armazenamento vesical são os mais frequentes em pacientes portadores de EM. Urgência, aumento da frequência miccional e urge-incontinência podem estar presentes isoladamente, em $32-85 \%$ dos pacientes (Tabela 5). Em nosso estudo, encontramos sintomas de armazenamento vesical em uma frequência semelhante à encontrada por outros autores em pacientes com EM (Tabela 5). Urge-incontinência, aumento da frequência e urgência miccional estavam presentes em 33,3\%, $43 \%$ e $50 \%$ dos pacientes, respectivamente (Tabela 5 ).

Sintomas de esvaziamento vesical em pacientes portadores de EM, se avaliados de forma geral, podem ter uma frequência variável de 37 a $72 \%$ segundo alguns autores ${ }^{(91-96)}$. De modo geral, a maioria destes estudos não distingue exatamente quais são estes sintomas de esvaziamento, como ocorre em relação aos sintomas de enchimento. Nos trabalhos em que esta medida foi adotada, quando avaliados isoladamente, sintomas de esvaziamento vesical tendem a apresentar uma prevalência ainda menor. Hesitação, por exemplo, único sintoma de esvaziamento avaliado na metanálise de Litwiller et al. (1999) e também citado por Ukkonen em 2004, pode estar presente entre $25-58 \%$ dos pacientes (Tabela 5). Uma maior prevalência dos sintomas de esvaziamento foi observada somente por Shimizu et al. (1997), que relataram prevalência de $80 \%$ de sintomas de esvaziamento em pacientes portadores de EM ${ }^{(97)}$. Esta discrepância observada somente nestes pacientes japoneses ${ }^{(97)}$, se comparada aos 
estudos ocidentais, talvez se deva ao número reduzido de pacientes ${ }^{(10)}$ e a uma característica própria da amostra avaliada. Neste estudo especificamente, foram incluídos portadores da forma óptico espinhal da EM, hoje sabidamente reconhecida como constituinte do espectro NMO, fazendo com que esta amostra não fosse composta somente por pacientes portadores de EM. Porém, se compararmos estes dados aos nossos, esta elevada frequência dos sintomas de esvaziamento não se confirma. Apesar de também termos encontrado alta prevalência destes sintomas, nossos dados parecem estar mais próximos daqueles encontrados em pacientes portadores de EM, posto que a prevalência de cada um dos sintomas de esvaziamento avaliados no nosso estudo esteve entre $43-50 \%$.

Tabela 5 - Prevalência de sintomas do trato urinário inferior em pacientes com Esclerose Múltipla e na presente série

\begin{tabular}{|c|c|c|c|c|c|c|c|c|}
\hline & Ano & Doença & $\mathrm{N}$ & Urgência & Frequência & $\begin{array}{c}\text { Urge- } \\
\text { incontinência }\end{array}$ & Hesitação & Retenção \\
\hline Philp ${ }^{(98)}$ & 1981 & EM & 52 & 61 & 59 & 47 & 25 & 8 \\
\hline Goldstein I ${ }^{(94)}$ & 1982 & EM & 86 & 32 & 32 & 49 & - & - \\
\hline Awad SA ${ }^{(99)}$ & 1984 & EM & 47 & 85 & 65 & 72 & 36 & - \\
\hline Gonor SE ${ }^{(100)}$ & 1985 & EM & 64 & 70 & 48 & 56 & 30 & - \\
\hline Betts CD ${ }^{(101)}$ & 1993 & EM & 170 & 85 & 82 & 63 & 49 & - \\
\hline$\underset{(102)}{\text { Hennessey A }}$ & 1999 & EM & 191 & 71 & 76 & 19 & 48 & - \\
\hline $\begin{array}{l}\text { Borello- } \\
\text { France }^{(103)}\end{array}$ & 2004 & EM & 133 & 61 & 71 & 83 & - & - \\
\hline Ukkonen ${ }^{(104)}$ & 2004 & EM & 24 & 83 & 54 & 75 & 58 & - \\
\hline Quarto $\mathrm{G}^{(105)}$ & 2007 & EM & 107 & 61 & 83 & 32 & - & - \\
\hline Este estudo & 2013 & NMO-SD & 30 & 50 & 43 & 33 & 43 & - \\
\hline
\end{tabular}


Ao avaliarmos quantitativamente os STUI, optamos por aplicar questionários iguais para homens e mulheres. Isso porque o uso de questionários distintos fragmentaria a amostra e dificultaria comparações.

O OAB-V8 foi inicialmente desenvolvido em inglês para identificar pacientes com Bexiga Hiperativa, para quantificar seus sintomas e para medir o impacto destes sobre a qualidade de vida de pacientes de ambos os sexos $^{(72)}$. Em trabalho publicado em 2007, Acquadro et al. traduziram-no e o validaram-no linguisticamente em 14 idiomas, inclusive para o português (corrente no Brasil), com o objetivo de uniformizar as informações colhidas em diferentes centros de pesquisa, permitindo assim uma comparação internacional dos resultados ${ }^{(106)}$.

O I-PSS é um questionário que foi inicialmente desenvolvido para avaliação de STUI em homens com hiperplasia prostática, mas atualmente sua utilização tem sido mais ampla. Seu uso tem sido proposto também para a avaliação de pacientes com disfunções miccionais de origem neurogênica e para quantificação de sintomas de esvaziamento em mulheres ${ }^{(107-109)}$. Sua validação para língua portuguesa (Brasil) foi proposta por Berger et al. em $1999^{(82)}$, e desde então o mesmo tem sido utilizado com frequência como parâmetro de avaliação de STUI em pacientes brasileiros ${ }^{(110-112)}$.

Em concordância com o estudo prévio de Blaivas et al. (1979) ${ }^{(113)}$ realizado em pacientes com EM, em nossa casuística, os pacientes com NMO-SD que apresentavam maior comprometimento neurológico foram aqueles que mostraram STUI mais severos. Estes pacientes com maior comprometimento neurológico também foram os mais frequentemente 
acometidos por DDE, que por sua vez, foi a disfunção miccional mais prevalente, ocorrendo em mais da metade dos pacientes $(59,3 \%)$. Segundo o mais recente comitê de padronização da terminologia de disfunções miccionais, organizado pela IUGA (International Urogynecological Association) e a ICS (International Continence Society), dissinergia detrusoresfincteriana é definida como uma contração detrusora simultânea a uma contração involuntária do músculo estriado uretral e/ou periuretral, sendo uma característica de disfunções miccionais neurogênicas ${ }^{(80)}$. Neste sentido, consideramos que seu registro no estudo urodinâmico, possa ocorrer em duas situações: (1) Nos pacientes portadores de disfunção miccional neurogênica que não têm controle miccional voluntário, onde a contração esfincteriana involuntária acontece juntamente a uma contração detrusora involuntária ainda durante a fase de enchimento vesical (cistometria). Esta situação é habitualmente diagnosticada como dissinergia detrusor- esfincteriana mais hiperatividade detrusora; (2) Nos pacientes portadores de disfunção miccional neurogênica, mas que ainda têm controle miccional voluntário. Esta situação normalmente acontece em lesões medulares incompletas, e a contração esfincteriana involuntária pode ocorrer tanto durante uma contração detrusora involuntária na fase de cistometria, como durante o esvaziamento vesical (estudo fluxo/pressão). Nesta última situação temos o diagnóstico de dissinergia detrusor esfincteriana sem necessariamente termos hiperatividade detrusora. Seguindo estes parâmetros classificamos os pacientes em sinérgicos e dissinérgicos, e estes últimos subdivididos naqueles com e sem HD. 
Em metanálise de 22 estudos contabilizando um total de 1882 pacientes, publicada em 1999, Litwiller et al relataram uma incidência de 25,4\% para DDE em pacientes portadores de EM (Tabela 6). Estudos publicados posteriormente a esta data podem mostrar uma incidência maior (23-71\%), fato que pode estar relacionado ao advento do melhor refinamento técnico utilizado para diagnóstico na última década (Tabela 7). Em nosso estudo, o diagnóstico de DDE foi realizado através da avaliação combinada de eletromiografia de superfície durante o estudo urodinâmico,e exames de imagem (fluoroscopia simultânea ou uretrocistografia miccional). Optamos por assim fazer objetivando um incremento na sensibilidade diagnóstica dos distúrbios miccionais. É de amplo conhecimento o fato de que, quando realizada com eletrodos de superfície, a EMG não é seletiva para o esfíncter uretral, geralmente sofrendo interferência da musculatura do assoalho pélvico e periesfincteriana, o que por vezes pode resultar em má qualidade do registro eletromiográfico. O posicionamento dos eletrodos às 2 horas e às 10 horas no períneo do paciente,também pode sofrer esta interferência do esfíncter anal, mas sem grande prejuízo à avaliação, visto a boa correlação entre a EMG anal e a EMG do esfíncter uretral externo ${ }^{(114)}$. Todas as avaliações urodinâmicas, em nosso estudo, foram realizadas com os pacientes sentados já que a maioria dos nossos pacientes ainda preservava motricidade e sensibilidade dos membros inferiores. Optamos por não utilizar eletrodos de agulhas, pois, apesar deste tipo de eletrodo nos fornecer um sinal com menos ruído e maior seletividade, apresenta o inconveniente de sair da posição caso o paciente se movimente. Esta seria uma de nossas 
limitações. Neste caso, o exato posicionamento das agulhas no esfíncter uretral durante todo o exame, talvez não fosse uma condição fácil de se atingir. Outro fator limitante seria o custo operacional deste método. Nosso estudo foi realizado sem subsídios financeiros, e o uso único de um conjunto de agulhas para cada paciente não é um procedimento padronizado em nossa instituição. Uma alternativa cabível seria o processo de reesterilização destas agulhas, mas esta é uma prática que tem sido cada vez mais coibida pelas agências de vigilância sanitária.

Em nossa série, além dos métodos que utilizamos para melhora diagnóstica, outro fator pode provavelmente ter influenciado na maior incidência de DDE. Todos os nossos pacientes apresentavam comprometimento medular nos níveis cervical e/ou torácico, condição que talvez possa ter contribuído para o referido aumento na incidência de DDE, visto a já conhecida correlação entre DDE e lesões medulares acima do segmento T6.

A avaliação do volume prostático em homens com NMO-SD e disfunção miccional deve ser realizada em todos os indivíduos na faixa etária acima de 40 anos. Esta conduta se faz necessária visto a maior prevalência de hiperplasia benigna e outras doenças da próstata, que podem estar diretamente correlacionadas à etiologia de disfunções miccionais, principalmente nos casos de obstrução infravesical. Na nossa série, o volume prostático $\geq 30 \mathrm{~cm}^{3}$ foi adotado como critério de exclusão. Esta medida indica que, em nossa amostra, a hiperplasia prostática não foi um fator importante a contribuir para os sintomas miccionais. Da mesma forma, 
ao adotarmos como critério de exclusão em mulheres a presença de distopias vaginais com grau $\geq 3$ (segundo a classificação de Baden) procuramos eliminar a possibilidade desta ser a eventual etiologia do distúrbio de esvaziamento.

Hiperatividade detrusora é o achado urodinâmico mais frequente em pacientes portadores de EM ${ }^{(91)}$, sendo igualmente esperado em pacientes com outras neuropatias que cursam com disfunção miccional. A prevalência de hiperatividade detrusora em nossos pacientes foi semelhante à encontrada em pacientes com EM, e relatada por outros autores (Tabelas 6 e 7).

Incapacidade para desenvolver micção e retenção urinária são sintomas pouco comuns em pacientes com EM (Tabela 5). Quando presentes parecem estar frequentemente associados à acontratilidade detrusora, cuja incidência pode variar de 0 a $40 \%{ }^{(93 ; 101)}$. Acontratilidade detrusora por sua vez pode ser um achado comum em pacientes na fase de choque medular e também naqueles com lesões sacrais no nível de S2 a S4. Neste estudo, a ausência de pacientes nestas condições, talvez possa explicar o fato de não termos encontrado nenhum paciente com incapacidade miccional total.

Devemos considerar que o achado urodinâmico de IUE (paciente 25) ao contrário dos outros diagnósticos encontrados neste estudo, provavelmente não apresenta correlação com o comprometimento neurológico em si. Os dados epidemiológicos da paciente (obesidade e multiparidade) e seu exame físico (presença de cistocele grau II e reflexos 
perineais preservados), associados à pressão de perda ao esforço obtida durante o estudo urodinâmico $\left(110 \mathrm{cmH}_{2} \mathrm{O}\right)$, sugerem que a IUE encontrada tenha como causa uma deficiência anatômica não relacionada à lesão neurológica. Neste caso, hipermobilidade uretral associada ou não à insuficiência esfincteriana, são presumidamente as causas mais frequentes.

Cinco pacientes $(16,6 \%)$ apresentaram estudo urodinâmico normal, fato similar às taxas encontradas na maior parte dos estudos realizados em pacientes portadores de EM (Tabela 6 e 7).

Tabela 6 - Anormalidades urodinâmicas em pacientes com Esclerose Múltipla avaliados antes de 2001 (Litwiller et al. 1999)

\begin{tabular}{|c|c|c|c|c|c|c|}
\hline & & $\mathrm{N}$ & $\begin{array}{l}\text { Hiperatividade. } \\
\text { Detrusora }(\%)\end{array}$ & DDE (\%) & $\begin{array}{c}\text { Acontratilidade } \\
\text { detrusora }(\%)\end{array}$ & $\begin{array}{c}\text { Normal } \\
(\%)\end{array}$ \\
\hline Andersonand Bradley ${ }^{(92)}$ & 1976 & 52 & $33(63)$ & $16(31)$ & $21(40)$ & $2(4)$ \\
\hline Awad et al ${ }^{(99)}$ & 1984 & 57 & $38(66)$ & $30(52)$ & $12(21)$ & $7(12)$ \\
\hline Beck et al ${ }^{(115)}$ & 1981 & 46 & $40(87)$ & $-(-)$ & $6(13)$ & $-(-)$ \\
\hline Betts et al ${ }^{(101)}$ & 1993 & 70 & $63(91)$ & $-(-)$ & $0(0)$ & $7(10)$ \\
\hline Blaivas et al ${ }^{(113)}$ & 1979 & 41 & $23(56)$ & $12(30)$ & $16(40)$ & $2(4)$ \\
\hline Bradley et al ${ }^{(116)}$ & 1973 & 99 & $58(60)$ & $20(20)$ & $40(40)$ & $1(1)$ \\
\hline Bradley ${ }^{(93)}$ & 1978 & 302 & $127(62)$ & $-(-)$ & $103(34)$ & $10(24)$ \\
\hline Eardley et al ${ }^{(117)}$ & 1991 & 24 & $15(63)$ & $6(27)$ & $3(13)$ & $6(25)$ \\
\hline Goldstein et al ${ }^{(94)}$ & 1982 & 86 & $65(76)$ & $57(66)$ & $16(19)$ & $5(5.8)$ \\
\hline Gonor et al ${ }^{(100)}$ & 1985 & 64 & $40(78)$ & $8(12)$ & $13(20)$ & $1(2)$ \\
\hline HinsonandBoone ${ }^{(118)}$ & 1996 & 70 & $44(63)$ & $15(21)$ & $20(28)$ & $6(9)$ \\
\hline Koldewijn et al ${ }^{(95)}$ & 1995 & 212 & $72(34)$ & $27(13)$ & $32(8)$ & $76(36)$ \\
\hline MayoandChetner ${ }^{(119)}$ & 1992 & 89 & $69(78)$ & $5(6)$ & $5(6)$ & $11(12)$ \\
\hline McGuireandSavastano ${ }^{(120)}$ & 1984 & 46 & $33(72 \%)$ & $21(46)$ & $13(28)$ & 0 \\
\hline Petersenand Pedersen ${ }^{(121)}$ & 1984 & 88 & 73(83) & $36(41)$ & $14(16)$ & $1(1)$ \\
\hline Philip et al ${ }^{(98)}$ & 1981 & 52 & $51(99)$ & $16(37)$ & $0(0)$ & $1(1,9)$ \\
\hline PiazzaandDiokno ${ }^{(122)}$ & 1979 & 31 & $23(74)$ & $9(47)$ & $2(6)$ & $3(9)$ \\
\hline Schoenberg et al ${ }^{(123)}$ & 1979 & 39 & $27(69)$ & $20(5)$ & $2(6)$ & $6(15)$ \\
\hline Sirls et al ${ }^{(124)}$ & 1994 & 113 & $79(70)$ & $15(27,8)$ & $17(15)$ & $7(6)$ \\
\hline Summers ${ }^{(125)}$ & 1978 & 50 & $26(52)$ & $6(12)$ & $6(12)$ & $9(18)$ \\
\hline Van PoppelandBaert ${ }^{(126)}$ & 1983 & 160 & $105(66)$ & $38(24)$ & $38(24)$ & $16(10)$ \\
\hline Weinstein et al ${ }^{(127)}$ & 1988 & 91 & $64(70)$ & $16(18)$ & $15(16)$ & $11(12)$ \\
\hline Total/ Total No.(\%) & 1999 & 1882 & $1194(62,1)$ & $73 / 1464(25,4)$ & $394(20,1)$ & $188(10)$ \\
\hline
\end{tabular}

DDE: Dissinergia detrusor-esfincteriana 
Tabela 7 - Anormalidades urodinâmicas em pacientes com Esclerose Múltipla avaliados após 2001, e na presente série

\begin{tabular}{lccccccc}
\hline & & Doença & N & $\begin{array}{c}\text { Hiperatividade } \\
\text { detrusora }\end{array}$ & DDE & $\begin{array}{c}\text { Acontratilidade } \\
\text { Detrusora }\end{array}$ & Normal \\
\hline Ciancio et al. $^{(128)}$ & 2001 & EM & 22 & $10(45 \%)$ & $5(23 \%)$ & $3(14 \%)$ & $3(14 \%)$ \\
Ukkonen et al. $^{(104)}$ & 2004 & EM & 24 & $14(58 \%)$ & $17(71 \%)$ & $4(17 \%)$ & $6(25 \%)$ \\
Lemack et al. $^{(129)}$ & 2005 & EM & 66 & $49(74 \%)$ & $22(33 \%)$ & $5(8 \%)$ & - \\
\hline Onal et al. ${ }^{\left({ }^{1}\right)}$ & 2009 & EM & 75 & $26(35 \%)$ & $30(40 \%)$ & $1(1 \%)$ & $11(15 \%)$ \\
Este estudo & 2013 & NMO & 30 & $17(56,6 \%)$ & $18(60 \%)$ & 0 & $5(16,4 \%)$ \\
\hline
\end{tabular}

DDE: Dissinergia detrusor-esfincteriana

Como já mencionado, anormalidades urodinâmicas são frequentes em pacientes portadores de distúrbios neurológicos, mas sua presença nem sempre pode estar relacionada com STUI. Estudo conduzido por Belmemans et al. (1991) em pacientes portadores de EM, mostrou que a incidência de anormalidades urodinâmicas foi de 100\% em pacientes considerados sintomáticos para STUI e de $52 \%$ em pacientes assintomáticos (130). Estes dados se assemelham aos dados do nosso estudo, nos quais $92 \%(23 / 25)$ dos pacientes sintomáticos e somente $40 \%$ (2/5) dos assintomáticos apresentaram alterações urodinâmicas. A correta diferenciação entre sintomático e assintomático pode ser, como já mencionado, difícil de ser feita subjetivamente. Para isso, o uso de questionários de quantificação dos sintomas urinários tem sido bastante útil. Questionários como o I-PSS, quando utilizados em mulheres e em pacientes portadores de EM, mostraram-se bons preditores para a presença de disfunção miccional ao estudo urodinâmico ${ }^{(108 ; 131)}$. Em nosso estudo, um 
elevado escore de sintomas, obtido através dos questionários I-PSS e OABV8 mostrou-se fortemente correlacionado com a presença de DDE.

A correlação entre disfunção miccional e comprometimento neurológico/progressão da doença em pacientes portadores de EM ainda não está bem estabelecida. Kragtt et al. (2004) mostraram não haver correlação entre múltiplos parâmetros de severidade da EM e disfunção miccional ${ }^{(132)}$. Lemack et al. (2007) sugerem que DDE não pode ser prevista com base na idade, tempo desde o diagnóstico de EM, ou pela presença de doença progressiva secundária, se comparados ao padrão recorrência/remissão ${ }^{(133)}$. Por outro lado, estudos como o de Kirchhof et al. (2000) sugerem correlação positiva entre doença neurológica progressiva, medida pelo EDSS, e a presença de sinais sugestivos de disfunção miccional ${ }^{(134)}$. Em nosso estudo o comprometimento neurológico além de ter se mostrado fortemente correlacionado com a presença de DDE, também apresentou forte correlação com a presença de sintomas urinários (I-PSS e OAB-V8).

A presença de STUI em pacientes portadores de doenças neurológicas, incluindo EM, tem sido frequentemente correlacionadas à diminuição da qualidade de vida ${ }^{(135 ; 136)}$. Esta também foi uma característica encontrada em nossos pacientes, já que qualidade de vida relacionada aos sintomas urinários, avaliada pela questão Qualidade de Vida do I-PSS, mostrou-se severamente comprometida pela presença dos mesmos, avaliados pelos escores de sintomas do I-PSS e do OAB-V8. Da mesma forma, quando avaliamos a qualidade de vida de forma geral através do 
questionário LiSat-9, encontramos uma forte tendência de correlação com os sintomas urinários avaliados pelo OAB-V8.

Diminuição da QV quando avaliada como um todo, tem sido frequentemente correlacionada com limitações diversas do cotidiano de homens e mulheres portadores de lesões medulares ${ }^{(137)}$. Neste sentido, o questionário LiSat-9 tem sido utilizado como medida da QV neste grupo de pacientes, onde a diminuição da pontuação em cada questão está associada a um maior comprometimento de cada domínio avaliado (138;139). Desenvolvido e inicialmente proposto na Suécia ${ }^{(85 ; 138 ; 139)}$, seu uso posteriormente se estendeu para estudos multicêntricos, que randomizavam indivíduos de diferentes idiomas (China e Reino Unido; Suécia e Japão, Reino Unido, Alemanha, Áustria e Suíça), mesmo se considerando o potencial risco de não validação cultural em todos os países ${ }^{(140-142)}$. Em um trabalho realizado em 6 diferentes centros, incluindo o Brasil, Geyh et al. (2010) apresentaram o processo de validação do LiSat-9 e de outras três escalas de avaliação da qualidade de vida em pacientes vítimas de lesão medular (Satisfaction with Life Scale, World Health Organization Quality of Life, e Personal Well-Being Index) ${ }^{(143)}$. Optamos por utilizá-lo por se tratar de um instrumento conciso, de rápida execução e principalmente, por já ter sido utilizado universalmente. Em nossa avaliação os pacientes portadores de NMO-SD, assim como acontece nos pacientes vítimas de TRM, têm semelhante comprometimento da QV, tendo em vista os baixos escores obtidos através do LiSat-9. Não obstante, observamos que os pacientes com 
menor QV foram aqueles que apresentaram maior comprometimento neurológico.

Desta forma nossos dados referentes à QV, sejam relacionados aos sintomas urinários ou à QV em geral, vêm enfatizar a importância de se prestar cuidados específicos em questões como vida familiar, lazer, situação financeira, trabalho e STUI, para otimizar a qualidade de vida de cada paciente durante o seu processo de reabilitação.

Pacientes portadores de disfunção miccional neurogênica representam grupo de risco para desenvolvimento de deterioração do trato urinário superior. Neste cenário, dissinergia detrusor-esfincteriana e uso prolongado de cateter vesical de demora representam risco elevado de lesão do trato urinário superior ${ }^{(144)}$. Nestas situações, a elevação das pressões detrusoras devido à baixa complacência parece ser o fator mais importante ${ }^{(145 ; 146)}$. Assim como nos pacientes portadores de EM, nos quais a incidência de anormalidades no trato urinário superior é baixa, nenhum de nossos pacientes apresentou ao estudo ultrassonográfico dilatação do trato urinário superior ou elevação dos níveis sérico de creatinina ${ }^{(129 ; 147)}$. Apesar de termos encontrado uma elevada incidência de DDE em nosso grupo de pacientes, talvez a ausência de comprometimento do TUS possa estar correlacionada ao pouco tempo de doença neurológica (aproximadamente 3 anos) e, consequentemente, ao pouco tempo em que o trato urinário superior esteve exposto a elevadas pressões detrusoras. Concomitantemente, ressaltamos que nenhum de nossos pacientes estava em uso prolongado de cateter vesical de demora. Um seguimento a longo 
prazo poderá ou não confirmar estes achados, bem como determinar se, no futuro, estes pacientes apresentarão algum tipo de mudança no padrão miccional, assim como ocorre em EM ${ }^{(118 ; 128)}$. 
6 CONCLUSÕES 
Para a presente casuística de 30 pacientes portadores do espectro da NMO, de acordo com os critérios diagnósticos propostos por Wingerchuck et al. (2007), é possível concluir que:

1. Existe alta prevalência de sintomas do trato urinário inferior entre os pacientes portadores do espectro da Neuromielite Óptica sendo os sintomas de urgência e noctúria os mais prevalentes.

2. A dissinergia detrusor-esfincteriana e a hiperatividade detrusora são as anormalidades urodinâmicas mais frequentes. Apenas 16,6\% dos pacientes não apresentaram alterações urodinâmicas.

3. Sintomas do trato urinário inferior se correlacionam com a gravidade da doença neurológica.

4. Parcela significativa dos pacientes avaliados apresenta comprometimento da qualidade de vida relacionada aos sintomas do trato urinário inferior.

5. A severidade da doença neurológica correlaciona-se com a qualidade de vida geral. 
ANEXOS 
Anexo A: Escala expandida do estado de incapacidade (EDSS)

\section{EDSS}

0 Exame neurológico normal. Todos indicadores de grau 0 nos sistemas funcionais (SF).

1.0 Ausência de incapacidade funcional, sinais neurológicos mínimos num dos SF

1.5 Ausência de incapacidade funcional, sinais neurológicos mínimos em mais de um SF

2.0 Incapacidade funcional mínima num SF

2.5 Incapacidade funcional mínima em dois SF

3.0 Incapacidade funcional moderada num SF ou incapacidade ligeira em três ou quatro SF, embora com plena capacidade ambulatória

3.5 Plena capacidade ambulatória, mas com incapacidade funcional moderada num SF, e um ou dois SF com grau 2, ou dois SF com grau 3, ou cinco SF com grau 2

4.0 Plena capacidade ambulatória sem necessidade de assistência, plena independência funcional, actividade durante cerca de 12 horas por dia, apesar de alguma incapacidade funcional relativamente grave, caracterizada por um SF com grau 4 (os restantes SF com graus 0 ou 1) ou combinações de graus inferiores ultrapassando os limites dos níveis anteriores. Capacidade ambulatória num percurso de cerca de 300 metros sem assistência ou descanso

4.5 Plena capacidade ambulatória sem assistência, actividade normal durante a maior parte do dia, capacidade de trabalhar durante um dia completo, eventualmente com algumas limitações à actividade plena ou com necessidades de assistência mínima; estado caracterizado por uma incapacidade funcional relativamente grave, apresentando um SF com grau 4 (os restantes com grau 0 ou 1 ), ou combinações de grau inferior, ultrapassando os limites dos níveis anteriores. Capacidade ambulatória num percurso de cerca de 300 metros sem assistência ou descanso

5.0 Capacidade ambulatória num percurso de cerca de 200 metros sem assistência ou descanso; incapacidade funcional suficientemente grave para afectar adversamente o desempenho das actividades diárias (por exemplo, realizar o trabalho de um dia sem tomar medidas especiais). Um SF com grau 5 isolado, os restantes com grau 0 ou 1; ou combinações de graus inferiores, que ultrapassam geralmente os indicados para o nível 4.0

5.5 Capacidade ambulatória num percurso de cerca de 100 metros sem assistência ou descanso; incapacidade funcional suficientemente grave para 
impedir o desempenho das actividades diárias. Um SF com grau 5 isolado, os restantes com grau 0 ou 1; ou combinações de graus inferiores, que ultrapassam geralmente os indicados para o nível 4.0

6.0 Apoio unilateral intermitente ou constante (bengala, canadiana ou outras próteses) necessário para andar cerca de 100 metros, com ou sem descanso. Combinações com mais de dois SF com grau 3+

6.5 Apoio bilateral constante (bengalas, canadianas ou outras próteses) necessário para andar cerca de 20 metros sem descanso. Combinações com mais de dois SF com grau 3+

7.0 Incapacidade de andar mais de 5 metros, mesmo com apoios, necessidade de utilizar uma cadeira de rodas; doente desloca-se sozinho na cadeira de rodas pelo menos 12 horas por dia. Combinações com mais de um SF com grau 4+; muito raramente, grau piramidal 5 isolado

7.5 Incapacidade de dar mais de alguns passos; necessidade de utilizar uma cadeira de rodas; doente poderá necessitar de ajuda nas suas deslocações; doente consegue manipular a cadeira, mas não consegue aguentar-se numa cadeira de rodas normal durante o dia inteiro; poderá necessitar de uma cadeira de rodas eléctrica. Combinações com mais de um SF com grau 4+

8.0 Doente essencialmente confinado ao seu leito ou cadeira, ou deambulando de cadeira de rodas com ajuda de terceiros, podendo estar fora da cama durante a maior parte do dia; preservação de muitas das funções necessárias para cuidar de si próprio; de uma maneira geral, ainda consegue usar os braços de forma eficaz. Combinações com mais de dois SF, normalmente com grau 4+ em diversos sistemas funcionais

8.5 Doente essencialmente confinado ao leito durante a maior parte do dia; ainda consegue usar o(s) braço(s) de maneira eficaz; preservação de alguma capacidade para cuidar de si próprio. (equivalentes habituais de SF são combinações, normalmente com grau 4+ em diversos sistemas funcionais)

9.0 Doente acamado e totalmente dependente; capaz de comunicar e de comer. Combinações de SF maioritariamente de grau 4+

9.5 Doente acamado e totalmente dependente, incapaz de comunicar e de comer. Combinações de SF quase todos com grau 4+

10.0 Morte devida à Esclerose Múltipla. 
Anexo B: Questionário de avaliação da bexiga hiperativa (OAB-V8)

\begin{tabular}{|c|c|c|c|c|c|c|}
\hline $\begin{array}{l}\text { Quanto você tem } \\
\text { sido incomodado(a) } \\
\text { por... }\end{array}$ & & & 2 & & & 5 \\
\hline $\begin{array}{l}\text { 1. ...urinar } \\
\text { frequentemente } \\
\text { durante o dia? }\end{array}$ & Nada & $\begin{array}{l}\text { Quase } \\
\text { nada }\end{array}$ & Um pouco & O suficiente & Muito & Muitíssimo \\
\hline $\begin{array}{l}\text { 2. ...uma vontade } \\
\text { urgente e } \\
\text { desconfortável de } \\
\text { urinar? }\end{array}$ & Nada & $\begin{array}{l}\text { Quase } \\
\text { nada }\end{array}$ & Um pouco & O suficiente & Muito & Muitíssimo \\
\hline $\begin{array}{l}\text { 3. ...uma vontade } \\
\text { repentina e urgente de } \\
\text { urinar, com pouco ou } \\
\text { nenhum aviso prévio? }\end{array}$ & Nada & $\begin{array}{l}\text { Quase } \\
\text { nada }\end{array}$ & Um pouco & O suficiente & Muito & Muitíssimo \\
\hline $\begin{array}{l}\text { 4. ...perdas acidentais } \\
\text { de pequenas } \\
\text { quantidades de urina? }\end{array}$ & Nada & $\begin{array}{l}\text { Quase } \\
\text { nada }\end{array}$ & Um pouco & O suficiente & Muito & Muitíssimo \\
\hline $\begin{array}{l}\text { 5. ...urinar na cama } \\
\text { durante a noite? }\end{array}$ & Nada & $\begin{array}{l}\text { Quase } \\
\text { nada }\end{array}$ & Um pouco & O suficiente & Muito & Muitíssimo \\
\hline $\begin{array}{l}\text { 6. ...acordar durante a } \\
\text { noite porque teve de } \\
\text { urinar? }\end{array}$ & Nada & $\begin{array}{c}\text { Quase } \\
\text { nada }\end{array}$ & Um pouco & O suficiente & Muito & Muitíssimo \\
\hline $\begin{array}{l}\text { 7. ...uma vontade } \\
\text { incontrolável e urgente } \\
\text { de urinar? }\end{array}$ & Nada & $\begin{array}{l}\text { Quase } \\
\text { nada }\end{array}$ & Um pouco & O suficiente & Muito & Muitíssimo \\
\hline $\begin{array}{l}\text { 8. ....perda de urina } \\
\text { associada a forte } \\
\text { vontade de urinar? }\end{array}$ & Nada & $\begin{array}{l}\text { Quase } \\
\text { nada }\end{array}$ & Um pouco & O suficiente & Muito & Muitíssimo \\
\hline
\end{tabular}


Anexo C: Escore internacional de sintomas prostáticos (I-PSS)

\begin{tabular}{|l|c|c|c|c|c|c|}
\hline & $\begin{array}{c}\text { Nenhuma } \\
\text { vez }\end{array}$ & $\begin{array}{c}\text { Menos } \\
\text { de 1 vez } \\
\text { cada 5 }\end{array}$ & $\begin{array}{c}\text { Menos } \\
\text { que a } \\
\text { metade } \\
\text { das } \\
\text { vezes }\end{array}$ & $\begin{array}{c}\text { Cerca da } \\
\text { metade } \\
\text { das } \\
\text { vezes }\end{array}$ & $\begin{array}{c}\text { Mais que } \\
\text { a metade } \\
\text { das } \\
\text { vezes }\end{array}$ & $\begin{array}{c}\text { Quase } \\
\text { sempre }\end{array}$ \\
\hline $\begin{array}{l}\text { 1-No último mês, quantas } \\
\text { vezes você ficou com a } \\
\text { sensação de não esvaziar } \\
\text { completamente a bexiga } \\
\text { após urinar? }\end{array}$ & 0 & 1 & 2 & 3 & 4 & 5 \\
\hline $\begin{array}{l}\text { 2-No último mês, quantas } \\
\text { vezes você teve que urinar } \\
\text { novamente antes de 2 horas } \\
\text { depois de urinar? }\end{array}$ & 0 & 1 & 2 & 3 & 4 & 5 \\
\hline $\begin{array}{l}\text { 3-No ultimo mês, quantas } \\
\text { vezes você teve o jato } \\
\text { urinário interrompido várias } \\
\text { vezes enquanto urinava? }\end{array}$ & 0 & 1 & 2 & 3 & 4 & 5 \\
\hline $\begin{array}{l}\text { 4-No último mês, quantas } \\
\text { vezes você teve dificuldade } \\
\text { em controlar e evitar o } \\
\text { desejo de urinar }\end{array}$ & 0 & 1 & 2 & 3 & 4 & 5 \\
\hline $\begin{array}{l}\text { 5-No último mês, quantas } \\
\text { você teve o jato urinário } \\
\text { fraco? }\end{array}$ & 0 & 1 & 2 & 3 & 4 & 5 \\
\hline $\begin{array}{l}\text { 6-No último mês, quantas } \\
\text { vezes você teve que fazer } \\
\text { força para iniciar o ato de } \\
\text { urinar? }\end{array}$ & 0 & 1 & 2 & 3 & 4 & 5 \\
\hline & 0 & 1 & 2 & 3 & 4 & 5 \\
\hline $\begin{array}{l}\text { 7-No último mês, quantas } \\
\text { vezes, na média, você teve } \\
\text { que levantar da cama para } \\
\text { urinar à noite? }\end{array}$ & Nenhuma & 1 vez & 2 vezes & 3 vezes & 4 vezes & 5 ou mais \\
vezes
\end{tabular}

ÍNDICE DE AVALIAÇÃO DE QUALIDADE DE VIDA

\begin{tabular}{|l|c|c|c|c|c|c|c|}
\hline & Feliz & Bem & $\begin{array}{c}\text { Em geral } \\
\text { bem }\end{array}$ & Regular & Desconforto & Infeliz & Terrível \\
\hline $\begin{array}{l}\text { 8-Se você permanecer o } \\
\text { resto da vida com a } \\
\text { condição urinária atual, } \\
\text { como você se sentirá? }\end{array}$ & 0 & 1 & 2 & 3 & 4 & 5 & 6 \\
\hline
\end{tabular}


Anexo D: Questionário de satisfação com a vida (LiSat-9)

Aqui há um número de declarações que indicam sua satisfação com diferentes aspectos da sua vida.

Para cada uma das declarações, por favor, marque um número de 1 a 6 , de acordo com a tabela abaixo:

\begin{tabular}{|l|}
\hline $1=$ muito insatisfeito \\
\hline $2=$ insatisfeito \\
\hline $3=$ pouco insatisfeito \\
\hline $4=$ pouco satisfeito \\
\hline $5=$ satisfeito \\
\hline 6 = muito satisfeito \\
\hline
\end{tabular}

\begin{tabular}{|l|c|c|c|c|c|c|}
\hline Em relação à minha vida em geral, estou & 1 & 2 & 3 & 4 & 5 & 6 \\
\hline $\begin{array}{l}\text { Em relação à minha capacidade para auto cuidados } \\
\text { (vestir, higiene, transferências), estou }\end{array}$ & 1 & 2 & 3 & 4 & 5 & 6 \\
\hline Quanto à minha situação profissional, estou & 1 & 2 & 3 & 4 & 5 & 6 \\
\hline Quanto à minha situação financeira, estou & 1 & 2 & 3 & 4 & 5 & 6 \\
\hline Quanto à minha situação de lazer, estou & 1 & 2 & 3 & 4 & 5 & 6 \\
\hline Quanto à minha vida sexual, estou & 1 & 2 & 3 & 4 & 5 & 6 \\
\hline Quanto ao meu relacionamento com minha (o) parceira (o), estou & 1 & 2 & 3 & 4 & 5 & 6 \\
\hline Quanto à minha vida com minha família, estou & 1 & 2 & 3 & 4 & 5 & 6 \\
\hline Quanto ao meu contato com amigos e conhecidos, estou & 1 & 2 & 3 & 4 & 5 & 6 \\
\hline
\end{tabular}


(1) Wingerchuk DM, Pittock SJ, Lucchinetti CF, Lennon VA, Weinshenker BG. A secondary progressive clinical course is uncommon in neuromyelitis optica. Neurology. 2007 Feb 20;68(8):603-5.

(2) De SJ. Neuromyelitis optica. Arch Neurol. 2003 Sep;60(9):1336-8.

(3) Miyazawa I, Fujihara K, Itoyama Y. Eugene Devic (1858-1930). J Neurol. 2002 Mar;249(3):351-2.

(4) Wingerchuk DM, Hogancamp WF, O'Brien PC, Weinshenker BG. The clinical course of neuromyelitis optica (Devic's syndrome). Neurology. 1999 Sep 22;53(5):1107-14.

(5) Lennon VA, Wingerchuk DM, Kryzer TJ, Pittock SJ, Lucchinetti CF, Fujihara K, Nakashima I, Weinshenker BG. A serum autoantibody marker of neuromyelitis optica: distinction from multiple sclerosis. Lancet. 2004 Dec 11;364(9451):2106-12.

(6) Lennon VA, Kryzer TJ, Pittock SJ, Verkman AS, Hinson SR. IgG marker of optic-spinal multiple sclerosis binds to the aquaporin-4 water channel. J Exp Med. 2005 Aug 15;202(4):473-7.

(7) Roemer SF, Parisi JE, Lennon VA, Benarroch EE, Lassmann H, Bruck W, Mandler RN, Weinshenker BG, Pittock SJ, Wingerchuk DM, Lucchinetti CF. Pattern-specific loss of aquaporin-4 immunoreactivity distinguishes neuromyelitis optica from multiple sclerosis. Brain. 2007 May;130(Pt 5):1194-205.

(8) Kozono D, Yasui M, King LS, Agre P. Aquaporin water channels: atomic structure molecular dynamics meet clinical medicine. J Clin Invest. 2002 Jun;109(11):1395-9. 
(9) Jarius S, Paul F, Franciotta D, Waters P, Zipp F, Hohlfeld R, Vincent A, Wildemann B. Mechanisms of disease: aquaporin-4 antibodies in neuromyelitis optica. Nat Clin Pract Neurol. 2008 Apr;4(4):202-14.

(10) Pittock SJ, Weinshenker BG, Lucchinetti CF, Wingerchuk DM, Corboy JR, Lennon VA. Neuromyelitis optica brain lesions localized at sites of high aquaporin 4 expression. Arch Neurol. 2006 Jul;63(7):964-8.

(11) Wingerchuk DM, Lennon VA, Pittock SJ, Lucchinetti CF, Weinshenker BG. Revised diagnostic criteria for neuromyelitis optica. Neurology. 2006 May 23;66(10):1485-9.

(12) Jacob A, Matiello M, Wingerchuk DM, Lucchinetti CF, Pittock SJ, Weinshenker BG. Neuromyelitis optica: changing concepts. J Neuroimmunol. 2007 Jul;187(1-2):126-38.

(13) Kim SH, Kim SM, Vincent A, Ahn SW, Hong YH, Park KS, Sung JJ, Lee KW. Clinical characteristics, prognosis, and seropositivity to the anti-aquaporin-4 antibody in Korean patients with longitudinally extensive transverse myelitis. J Neurol. 2010 Jun;257(6):920-5.

(14) Marignier R, De SJ, Vukusic S, Durand-Dubief F, Zéphir H, Vermersch P, Cabre P, Cavillon G, Honnorat J, Confavreux C. NMO-lgG and Devic's neuromyelitis optica: a French experience. Mult Scler. 2008 May;14(4):440-5.

(15) Wingerchuk DM, Lennon VA, Lucchinetti CF, Pittock SJ, Weinshenker BG. The spectrum of neuromyelitis optica. Lancet Neurol. 2007 Sep; 6(9):805-15. 
(16) Bizzoco E, Lolli F, Repice AM, Hakiki B, Falcini M, Barilaro A, Taiuti R, Siracusa G, Amato MP, Biagioli T, Lori S, Moretti M, Vinattieri A, Nencini $P$, Massacesi L, Matà S. Prevalence of neuromyelitis optica spectrum disorder and phenotype distribution. J Neurol. 2009 Nov; 256(11):1891-8.

(17) De SJ, Lebrun C, Stojkovic T, Ferriby D, Chatel M, Vermersch P. Is Devic's neuromyelitis optica a separate disease? A comparative study with multiple sclerosis. Mult Scler. 2003 Oct;9(5):521-5.

(18) Barbieri F, Buscaino GA. Neuromyelitis optica in the elderly. Acta Neurol (Napoli). 1989 Aug;11(4):247-51.

(19) Levy M, Birnbaum J, Kerr D. Finding NMO: neuromyelitis optica in children. Neurology. 2008 Jan 29;70(5):334-5.

(20) Chopra JS, Radhakrishnan K, Sawhney BB, Pal SR, Banerjee AK. Multiple sclerosis in North-West India. Acta Neurol Scand 1980 Nov;62(5):312-21.

(21) Gangopadhyay G, Das SK, Sarda P, Saha SP, Gangopadhyay PK, Roy TN, Maity B. Clinical profile of multiple sclerosis in Bengal. Neurol India. 1999 Mar;47(1):18-21.

(22) Nakashima I, Fujihara K, Takase S, Itoyama Y. Decrease in multiple sclerosis with acute transverse myelitis in Japan. Tohoku J Exp Med. 1999 May;188(1):89-94.

(23) Papais-Alvarenga RM, Miranda-Santos CM, Puccioni-Sohler M, de Almeida AM, Oliveira S, Basilio De Oliveira CA, Alvarenga H, Poser CM. Optic neuromyelitis syndrome in Brazilian patients. J Neurol Neurosurg Psychiatry. 2002 Oct;73(4):429-35. 
(24) Misu T, Fujihara K, Kakita A, Konno H, Nakamura M, Watanabe S, Takahashi T, Nakashima I, Takahashi H, Itoyama Y. Loss of aquaporin 4 in lesions of neuromyelitis optica: distinction from multiple sclerosis. Brain. 2007 May;130(Pt 5):1224-34.

(25) Takahashi T, Fujihara K, Nakashima I, Misu T, Miyazawa I, Nakamura M, Watanabe S, Shiga Y, Kanaoka C, Fujimori J, Sato S, Itoyama Y. Anti-aquaporin-4 antibody is involved in the pathogenesis of NMO: a study on antibody titre. Brain. 2007 May;130(Pt 5):1235-43.

(26) Kira J. Neuromyelitis optica and opticospinal multiple sclerosis: Mechanisms and pathogenesis. Pathophysiology. 2011 Feb;18(1):6979.

(27) Correale J, Fiol M. Activation of humoral immunity and eosinophils in neuromyelitis optica. Neurology. 2004 Dec 28;63(12):2363-70.

(28) Lucchinetti CF, Mandler RN, McGavern D, Bruck W, Gleich G, Ransohoff RM, Trebst C, Weinshenker B, Wingerchuk D, Parisi JE, Lassmann $\mathrm{H}$. A role for humoral mechanisms in the pathogenesis of Devic's neuromyelitis optica. Brain. 2002 Jul;125(Pt 7):1450-61.

(29) McKeon A, Lennon VA, Jacob A, Matiello M, Lucchinetti CF, Kale N, Chan KH, Weinshenker BG, Apiwattinakul M, Wingerchuk DM, Pittock SJ. Coexistence of myasthenia gravis and serological markers of neurological autoimmunity in neuromyelitis optica. Muscle Nerve. 2009 Jan;39(1):87-90.

(30) Weinshenker BG, Wingerchuk DM, Vukusic S, Linbo L, Pittock SJ, Lucchinetti CF, Lennon VA. Neuromyelitis optica IgG predicts relapse after longitudinally extensive transverse myelitis. Ann Neurol. 2006 Mar;59(3):566-9. 
(31) Misu T, Fujihara K, Nakashima I, Sato S, Itoyama Y. Intractable hiccup and nausea with periaqueductal lesions in neuromyelitis optica. Neurology. 2005 Nov 8;65(9):1479-82.

(32) Poppe AY, Lapierre Y, Melancon D, Lowden D, Wardell L, Fullerton LM, Bar-Or A. Neuromyelitis optica with hypothalamic involvement. Mult Scler. 2005 Oct;11(5):617-21.

(33) McKeon A, Lennon VA, Lotze T, Tenenbaum S, Ness JM, Rensel M, Kuntz NL, Fryer JP, Homburger H, Hunter J, Weinshenker BG, Krecke K, Lucchinetti CF, Pittock SJ. CNS aquaporin-4 autoimmunity in children. Neurology. 2008 Jul 8;71(2):93-100.

(34) Cree BA, Goodin DS, Hauser SL. Neuromyelitis optica. Semin Neurol. 2002 Jun;22(2):105-22.

(35) Giorgi D, Balacco GC, Bonomo L. The association of optic neuropathy with transverse myelitis in systemic lupus erythematosus.

Rheumatology (Oxford). 1999 Feb;38(2):191-2.

(36) Yamamoto T, Ito S, Hattori T. Neurological picture. Acute longitudinal myelitis as the initial manifestation of Sjogren's syndrome. J Neurol Neurosurg Psychiatry. 2006 Jun;77(6):780.

(37) Misu T, Takahashi T, Nakashima I, Fujihara K, Itoyama Y. [Neuromyelitis optica and anti-aquaporin 4 antibody--distinct from multiple sclerosis]. Rinsho Byori. 2009 Mar;57(3):262-70.

(38) Nishiyama S, Ito T, Misu T, Takahashi T, Kikuchi A, Suzuki N, Jin K, Aoki M, Fujihara K, Itoyama Y. A case of NMO seropositive for aquaporin-4 antibody more than 10 years before onset. Neurology. 2009 Jun 2;72(22):1960-1. 
(39) Cabrera-Gómez JA, Bonnan M, González-Quevedo A, Saiz-Hinarejos A, Marignier R, Olindo S, Graus F, Smadja D, Merle H, Thomas L, Gómez-García A, Cabre P. Neuromyelitis optica positive antibodies confer a worse course in relapsing-neuromyelitis optica in Cuba and French West Indies. Mult Scler. 2009 Jul;15(7):828-33.

(40) Collongues N, Marignier R, Zephir H, Papeix C, Blanc F, Ritleng C, Tchikviladzé M, Outteryck O, Vukusic S, Fleury M, Fontaine B, Brassat D, Clanet M, Milh M, Pelletier J, Audoin B, Ruet A, LebrunFrenay C, Thouvenot E, Camu W, Debouverie M, Créange A, Moreau T, Labauge P, Castelnovo G, Edan G, Le Page E, Defer G, Barroso B, Heinzlef O, Gout O, Rodriguez D, Wiertlewski S, Laplaud D, Borgel F, Tourniaire P, Grimaud J, Brochet B, Vermersch P, Confavreux C, de Seze J. Neuromyelitis optica in France: a multicenter study of 125 patients. Neurology. 2010 Mar 2;74(9):736-42.

(41) Adoni T, Lino AM, Marchiori PE, Kok F, Callegaro D. Seroprevalence of NMO-IgG antibody in Brazilian patients with neuromyelitis optica. Arq Neuropsiquiatr. 2008 Jun;66(2B):295-7.

(42) Bichuetti DB, Oliveira EM, Souza NA, Rivero RL, Gabbai AA. Neuromyelitis optica in Brazil: a study on clinical and prognostic factors. Mult Scler. 2009 May;15(5):613-9.

(43) Saiz A, Zuliani L, Blanco Y, Tavolato B, Giometto B, Graus F. Revised diagnostic criteria for neuromyelitis optica (NMO). Application in a series of suspected patients. J Neurol. 2007 Sep;254(9):1233-7.

(44) Adoni T, Lino AM, da Gama PD, Apóstolos-Pereira SL, Marchiori PE, Kok F, Callegaro D. Recurrent neuromyelitis optica in Brazilian patients: clinical, immunological, and neuroimaging characteristics. Mult Scler. 2010 Jan;16(1):81-6. 
(45) Cassinotto C, Deramond H, Olindo S, Aveillan M, Smadja D, Cabre P. $\mathrm{MRI}$ of the spinal cord in neuromyelitis optica and recurrent longitudinal extensive myelitis. J Neuroradiol. 2009 Oct;36(4):199-205.

(46) Krampla W, boul-Enein F, Jecel J, Lang W, Fertl E, Hruby W, Kristoferitsch W. Spinal cord lesions in patients with neuromyelitis optica: a retrospective long-term MRI follow-up study. Eur Radiol. 2009 Oct;19(10):2535-43.

(47) Cabrera-Gomez JA, Quevedo-Sotolongo L, Gonzalez-Quevedo A, Lima S, Real-Gonzalez Y, Cristofol-Corominas M, Romero-García K, Ugarte-Sánchez C, Jordán-González J, de la Nuez JE, Lahera JG, Tellez R, Pedroso-lbañez I, Roca RR, Cabrera-Núñez AY. Brain magnetic resonance imaging findings in relapsing neuromyelitis optica. Mult Scler. 2007 Mar;13(2):186-92.

(48) Pittock SJ, Lennon VA, Krecke K, Wingerchuk DM, Lucchinetti CF, Weinshenker BG. Brain abnormalities in neuromyelitis optica. Arch Neurol. 2006 Mar;63(3):390-6.

(49) Barkhof F, Filippi M, Miller DH, Scheltens P, Campi A, Polman CH, Comi G, Adèr HJ, Losseff N, Valk J. Comparison of MRI criteria at first presentation to predict conversion to clinically definite multiple sclerosis. Brain. 1997 Nov;120 (Pt 11):2059-69.

(50) Nakashima I, Fujihara K, Miyazawa I, Misu T, Narikawa K, Nakamura M, Watanabe S, Takahashi T, Nishiyama S, Shiga Y, Sato S, Weinshenker BG, Itoyama Y. Clinical and MRI features of Japanese patients with multiple sclerosis positive for NMO-IgG. J Neurol Neurosurg Psychiatry. 2006 Sep;77(9):1073-5. 
(51) Chan KH, Tsang KL, Fong GC, Ho SL, Cheung RT, Mak W. Idiopathic inflammatory demyelinating disorders after acute transverse myelitis. Eur J Neurol. 2006 Aug;13(8):862-8.

(52) Mandler RN, Ahmed W, Dencoff JE. Devic's neuromyelitis optica: a prospective study of seven patients treated with prednisone and azathioprine. Neurology. 1998 Oct;51(4):1219-20.

(53) Watanabe S, Misu T, Miyazawa I, Nakashima I, Shiga Y, Fujihara K, Itoyama $Y$. Low-dose corticosteroids reduce relapses in neuromyelitis optica: a retrospective analysis. Mult Scler. 2007 Sep;13(8):968-74.

(54) Papeix C, Vidal JS, De SJ, Pierrot-Deseilligny C, Tourbah A, Stankoff B, Lebrun C, Moreau T, Vermersch P, Fontaine B, Lyon-Caen O, Gout O. Immunosuppressive therapy is more effective than interferon in neuromyelitis optica. Mult Scler. 2007 Mar;13(2):256-9.

(55) Bonnan M, Valentino R, Olindo S, Mehdaoui H, Smadja D, Cabre P. Plasma exchange in severe spinal attacks associated with neuromyelitis optica spectrum disorder. Mult Scler. 2009 Apr;15(4):487-92.

(56) Cree BA, Lamb S, Morgan K, Chen A, Waubant E, Genain C. An open label study of the effects of rituximab in neuromyelitis optica. Neurology. 2005 Apr 12;64(7):1270-2.

(57) Weinstock-Guttman B, Ramanathan M, Lincoff N, Napoli SQ, Sharma J, Feichter J, Bakshi R. Study of mitoxantrone for the treatment of recurrent neuromyelitis optica (Devic disease). Arch Neurol. 2006 Jul;63(7):957-63. 
(58) Wingerchuk DM, Weinshenker BG. Neuromyelitis optica: clinical predictors of a relapsing course and survival. Neurology. 2003 Mar $11 ; 60(5): 848-53$.

(59) Bichuetti DB, Lobato de Oliveira EM, Oliveira DM, Morin de SN, Gabbai AA. Neuromyelitis optica treatment: analysis of 36 patients. Arch Neurol. 2010 Sep;67(9):1131-6.

(60) Matiello M, Lennon VA, Jacob A, Pittock SJ, Lucchinetti CF, Wingerchuk DM, Weinshenker BG. NMO-IgG predicts the outcome of recurrent optic neuritis. Neurology. 2008 Jun 3;70(23):2197-200.

(61) Palace J, Leite MI, Nairne A, Vincent A. Interferon Beta treatment in neuromyelitis optica: increase in relapses and aquaporin 4 antibody titers. Arch Neurol. 2010 Aug;67(8):1016-7.

(62) Fitzgerald MP, Mueller E. Physiology of the lower urinary tract. Clin Obstet Gynecol. 2004 Mar;47(1):18-27.

(63) Birder L, de GW, Mills I, Morrison J, Thor K, Drake M. Neural control of the lower urinary tract: peripheral and spinal mechanisms. Neurourol Urodyn. 2010;29(1):128-39.

(64) Birder L, de GW, Mills I, Morrison J, Thor K, Drake M. Neural control of the lower urinary tract: peripheral and spinal mechanisms. Neurourol Urodyn. 2010;29(1):128-39.

(65) de Groat WC. A neurologic basis for the overactive bladder. Urology. 1997 Dec;50(6A Suppl):36-52.

(66) de Groat WC. Integrative control of the lower urinary tract: preclinical perspective. Br J Pharmacol. 2006 Feb;147 Suppl 2:S25-S40. 
(67) Wein AJ, Dmochowski RR. Neuromuscular dysfunction of the lower urunary tract. In: Wein AJ, Kavoussi LR, Novick AC, Partin AW, Peters CA, editors. Campbell-Walsh Urology. 10 ed. Philadelfia: Elsevier Saunders; 2012. p. 1909-46.

(68) de Groat WC. Anatomy of the central neural pathways controlling the lower urinary tract. Eur Urol. 1998;34 Suppl 1:2-5.

(69) Baden WF, Walker TA, Lindsey JH. The vaginal profile. Tex Med. 1968 May;64(5):56-8.

(70) Kurtzke JF. Rating neurologic impairment in multiple sclerosis: an expanded disability status scale (EDSS). Neurology. 1983 Nov;33(11):1444-52.

(71) Barry MJ, Fowler FJ, Jr., O'Leary MP, Bruskewitz RC, Holtgrewe HL, Mebust WK, Cockett AT. The American Urological Association symptom index for benign prostatic hyperplasia. The Measurement Committee of the American Urological Association. J Urol. 1992 Nov;148(5):1549-57.

(72) Coyne KS, Zyczynski T, Margolis MK, Elinoff V, Roberts RG. Validation of an overactive bladder awareness tool for use in primary care settings. Adv Ther. 2005 Jul;22(4):381-94.

(73) Badia X, Garcia-Losa M, Dal-Re R. Ten-language translation and harmonization of the International Prostate Symptom Score: developing a methodology for multinational clinical trials. Eur Urol. 1997;31(2):129-40.

(74) Gregoire JP, Moisan J, Labrecque M, Cusan L, Diamond P. [Validation of a French adaptation of the international prostatic symptom score]. Prog Urol. 1996 Apr;6(2):240-9. 
(75) Vela NR, Martin Moreno JM, Calahorra FJ, Damian MJ, Hernandez CA, Boyle P. [Cultural and linguistic validation, in Spanish, of the International Prostatic Symptoms Scale (I-PSS)]. Actas Urol Esp. 1994 Sep;18(8):841-7.

(76) Tan HY, Choo WC, Archibald C, Esuvaranathan K. A community based study of prostatic symptoms in Singapore. J Urol. 1997 Mar;157(3):890-3.

(77) Bosch JL, Weiss JP. The prevalence and causes of nocturia. J Urol. 2013 Jan;189(1 Suppl):S86-S92.

(78) Kim SO, Choi HS, Kim YJ, Kim HS, Hwang IS, Hwang EC, Oh KJ, Jung SI, Kang TW, Kwon D, Park K, Ryu SB. Impact of nocturia on health-related quality of life and medical outcomes study sleep score in men. Int Neurourol J. 2011 Jun;15(2):82-6.

(79) Boongird S, Shah N, Nolin TD, Unruh ML. Nocturia and aging: diagnosis and treatment. Adv Chronic Kidney Dis. 2010 Jul;17(4):e27e40.

(80) Haylen BT, de RD, Freeman RM, Swift SE, Berghmans B, Lee J, Monga A, Petri E, Rizk DE, Sand PK, Schaer GN. An International Urogynecological Association (IUGA)/International Continence Society (ICS) joint report on the terminology for female pelvic floor dysfunction. Int Urogynecol J. 2010 Jan;21(1):5-26.

(81) Schafer W, Abrams P, Liao L, Mattiasson A, Pesce F, Spangberg A, Sterling AM, Zinner NR, van Kerrebroeck P; International Continence Society. Good urodynamic practices: uroflowmetry, filling cystometry, and pressure-flow studies. Neurourol Urodyn. 2002;21(3):261-74. 
(82) Berger M, Luz Junior P, Silva Neto B, Koff W. Validação estatistica do escore internacional de sintomas prostáticos (I-PSS) na língua portuguesa / Statistical validation of the international prostatic symptom score (I-PSS) in Portuguese. J Bras Urol. 1999;25(2):22534.

(83) Okamura K, Usami T, Nagahama K, Maruyama S, Mizuta E. "Quality of life" assessment of urination in elderly Japanese men and women with some medical problems using International Prostate Symptom Score and King's Health Questionnaire. Eur Urol. 2002 Apr;41(4):4119.

(84) Terai A, Matsui Y, Ichioka K, Ohara H, Terada N, Yoshimura K. Comparative analysis of lower urinary tract symptoms and bother in both sexes. Urology. 2004 Mar;63(3):487-91.

(85) Fugl-Meyer AR, Bränholm I, Fugl-Meyer K. Happiness and domainspecific life satisfaction in adult northern Swedes. Clin Rehabil. 1991;5:25-33.

(86) Argyriou AA, Makris N. Neuromyelitis optica: a distinct demyelinating disease of the central nervous system. Acta Neurol Scand. 2008 Oct;118(4):209-17.

(87) McKeon A, Fryer JP, Apiwattanakul M, Lennon VA, Hinson SR, Kryzer TJ, Lucchinetti CF, Weinshenker BG, Wingerchuk DM, Shuster EA, Pittock SJ. Diagnosis of neuromyelitis spectrum disorders: comparative sensitivities and specificities of immunohistochemical and immunoprecipitation assays. Arch Neurol. 2009 Sep;66(9):1134-8.

(88) Onal B, Siva A, Buldu I, Demirkesen O, Cetinel B. Voiding dysfunction due to multiple sclerosis: a large scale retrospective analysis. Int Braz J Urol. 2009 May;35(3):326-33. 
(89) Ghezzi A, Bergamaschi R, Martinelli V, Trojano M, Tola MR, Merelli E, Mancardi L, Gallo P, Filippi M, Zaffaroni M, Comi G; Italian Devic's Study Group (IDESG). Clinical characteristics, course and prognosis of relapsing Devic's Neuromyelitis Optica. J Neurol. 2004 Jan;251(1):47-52.

(90) Rivera JF, Kurtzke JF, Booth VJ, Corona VT. Characteristics of Devic's disease (neuromyelitis optica) in Mexico. J Neurol. 2008 May;255(5):710-5.

(91) Litwiller SE, Frohman EM, Zimmern PE. Multiple sclerosis and the urologist. J Urol. 1999 Mar;161(3):743-57.

(92) Andersen JT, Bradley WE. Abnormalities of detrusor and sphincter function in multiple sclerosis. Br J Urol. 1976 Jun;48(3):193-8.

(93) Bradley WE. Urinary bladder dysfunction in multiple sclerosis. Neurology. 1978 Sep;28(9 Pt 2):52-8.

(94) Goldstein I, Siroky MB, Sax DS, Krane RJ. Neurourologic abnormalities in multiple sclerosis. J Urol. 1982 Sep;128(3):541-5.

(95) Koldewijn EL, Hommes OR, Lemmens WA, Debruyne FM, van Kerrebroeck PE. Relationship between lower urinary tract abnormalities and disease-related parameters in multiple sclerosis. $J$ Urol. 1995 Jul;154(1):169-73.

(96) McDonald WI. The dynamics of multiple sclerosis. The Charcot Lecture. J Neurol. 1993 Jan;240(1):28-36. 
(97) Shimizu K, Yasukawa M, Yamamoto M, Hirao Y, Momose H, Kashiwai $\mathrm{H}$, Kawata $\mathrm{Y}$, Yamada K. [Clinical findings of neurogenic bladder in patients with Parkinson's disease, multiple sclerosis and spinocerebellar degeneration]. Hinyokika Kiyo. 1997 Nov;43(11):7659.

(98) Philp T, Read DJ, Higson RH. The urodynamic characteristics of multiple sclerosis. Br J Urol. 1981 Dec;53(6):672-5.

(99) Awad SA, Gajewski JB, Sogbein SK, Murray TJ, Field CA. Relationship between neurological and urological status in patients with multiple sclerosis. J Urol. 1984 Sep;132(3):499-502.

(100) Gonor SE, Carroll DJ, Metcalfe JB. Vesical dysfunction in multiple sclerosis. Urology. 1985 Apr;25(4):429-31.

(101) Betts CD, D'Mellow MT, Fowler CJ. Urinary symptoms and the neurological features of bladder dysfunction in multiple sclerosis. J Neurol Neurosurg Psychiatry. 1993 Mar;56(3):245-50.

(102) Hennessey A, Robertson NP, Swingler R, Compston DA. Urinary, faecal and sexual dysfunction in patients with multiple sclerosis. $J$ Neurol. 1999 Nov;246(11):1027-32.

(103) Borello-France D, Leng W, O'Leary M, Xavier M, Erickson J, Chancellor MB, Cannon TW. Bladder and sexual function among women with multiple sclerosis. Mult Scler. 2004 Aug;10(4):455-61.

(104) Ukkonen M, Elovaara I, Dastidar P, Tammela TL. Urodynamic findings in primary progressive multiple sclerosis are associated with increased volumes of plaques and atrophy in the central nervous system. Acta Neurol Scand. 2004 Feb;109(2):100-5. 
(105) Quarto G, Autorino R, Gallo A, De SM, D'Armiento M, Perdonà S, Damiano R. Quality of life in women with multiple sclerosis and overactive bladder syndrome. Int Urogynecol J Pelvic Floor Dysfunct. 2007 Feb;18(2):189-94.

(106) Acquadro C, Kopp Z, Coyne KS, Corcos J, Tubaro A, Choo MS, Oh SJ. Translating overactive bladder questionnaires in 14 languages. Urology. 2006 Mar;67(3):536-40.

(107) Araki I, Kuno S. Assessment of voiding dysfunction in Parkinson's disease by the international prostate symptom score. J Neurol Neurosurg Psychiatry. 2000 Apr;68(4):429-33.

(108) Groutz A, Blaivas JG, Fait G, Sassone AM, Chaikin DC, Gordon D. The significance of the American Urological Association symptom index score in the evaluation of women with bladder outlet obstruction. J Urol. 2000 Jan;163(1):207-11.

(109) Lepor H, Machi G. Comparison of AUA symptom index in unselected males and females between fifty-five and seventy-nine years of age. Urology. 1993 Jul;42(1):36-40.

(110) Antunes AA, Carnevale FC, da Motta Leal Filho JM, Yoshinaga EM, Cerri LM, Baroni RH, Marcelino AS, Cerri GG, Srougi M. Clinical, laboratorial, and urodynamic findings of prostatic artery embolization for the treatment of urinary retention related to benign prostatic hyperplasia. A prospective single-center pilot study. Cardiovasc Intervent Radiol. 2013 Aug;36(4):978-86.

(111) de Lima ML, Netto NR, Jr. Urodynamic studies in the surgical treatment of benign prostatic hyperplasia. Int Braz J Urol. 2003 Sep;29(5):418-22. 
(112) Marmiroli R, Antunes AA, Reis ST, Nakano E, Srougi M. Standard surgical treatment for benign prostatic hyperplasia is safe for patients over 75 years: analysis of 100 cases from a high-volume urologic center. Clinics (Sao Paulo). 2012 Dec;67(12):1415-8.

(113) Blaivas JG, Bhimani G, Labib KB. Vesicourethral dysfunction in multiple sclerosis. J Urol. 1979 Sep;122(3):342-7.

(114) Helmut G Madersbacher. Pathophysiology of the vesico-sphincteric dyssynergia. In: Jacques Corcos, Erik Schick, editors. Textbook of the Neurogenic Bladder. Second edition ed. London: Informa Healthcare; 2008. p. 204.

(115) Beck RW, Cleary PA, Anderson MM, Jr., Keltner JL, Shults WT, Kaufman DI, Buckley EG, Corbett JJ, Kupersmith MJ, Miller NR et al. A randomized, controlled trial of corticosteroids in the treatment of acute optic neuritis. The Optic Neuritis Study Group. N Engl J Med. 1992 Feb 27;326(9):581-8.

(116) Bradley WE, Logothetis JL, Timm GW. Cystometric and sphincter abnormalities in multiple sclerosis. Neurology. 1973 Oct;23(10):11319.

(117) Eardley I, Nagendran K, Lecky B, Chapple CR, Kirby RS, Fowler CJ. Neurophysiology of the striated urethral sphincter in multiple sclerosis. Br J Urol. 1991 Jul;68(1):81-8.

(118) Hinson JL, Boone TB. Urodynamics and multiple sclerosis. Urol Clin N Amer. 1996;23:475.

(119) Mayo ME, Chetner MP. Lower urinary tract dysfunction in multiple sclerosis. Urology. 1992 Jan;39(1):67-70. 
(120) McGuire EJ, Savastano JA. Urodynamic findings and long-term outcome management of patients with multiple sclerosis-induced lower urinary tract dysfunction. J Urol. 1984 Oct;132(4):713-5.

(121) Petersen T, Pedersen E. Neurourodynamic evaluation of voiding dysfunction in multiple sclerosis. Acta Neurol Scand. 1984 Jun;69(6):402-11.

(122) Piazza DH, Diokno AC. Review of neurogenic bladder in multiple sclerosis. Urology. 1979 Jul;14(1):33-5.

(123) Schoenberg HW, Gutrich J, Banno J. Urodynamic patterns in multiple sclerosis. J Urol. 1979 Nov;122(5):648-50.

(124) Sirls LT, Zimmern PE, Leach GE. Role of limited evaluation and aggressive medical management in multiple sclerosis: a review of 113 patients. J Urol. 1994 Apr;151(4):946-50.

(125) Summers JL. Neurogenic bladder in the woman with multiple sclerosis. J Urol. 1978 Nov;120(5):555-6.

(126) Van PH, Baert L. Treatment of multi-resistant urinary tract infections in patients with multiple sclerosis. Pharm Weekbl Sci. 1987 Dec 11;9 Suppl:S76-S77.

(127) Weinstein MS, Cardenas DD, O'Shaughnessy EJ, Catanzaro ML. Carbon dioxide cystometry and postural changes in patients with multiple sclerosis. Arch Phys Med Rehabil. 1988 Nov;69(11):923-7.

(128) Ciancio SJ, Mutchnik SE, Rivera VM, Boone TB. Urodynamic pattern changes in multiple sclerosis. Urology. 2001 Feb;57(2):239-45. 
(129) Lemack GE, Hawker K, Frohman E. Incidence of upper tract abnormalities in patients with neurovesical dysfunction secondary to multiple sclerosis: analysis of risk factors at initial urologic evaluation. Urology. 2005 May;65(5):854-7.

(130) Bemelmans BL, Hommes OR, van Kerrebroeck PE, Lemmens WA, Doesburg WH, Debruyne FM. Evidence for early lower urinary tract dysfunction in clinically silent multiple sclerosis. J Urol. 1991 Jun;145(6):1219-24.

(131) Araki I, Matsui M, Ozawa K, Nishimura M, Kuno S, Saida T. Relationship between urinary symptoms and disease-related parameters in multiple sclerosis. J Neurol. 2002 Aug;249(8):1010-5.

(132) Kragt JJ, Hoogervorst EL, Uitdehaag BM, Polman CH. Relation between objective and subjective measures of bladder dysfunction in multiple sclerosis. Neurology. 2004 Nov 9;63(9):1716-8.

(133) Lemack GE, Frohman E, Ramnarayan P. Women with voiding dysfunction secondary to bladder outlet dyssynergia in the setting of multiple sclerosis do not demonstrate significantly elevated intravesical pressures. Urology. 2007 May;69(5):893-7.

(134) Kirchhof K, Fowler CJ. The value of the Kurtzke Functional Systems Scales in predicting incomplete bladder emptying. Spinal Cord. 2000 Jul;38(7):409-13.

(135) Akkoc Y, Karapolat H, Eyigor S, Yesil H, Yuceyar N. Quality of life in multiple sclerosis patients with urinary disorders: reliability and validity of the Turkish version of King's Health Questionnaire. Neurol Sci. 2011 Jun;32(3):417-21. 
(136) Mahajan ST, Patel PB, Marrie RA. Under treatment of overactive bladder symptoms in patients with multiple sclerosis: an ancillary analysis of the NARCOMS Patient Registry. J Urol. 2010 Apr;183(4):1432-7.

(137) Gurcay E, Bal A, Eksioglu E, Cakci A. Quality of life in patients with spinal cord injury. Int J Rehabil Res. 2010 Dec;33(4):356-8.

(138) Budh CN, Osteraker AL. Life satisfaction in individuals with a spinal cord injury and pain. Clin Rehabil. 2007 Jan;21(1):89-96.

(139) Lund ML, Nordlund A, Bernspang B, Lexell J. Perceived participation and problems in participation are determinants of life satisfaction in people with spinal cord injury. Disabil Rehabil. 2007 Sep 30;29(18):1417-22.

(140) Kennedy P, Lude P, Taylor N. Quality of life, social participation, appraisals and coping post spinal cord injury: a review of four community samples. Spinal Cord. 2006 Feb;44(2):95-105.

(141) Ide M, Fugl-Meyer AR. Life satisfaction in persons with spinal cord injury: a comparative investigation between Sweden and Japan. Spinal Cord. 2001 Jul;39(7):387-93.

(142) Songhuai L, Olver L, Jianjun L, Kennedy P, Genlin L, Duff J, ScottWilson U. A comparative review of life satisfaction, quality of life and mood between Chinese and British people with tetraplegia. Spinal Cord. 2009 Jan;47(1):82-6.

(143) Geyh S, Fellinghauer BA, Kirchberger I, Post MW. Cross-cultural validity of four quality of life scales in persons with spinal cord injury. Health Qual Life Outcomes. 2010;8:94. 
(144) Weld KJ, Graney MJ, Dmochowski RR. Clinical significance of detrusor sphincter dyssynergia type in patients with post-traumatic spinal cord injury. Urology. 2000 Oct 1;56(4):565-8.

(145) McGuire EJ, Woodside JR, Borden TA, Weiss RM. Prognostic value of urodynamic testing in myelodysplastic patients. J Urol. 1981 Aug;126(2):205-9.

(146) Weld KJ, Wall BM, Mangold TA, Steere EL, Dmochowski RR. Influences on renal function in chronic spinal cord injured patients. J Urol. 2000 Nov;164(5):1490-3.

(147) Krhut J, Hradilek P, Zapletalova O. Analysis of the upper urinary tract function in multiple sclerosis patients. Acta Neurol Scand. 2008 Aug;118(2):115-9. 
APÊNDICES 
Apêndice I - Aprovação da Comissão de Ética para Análise de Projetos de

Pesquisa - CAPPesq da Diretoria Clínica do Hospital das Clínicas e da

Faculdade de Medicina da Universidade de São Paulo

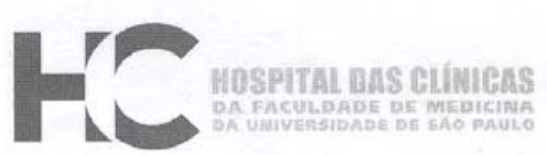

\section{APROVAÇÃO}

A Comissão de Ética para Análise de Projetos de Pesquisa CAPPesq da Diretoria Clínica do Hospital das Clínicas e da Faculdade de Medicina da Universidade de São Paulo, em sessão de 27/01/2010, APROVOU O Protocolo de Pesquisa n 1151/09, intitulado: "CARACTERIZAÇĀO DAS DISFUNÇŌES MICCIONAIS E SEXUAIS EM PACIENTES COM NEUROMIELITE ÓPTICA (DOENÇA DE DEVIC)" apresentado pelo Departamento de CIRURGIA, inclusive o Termo de Consentimento Livre e Esclarecido.

Cabe ao pesquisador elaborar e apresentar à CAPPesq, os relatórios parciais e final sobre a pesquisa (Resolução do Conselho Nacional de Saúde n० 196, de 10/10/1996, inciso IX.2, letra "c").

Pesquisador (a) Responsável: Cristiano Mendes Gomes

Pesquisador (a) Executante: Fabrício Leite de Carvalho

CAPPesq, 28 de Janeiro de 2010

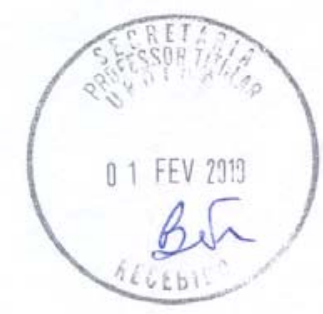

Prof. Dr. Eduardo Massad Presidente da Comissão de Ética para Análise de Projetos de Pesquisa

Comissão de Ética para Análise de Projetos de Pesquisa do HCFMUSP e da FMUSP Diretoria Clínica do Hospital das Clinicas da Faculdade de Medicina da Universidade de São Paulo Rua Ovídio Pires de Campos, 225, $5^{\circ}$ andar - CEP 05403010 - São Paulo - SP Fone: 01130696442 Fax: 01130696492 e-mail: cappesq@hcnet.usp.br / secretariacappesq2@hcnet.usp.br 
Apêndice II - Termo de consentimento livre e esclarecido

HOSPITAL DAS CLÍNICAS DA FACULDADE DE MEDICINA DA UNIVERSIDADE DE SÃO PAULO-HCFMUSP

TERMO DE CONSENTIMENTO LIVRE E ESCLARECIDO

DADOS DE IDENTIFICAÇÃO DO SUJEITO DA PESQUISA OU RESPONSÁVEL LEGAL

1.NOME:

DOCUMENTO DE IDENTIDADE N : SEXO : $M \square F$

DATA NASCIMENTO: ......................

ENDEREÇO $\mathrm{N}^{\circ}$ APTO:

BAIRRO: CIDADE

CEP TELEFONE: DDD (............)

2.RESPONSÁVEL LEGAL

NATUREZA (grau de parentesco, tutor, curador etc.)

DOCUMENTO DE IDENTIDADE SEXO: $M \square F \square$

DATA NASCIMENTO.: .....................

ENDEREÇO: $\mathrm{N}^{\circ}$ APTO:

BAIRRO: CIDADE:

CEP: TELEFONE: DDD

\section{DADOS SOBRE A PESQUISA}

1. TÍTULO DO PROTOCOLO DE PESQUISA Caracterização dos distúrbios miccionais e sexuais em pacientesportadoresde neuromielite óptica

2. PESQUISADOR : Dr Cristiano Mendes Gomes

CARGO/FUNÇÃO: Médico Assistente INSCRIÇÃO CONSELHO REGIONAL Nº 69405 UNIDADE DO HCFMUSP: Divisão de Clínica Urológica/ Instituto Central

3. AVALIAÇÃO DO RISCO DA PESQUISA:

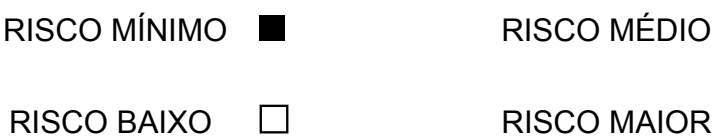

4. DURAÇÃO DA PESQUISA : .01/10/2009 a 01/10/2010 


\title{
HOSPITAL DAS CLÍNICAS DA FACULDADE DE MEDICINA DA UNIVERSIDADE DE SÃO PAULO-
} HCFMUSP

\begin{abstract}
Justificativa e objetivos da pesquisa: Pacientes com Neuromielite óptica podem apresentar sintomas relacionados ao controle da bexiga que incluem incontinência urinária, ter que urinar várias vezes, jato urinário fraco e demora para iniciar a micção. Os sintomas podem ser causados somente pela neuromielite óptica ou podem ter outras causas agravantes, como doenças da próstata e da bexiga e infecções urinárias. Outros sintomas como aqueles relacionados á esfera sexual também podem ocorrer em pacientes portadores de doenças neurológicas como a neuromielite. $\mathrm{O}$ tratamento adequado destes requer um diagnóstico bem feito, que inclui história clínica, exames laboratoriais, ultra-som e exame urodinâmico. A realização destes exames irá auxiliar na escolha da melhor forma de tratamento para a sua doença.
\end{abstract}

Procedimentos que serão utilizados e propósitos: Sua participação nesta pesquisa não irá mudar nada em relação ao tratamento da sua neuromielite ou dos sintomas urinários e sexuais que você possa ter. Os exames que serão realizados fazem parte da avaliação rotineira dos pacientes e são os mesmos que você faria independentemente da sua participação neste estudo. Apenas serão acrescentados questionários de sintomas (perguntas específicas para avaliar seus sintomas urinários e possíveis disfunções no campo sexual) que você será solicitado a responder, e que será aplicado pelo médico pesquisador.

Desconfortos e riscos esperados: Não há riscos ou possíveis seqüelas associados à participação neste estudo. Isto é, os exames que serão realizados embora tenham pequenos riscos associados, já são rotineiramente empregados nestes pacientes. Tais riscos são muito baixos e a participação ou não no estudo não afeta estes riscos pois os critérios para a utilização destes exames já são rotineiramente empregados.

Benefícios que poderão ser obtidos: Este estudo irá demonstrar a frequência e severidade dos sintomas urinários e sexuais nos pacientes com neuromielite óptica atendidos em nosso hospital. Ainda não existem informações científicas precisas sobre as características das disfunções miccionais e sexuais relacionadas á neuromielite óptica. As informações colhidas neste estudo poderão ser muito úteis para que possamos tratar de forma mais eficiente estes sintomas que afetam muito a qualidade de vida dos pacientes que possuem neuromielite óptica.

Procedimentos alternativos que possam ser vantajosos para o indivíduo: Fui informado claramente de que os exames diagnósticos incluídos neste estudo são rotineiramente realizados na avaliação dos pacientes com neuromielite óptica que tenham sintomas urinários. Desta forma, este estudo não inclui nenhum tipo de exame novo, mas apenas normatiza e caracteriza detalhadamente a apresentação clínica dos pacientes.

\section{Esclarecimentos dados pelo pesquisador sobre garantias do sujeito da pesquisa:}

Em qualquer etapa do estudo, você terá acesso aos profissionais responsáveis pela pesquisa para esclarecimento de eventuais dúvidas O investigador principal é o Dr Cristiano Mendes Gomes, que pode ser encontrado no Instituto Central do Hospital das Clínicas da FMUSP, 7 andar, Divisão de Clínica Urológica, ou pelo telefone 3081-1091. Se você tiver alguma consideração ou dúvida sobre a ética da pesquisa, entre em contato com o Comitê de Ética em Pesquisa (CEP) - Rua Ovídio Pires de Campos, $225-5^{\circ}$ andar - tel: 3069-6442 ramais 16, 17, 18 ou 20, FAX: 3069-6442 ramal 26 - E-mail: cappesq@hcnet.usp.br.

Fica mantido o seu direito de assistência no HCFMUSP, por eventuais danos à saúde, decorrentes da pesquisa.

Você terá total liberdade de retirar meu consentimento a qualquer momento e de deixar de participar do estudo, sem que isto traga prejuízo à continuidade da assistência

Será mantido o direito de você ser atualizado sobre os resultados parciais da pesquisa

Não haverá despesas pessoais para você em qualquer fase do estudo, incluindo exames e consultas. Também não haverá compensação financeira relacionada à sua participação.

Fica definido o compromisso do pesquisador de utilizar os dados e o material coletado somente para esta pesquisa. 


\section{HOSPITAL DAS CLÍNICAS DA FACULDADE DE MEDICINA DA UNIVERSIDADE DE SÃO PAULO-} HCFMUSP

Estou ciente de que as informações a respeito dos meus sintomas urinários e possíveis disfunções no campo sexual serão mantidas em sigilo e protegidas no arquivo de prontuários do Hospital das Clínicas. Essas informações obtidas serão analisadas em conjunto com outros pacientes, não sendo divulgado a identificação de nenhum paciente;

Acredito ter sido suficientemente informado a respeito das informações que li ou que me foram lidas, descrevendo o estudo Caracterização das Disfunções Miccionais e Sexuais em Pacientes com Neuromielite Óptica.

Eu discuti com o Dr Fabrício Leite de Carvalho (pesquisador executante) sobre a minha decisão em participar deste estudo. Ficou claro para mim quais são os propósitos do estudo, os procedimentos a serem realizados, seus desconfortos e riscos, as garantias de confidencialidade, e de esclarecimentos permanentes. Da mesma forma, ficou claro também que minha participação é isenta de despesas e que tenho garantia de acesso a tratamento hospitalar quando necessário. Concordo voluntariamente em participar deste estudo, e poderei retirar o meu consentimento a qualquer momento, antes ou durante o mesmo, sem penalidades ou prejuízo ou perda de qualquer benefício que eu possa ter adquirido, ou no meu atendimento neste serviço.

Assinatura do sujeito da pesquisa

Data

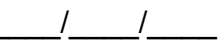

Assinatura da testemunha

(para casos de pacientes menores de 18 anos, analfabetos, semi-analfabetos ou portadores de deficiência auditiva ou visual).

\section{(Somente para o responsável do projeto)}

Declaro que obtive de forma apropriada e voluntária o Consentimento Livre e Esclarecido deste paciente ou representante legal para a participação neste estudo.

Data 1

Assinatura do responsável pelo estudo 